\title{
SOCIAL THINKING AND HISTORY
}

\section{A SOCIOCULTURAL PSYCHOLOGICAL PERSPECTIVE ON REPRESENTATIONS OF THE PAST}

\section{Constance de Saint Laurent}

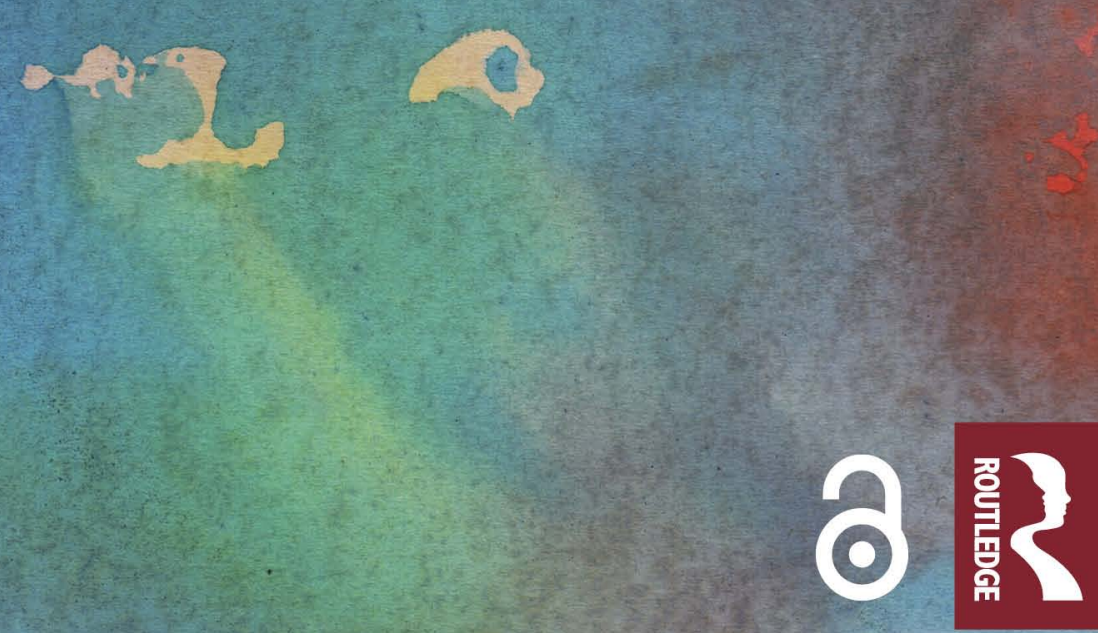




\section{Social Thinking and History}

Social Thinking and History demonstrates that our representations of history are constructed through complex psychosocial processes in interaction with multiple others, and that they evolve throughout our lifetime, playing an important role in our relation to our social environment.

Building on the literature on social thinking, collective memory, and sociocultural psychology, this book proposes a new perspective on how we understand and use our collective past. It focuses on how we actively think about history to construct representations of the world within which we live and how we learn to challenge or appropriate the stories we have heard about the past. Through the analysis of three studies of how history is understood and represented in different contexts - in political discourses in France, by intellectuals and artists in Belgium, and when discussing a current event in Poland - its aim is to offer a rich picture of our representations of the past and the role they play in everyday life.

This book will be of great interest to academics, researchers, and postgraduate students in the fields of psychology, memory studies, sociology, political science, and history. It will also make an interesting read for psychologists and human and social scientists working on collective memory.

Constance de Saint Laurent is a postdoctoral researcher for the Swiss National Science Foundation, at the University of Bologna and the Swiss Federal Institute of Technology (EPFL), Lausanne, Switzerland. 


\section{Cultural Dynamics of Social Representation \\ Edited by Jaan Valsiner \\ Centre of Cultural Psychology, Aalborg University, Denmark}

The series is dedicated to bringing the scholarly reader new ways of representing human lives in the contemporary social sciences. It is a part of a new direction cultural psychology - that has emerged at the intersection of developmental, dynamic and social psychologies, anthropology, education, and sociology. It aims to provide cutting-edge examinations of global social processes, which for every country are becoming increasingly multicultural; the world is becoming one "global village," with the corresponding need to know how different parts of that "village" function. Therefore, social sciences need new ways of considering how to study human lives in their globalising contexts. The focus of this series is the social representation of people, communities, and - last but not least - the social sciences themselves.

\section{Books in this series}

\section{Educational Dilemmas}

A Cultural Psychological Perspective

Luca Tateo

\section{Experiences and Explanations of ADHD}

An Ethnography of Adults Living with a Diagnosis

Mikka Nielsen

\section{Semiotic Construction of the Self in Multicultural Societies}

A Theory of Proculturation

Vladimer Lado Gamsakhurdia

\section{Social Thinking and History}

A Sociocultural Psychological Perspective on Representations of the Past Constance de Saint Laurent

For more information about this series, please visit: www.routledge.com/ Cultural-Dynamics-of-Social-Representation/book-series/CULTDYNAMIC 


\section{Social Thinking and History}

A Sociocultural Psychological Perspective on Representations of the Past

Constance de Saint Laurent 
First published 2021

by Routledge

2 Park Square, Milton Park, Abingdon, Oxon OXI4 4RN

and by Routledge

52 Vanderbilt Avenue, New York, NY I 0017

Routledge is an imprint of the Taylor \& Francis Group, an informa business

(C) 202I Constance de Saint Laurent

The right of Constance de Saint Laurent to be identified as the author of this work has been asserted by her in accordance with sections 77 and 78 of the Copyright, Designs and Patents Act 1988.

The Open Access version of this book, available at www.taylorfrancis. com, has been made available under a Creative Commons AttributionNon Commercial-No Derivatives 4.0 license.

British Library Cataloguing-in-Publication Data

A catalogue record for this book is available from the British Library

Library of Congress Cataloging-in-Publication Data

A catalog record has been requested for this book

ISBN: 978-I-I 38-60930-3 (hbk)

ISBN: 978-0-42-9465 I I-6 (ebk)

Typeset in Times New Roman

by Wearset Ltd, Boldon, Tyne and Wear 
To Vlad, Alice, and Zoé 


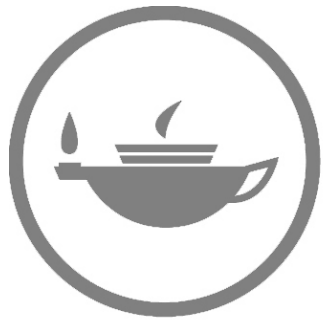

Taylor \& Francis Taylor \& Francis Group http://taylorandfrancis.com 


\section{Contents}

List of figures $\quad$ xi

List of tables $\quad$ xii

Series editor's introduction by Jaan Valsiner xiii

Acknowledgements xvii

Introduction 1

1 Sociocultural psychology 6

The sociocultural approach 6

A brief introduction to a complex history 11

Three sociocultural perspectives 13

Semiotic theories and perspectives 13

Dialogical theories and perspectives 14

Mediated activity theories and perspectives 16

Epistemological and methodological implications 17

Sociocultural psychology in this book 20

2 Social thinking and collective memory

Social thinking 27

Social cognition and reasoning 28

Social representation theory 31

Discursive theories 32

Ongoing debate 34

Social thinking for a realist sociocultural perspective 35

Collective memory 36

The historical roots of collective memory 37

Collected memory 38

Psychosocial memory 40 
Collective remembering 41

Discursive approach 42

Mediated approach 43

Narrative approach 45

\section{Thinking about the collective past: beyond} collective memory

Moving beyond collective memory 52

The problem with collective memory 52

A (not so) new vocabulary 53

Thinking about the collective past 54

A model of how we think about the collective past 54

Going further 56

Action 56

Other 58

Self 60

Tools and signs 61

Studying how we think about the collective past 63

Research questions 63

Methodological note 64

4 The collective past in interactions

Parliamentary debates on immigration 71

Analysing references to the collective past in interactions 73

Results 74

History of immigration 76

History of the French Republic 78

Discussion 82

Constructing meanings 82

Negotiation of meanings 84

Conclusion 86

\section{Trajectories of remembering}

Trajectories of remembering 92

Explaining differences 92

Trajectories and development 94

Analysing trajectories 96

Case 1: Dominique 98

Case 2: Genevieve 101 
Ruptures and resources 104

Personal world philosophies 106

\section{Resources and processes to think about the} collective past

Historical thinking 109

A Dialogical Experiment 111

Rationale 111

Design 112

Analysis 115

Thinking about the collective past 115

Summary of the data $\quad 115$

Resources 116

Media 116

Commonly held knowledge 118

Witness accounts 119

Processes 121

Analogies and generalisations 121

Imagination, identification, and perspective taking 125

Emergence in representations of the collective past 127

Four elements 127

Meaning 127

Sense 129

Factual knowledge 130

Schemas 131

A model of how we construct representations of the collective past 132

Conclusion 134

Conclusion

How we think about the collective past 138

Representing the collective past in interactions 139

Developing unique representations of the collective past 140

Constructing representations of the collective past 142

Collective memory from a sociocultural perspective 143

Collective memory as a symbolic resource 143

Collective memory as constructed in dialogues 144 
Collective memory as a developmental process 144

Collective memory as a thinking process 145

Collective memory as a tool to think about the world 145

Implications for education, policy, and society 146

Index 


\section{Figures}

3.1 Thinking about the collective past (TCP) as oriented, culturally mediated, and dialogical action

4.1 Key to the figures

4.2 References to the collective past in the parliamentary debates 75

4.3 References to events linked to immigration 79

4.4 References to events linked to the French Republic 82

5.1 Trajectory of remembering 95

6.1 Model of how we construct representations of the collective past 


\section{Tables}

6.1 Summary of the vignettes presented to the participants

6.2 Processes to think about the collective past 


\section{Series editor's introduction}

\section{Psychological processes in social representation: a step ahead}

Books - rather than the never-ending flow of journal articles - bring the serious reader a deep feeling of intellectual satisfaction. This book is precisely of that kind - its author explores how people understand and relate to the history of their societies. By adopting a sociocultural psychology perspective, the author is able to take into account the social and cultural dimensions of psychological processes that are involved in the dynamic act of representing historical material by our contemporary ordinary persons who are merely in contact with history via school education and social media. The author also builds her theoretical argument on the literature on collective memory, history education, social representations, and social cognition. The present book is an excellent example of interdisciplinary scholarship in practice.

The present book marks an important forward movement in the development of the social representation theory. Ever since the passing in 2014 of the hegemonic intellectual father of the theory, Serge Moscovici, the question of what next? has been haunting the community of social representation researchers. This is not an easy question to answer for people dedicated to the study of specific aspects of social representation as it is a difficult task to match the erudition and wide focus of the originator of the theory. One possible - and intellectually fruitful - perspective is the study of making sense of history by ordinary persons who face their own futures in their contemporary societies. It is, in a way, history-for-the-future that can be investigated through the social representing of the past.

Constance de Saint Laurent is one of the younger generation researchers of social representation who is at the forefront of this new direction in social representation research. Her work demonstrates the unity of careful attention to details of phenomena together with theoretical issues that still need to be resolved. She brings to the field a systematic developmental perspective - bringing the work on social representations out of its traditional place in social psychology. That developmental perspective is deeply dialogical in its nature. These two perspectives 
together - applied to the phenomena of understanding history - mark her unique contribution to the study of social representation.

The value of the concept of social representation (as a process of representing) has always been its simultaneous functioning at both levels - of the society and individual persons. This has also created a theoretical lure to see the form of such representational processes isomorphic between the levels. Thus, my personal ways of dealing with the uncertainty of a virus that is pandemic are assumed to match those of collective agents such as my family, community, or country. This isomorphism may be desired by the politicians - as it is easier to introduce social control under conditions of such unity of meanings of their commands and the interpretations of the masses of their followers. Doubts are not allowed under these conditions. To mobilise masses of people against a common enemy leaves little leeway for dissenting versions of social representations.

Human history is filled with examples where the natural basis for thinking doubt - is suspended. We live right now in the middle of one of these events. The overwhelming acceptance of economically disastrous measures under the current (March 2020) coronavirus pandemic illustrates the reduction of psychological resistances under conditions of dramatically presented threat. The "body count" of the infected and the dead - together with displays of the life-saving efforts of medical staff - is presented on all television screens. Social representations of other similar virus attacks are readily made. The panic that has emerged builds upon the dangers similar to the SARS virus attack in 2003 (9 per cent lethal outcomes of the infected) while the 2020 virus reached 3-4 per cent range. Comparisons with the "Spanish flu" of 1918-1919 have also been made. The generalisations made from the rapid day-by-day growth of numbers of infected persons are used to elicit proliferation of the collective feeling of discomfort with uncertainties - which is then used socio-politically to introduce a variety of measures that severely limit the normal ways ordinary persons lead their lives. The latter accept these measures as givens - for the collective good of being safe.

There is, however, an interesting difference in the social presentation of epidemics. While the coronavirus becomes socially presented in the context of fear, the similar quickly proliferating ordinary influenza virus is left without attention. Nobody worries about the "seasonal flu" going around - no businesses are closed because people sneeze or cough as a result of that ordinary infection, but the new "dangerous virus" requires drastic socio-political measures that hinder the whole economic structure of the world. How is such generalisation - leading to hyper-generalisation (Valsiner, 2020) of collective fear - possible?

There may exist forgotten collective experiences of the past that are not directly brought into the dialogue about the present but "linger on" somewhere in the background in the current meaning-making about the present and the future. There is in Europe the "silent representation" of danger that is built on the devastatingly (about 90 per cent) lethal outcomes - that of plague that recurrently devastated cities. Representing the past may entail a dialogue between preferential and "silenced" social representations in accordance to the socio-political needs of the time. Some 
representations (e.g., that of the plague) may be overly emotiogenic and are kept out of present discourse, while others instead are used ("Spanish flu") to frame the social events of today in the framework of the discomforting but action-prone versions of the history of the past. Collective memories matter, but they are guided by the societal memory-makers.

By the time the present book reaches its audience, the current virus attack will hopefully be an event of the past, becoming an object for socially representing our past. Yet we are left with the discomforting memories of our recent past the power of panic escalations. Yet what is needed is a psychological "vaccine" precisely against such escalations without allowing the existing mechanisms of resistance (Chaudhary, Hviid, Marsico, \& Villadsen, 2017) to have a role in moderating an avalanche of socially presented fear. Social representation theory in its new versions may be precisely the arena where such antidotes to public fears can be conceptualised. Processes of social representing involve suggestions encoded into the representation used (e.g., "health hazard") together with a resistance strategy that allows the person(s) to neutralize or begin to turn the fear into a challenge and start to enjoy it. The death rate of climbers who have reached the summit of Mt. Everest since it was first ascended in 1953 is 6.5 per cent $\left(280\right.$ out of $\left.4000^{1}\right)$ which is at least equal to or higher than that of the coronavirus lethal outcomes. Yet this statistic has not led Nepal or China to close down the hazardous activity of climbing. ${ }^{2}$ Of course, the relatively few (in contrast to virus-affected) numbers of people who have not only resisted the idea that mountain climbing is dangerous but made it important for their personal life accomplishment indicates that hazardous activities can be turned into desirable and pleasurable ones.

The dialogical nature of social representations in action is crucial for further development of the theory. Social representations are symbolic resources when put into the act of representing the past. The use of such resources makes it possible to flexibly present the same actual event (or historical figure) in possibly completely opposite ways. Napoleon Buonaparte can be made into a hero or a criminal, who - if he were living in the twenty-first century - would be summoned to the Hague to be tried for "crimes against humanity." Fortunately for him (as a real person) he is long dead - but not forgotten. The process of utilisation of symbolic resources is the core of a developmental view on social representation. The present book provides ample evidence for how that process is organised in a society. It will be an intellectual pleasure to read it, at a time where such pleasures are becoming increasingly rare.

Frankfurt-am-Main, March 2020

\section{Notes}

1 www.liveabout.com/death-on-mount-everest-755907

2 Yet on 15 March 2020, the Nepalese Government did close it for two months citing the coronavirus, claiming that with the thin air already making breathing hard, the possibility 
of coronavirus would make it more hazardous. www.businessinsider.de/international/ mount-everest-closed-spring-climbing-season-nepalese-government-coronavirus. China had also stopped issuing climbing permits.

\section{References}

Chaudhary, N., Hviid, P., Marsico, G., \& Villadsen, J. W. (Eds.). (2017). Resistance in everyday life: Constructing cultural experiences. Springer Nature.

Valsiner, J. (2020). Hyper-generalization by the human mind: The role of sign hierarchies in meaning-making processes. PsychoSozial Verlag. 


\section{Acknowledgements}

A book is always, to a certain extent, a collective endeavour. This is particularly true here. Over the years it took me to conduct the research presented here, to write the doctoral dissertation that stemmed from it, and to finish this book, I have benefitted from a wealth of support without which none of this would have been possible, and for which I am forever grateful. First and foremost, my family has been a continuous support emotionally, intellectually, and financially, throughout my studies and beyond. They have also often been the inspiration for this work, from the stories of "the war" that lulled my childhood, to their constant love for debate and discussion. This book would not exist without them. I am forever grateful for the opportunities they have given me.

I would also like to thank Tania Zittoun, who has supervised the doctoral dissertation from which this work stemmed, for her direction, input, and feedback. Beyond my thesis, she has offered me invaluable opportunities, collaborations, and the freedom to pursue my own goals. I have been extremely lucky to have her as a supervisor and as a guide during this intellectual journey. I would also like to express my gratitude to the colleagues with whom I shared this journey: Stéphanie Breux, Martina Cabra, Fabienne Gfeller, Hana Hawlina, Sophie Lambolez, Déborah Levitan, Léonie Liechti, Gabriel Macedo, Teuta Mehmeti, and Gail Womersley, as well as all the colleagues with whom I have had the pleasure to work while conducting this research.

I have also benefitted from a wealth of discussions with wonderful researchers, whose thinking and feedback have enriched my work. In particular, I would like to thank Sarah Awad, Ignacio Brescó de Luna, Alex Gillespie, Michèle Grossen, Pernille Hviid, Jack Martin, Cathy Nicholson, Sandra Obradović, Anne-Nelly Perret-Clermont, Jaan Valsiner, Jakob Waag Villasden, and Brady Wagoner, the members of the Kitchen seminar in Aalborg, the Studio in Neuchâtel, the Cupsynet Doctoral Network, and the COST Action Network on representations of history. This research would not have been possible without the constant debates and discussions I had the pleasure of being part of.

I would also like to thank Gabriela Ungureanu, for all her help, her support, and her constant good mood. She has been my lifeline when trying to balance professional and family life, and she has allowed me to enjoy both and sacrifice neither. 
I am extremely grateful to the people who took part in my studies and to those who made the fieldwork possible. The Théâtre Océan Nord and the Academy of Special Education in Warsaw welcomed me and supported me in realising the various studies presented in this book, and I thank them from the bottom of my heart. In particular, I would like to thank Adeline Rosenstein, Maciej Karwowski, Iza Lebuda, Léa Drouet, and Isabelle Nouzha, without whom this project would not have been possible.

I would also like to thank the Swiss National Science Foundation, the University of Neuchâtel, its Faculty of Arts and Human Sciences, its Institute of Psychology and Education, as well as the Swiss Academy of Humanities and Social Sciences for their financial support at different stages of this work. I am particularly grateful for the SNSF Postdoc.Mobility grant P400PS_180686, thanks to which I have been able to write this book, and to Knowledge Unlatched and Routledge for offering to make it open access.

Finally, I would like to thank Vlad Glăveanu, for his support, his encouragements, and his feedback. You have been there every step of the way, you have listened and discussed every section of this book, and, more importantly, you have always believed in this project even when I didn't believe in it myself. I am forever grateful to have you in my life. 


\section{Introduction}

References to history abound in everyday life, to the point that they often go unnoticed. We hear them in political discussions, where heads of states seen as undemocratic or discriminatory are routinely compared to Hitler, or overly opaque administrations are likened to the USSR. It is in the customary mention of the economic crisis of the 1930s every time the 2008 crisis comes up, or in the references to the Middle Ages and cavemen to characterise attitudes and behaviours we consider to be backward. No matter how ill-conceived most of these comparisons are - the Middle Ages, for instance, were truly not the dark ages many imagine - they help us anchor complex social issues into better-known examples in the past. In doing so, they allow us to make sense of the social world we live in, and to communicate with others about it. And this is possible because we do share a general representation of cavemen built on what we have learnt in school and, perhaps more fundamentally, on what we have seen in movies and on TV. That is, our representations of the past are often, in a large part, the product of popular culture uses of history, partial memories of what we have heard in school, and everyday mentions of the past that verge on reflexes more than on thoughtthrough comparisons.

Yet, the specific ways in which we remember history, where we have been, and how it brought us to where we are today, matters for a number of reasons. First, and at a very pragmatic level, it matters for questions of reparation and reconciliation: Agreeing on a common narrative about the past after a conflict means agreeing on who should carry the blame and pay reparations, who was victimised and who should now be protected. Second, remembering history matters for ethical reasons: We have a duty to remember those before us, especially those who participated, through their life or through their death, to the construction of the world as we know it today. Commemorations, thus, are an important part of social life, crystallised in various social institutions, from history museums to war memorials.

Third, the way we remember history plays an important role in how we understand the present. On the one hand, it can justify and explain the status quo by including it in a continuous narrative. On the other hand, it can serve as the basis for social critique by de-naturalising the present situation and highlighting the 
social and cultural conditions under which it was forged. This is, for instance, the work of Foucault's genealogical method (e.g., Foucault, 1993): By uncovering the historical roots of a phenomenon, not only does it become possible to shed a critical light on its existence, it reminds us that it is not a "natural" category but a recent historical development. Fourth, remembering history matters for the lessons it may teach us for the future. Indeed, what better source of knowledge about humanity, societies, and civilisations than our collective past? Being able to learn from the past has become an object of popular wisdom, as in the maxim: "Those who do not learn from history are doomed to repeat it."

These two last consequences of the way we represent the past - for the present and for the future - imply that how we understand history is not the product of simple reconstructions that aim at reflecting the reality of what happened as best as possible. Quite often, on the contrary, lay representations of history are constructed, mobilised, materialised, and transmitted for social and political purposes (e.g., Liu \& Hilton, 2005). From the politicians who want to impose a specific vision of the world and its future (e.g., de Saint Laurent et al., 2017), to the everyday glorification of the past to feel better about one's social group (e.g., Favero, 2010), our uses of the past reflect more the underlying motivations of the speaker than the factual reality of what happened. This is the aspect of historical representations that has been the most studied in psychology, under the heading of collective memory. Studies on the topic have highlighted the role of collective memory in intergroup conflict and international politics (e.g., Delori, 2011; Rosoux, 2001), in creating often exclusive social identities (e.g., Raudsepp \& Wagner, 2012), or in political rhetoric (e.g., Tileagă, 2013).

What the research on collective memory has thus shown, globally, is that we do not learn from the past but instead use it to defend our own interests. The danger is double here. On the one hand, not learning from history means repeating similar mistakes, being blind to important societal signs, and ignoring the past experiences that could allow us to better anticipate the future. On the other hand, and perhaps more importantly, constructing and propagating glorified versions of the past means defending some of the most negative aspects of our societies implying that periods characterised by slavery, sexism, segregationism, colonisation, or extreme poverty were actually a golden age one should be nostalgic for - and refusing to see our role in the status quo. By defending a version of the past where we are systematically the heroes championing justice, equality, and human rights, we become blind to the dynamics by which injustice, inequality, and dehumanisation are made possible, and how we, through the societies we live in, participate in them.

The ways in which we distort the past have very real consequences in the present, in particular, in terms of political decisions. Slogans like "Make America Great Again" during Trump's campaign or "We want our country back" during the Brexit one are direct references to glorified pasts that, in reality, correspond to periods of segregation or colonisation. Historical comparisons have abounded during both campaigns, be it in the discourses of politicians or of electors. In the 
months preceding Brexit, for instance, the comments posted below online articles were full of references to the "EUSSR" or the "Nazi European Union" (de Saint Laurent et al., 2017). See this Guardian comment thread published a few days before the vote:

USER 1: The EU is a bad idea implemented fraudulently and waste fully [sic]. It's the USSR of the 21 st century.

What followed this rather polite version of the EUSSR argument is, however, much more interesting:

USER 2: The USSR subjegated [sic] the whole of Eastern Europe by military force, brutally crushing revolts in Hungary and Czechoslovakia. It also sent millions of its own citizens to the Gulag. How is this similar to the EU?

Delusional.

USER 3: He obviously never lived in a Soviet vassal-state in the heyday of the USSR. I did: so for me the comparison with the EU is laughable beyond words. I've never been woken at 3:00 a.m. to look up the barrel of a Europoliceman's pistol during a raid in search of subversive literature, as happened once to my sister-in-law. Such incidents were so commonplace as to be hardly worth mentioning.

A better comparison might be the Austro-Hungarian Empire, a sclerotic, bumbling, bureaucratic organisation which never inspired much affection among its subjects - but which everyone missed terribly once it was gone.

USER 4: I think the Austro-Hungarian Empire had similarities to the European Union, but was also rather similar to the United Kingdom.

The comments from User 1 are quite symptomatic of both what has been found in research on collective memory, and of the discourses that surrounded the EU referendum at the time. However, the replies from other users were not the oddity in political discussions on social media, yet they have been completely overlooked by research on the topic - and to a certain extent by the media and political commentators in general, who tend to portray social media debates as caricaturally poor. Here, on the contrary, users draw on their knowledge and experiences of history to reflectively construct a comparison of the current situation of the EU with past events.

It is this active construction and use of representations of the historical past that this book aims to study. In other words, my objective is to explore how people actively think about history as a social object and employ it to understand the world they inhabit. It is also to show that reflective accounts of the past are not the prerogative of historians and intellectuals - in contrast to "lay" people who would blindly repeat self-serving narratives - but that, on the contrary, people do try to pay justice to the past and learn from it. The resources they have available for this, and the 
demands of the social context within which they find themselves may of course vary widely, and we do not all attempt, all the time, to be reflexive about history. Writing this book, for instance, has made me very critical of the narratives I have been taught in school about France, my home country, being the historical champion of human rights, while completely overlooking the meaning of its colonial past. But it does not mean that I have not overused, like many of us have in the past few years, the comparison between the 1930s and the current rise of populist politicians, no matter how much I have read how inaccurate this parallel is.

Yet, studying the more "reflective" side of collective memory matters, for two reasons. First, it is by understanding how people construct and discuss more thoughtful accounts of the past that we can encourage them to do so in the future. Instead of focusing solely on the "dangers" of collective memory, I believe we need to understand how people use and build complex representations of the world they live in. Second, no picture of collective memory would be complete if it failed to consider the wide spectrum on which it can manifest itself. Indeed, how can we understand a phenomenon if we primarily focus on its role in problematic social phenomena - such as nationalism or intergroup conflict - and overlook the other functions it may play in social life?

In order to study how people actively think about history and construct representations of it, I propose to adopt a specific theoretical perspective: That of sociocultural psychology. This approach considers the person as a thinking agent - and not as the passive recipient of problematic representations of the world - embedded within a specific social, cultural, and historical context - and thus with different tools, different objectives, and different understandings that participate in how she represents the world. Because this perspective understands human psyche as characterised by intentionality but does not lose sight of context within which the person develops and that shapes how she thinks, it is particularly adapted for our aims.

In Chapter 1, I introduce the sociocultural perspective adopted in this book and the theoretical principles upon which it rests. I summarise its main axioms: 1) the interdependence between person and culture; 2) intersubjectivity as constitutive of the self; and 3) the self as a developing agent; and I present a brief summary of its history. I discuss in more details three main approaches that have been developed within the sociocultural tradition and that illustrate its axioms: the semiotic, dialogical, and mediated activity perspectives. I conclude this chapter with the methodological and epistemological consequences of the sociocultural approach.

In Chapter 2, I discuss in turn the literature on social thinking and on collective memory, as well as how it can be articulated with the sociocultural perspective. This includes work on social cognition, social representations, discursive psychology, collective memory, and collective remembering. This serves as the basis of the theoretical perspective outlined in Chapter 3. In this third chapter, I start by arguing why we need to move beyond the term "collective memory" considering it both misleading and ambiguous - and by proposing a new vocabulary, speaking instead of Representations of the Collective Past (RCP) and of 
Thinking about the Collective Past (TCP). I then introduce a model of how we think about history, bridging together the literature on sociocultural psychology, social thinking, and collective memory.

Chapters 4, 5, and 6 each explore, empirically, different aspects of the model. In Chapter 4, I look at the role of social interactions in constructing representations of the collective past. More specifically, I analyse the references made to history in a series of parliamentary debates on immigration in France and how different political groups respond to each other. In Chapter 5, I present a study on the development of our relationships to the past, reconstructing the trajectories of intellectuals and artists who have become particularly critical of how history is represented in their country. And in Chapter 6, I propose a Dialogical Experiment to explore the resources and processes used when people think about the collective past. By confronting the participants with different perspectives on an event, this study allows me to highlight the tensions and elements that participate in the emergence of representations of the collective past.

In the concluding chapter, I take stock of the findings of the preceding chapters and discuss what the sociocultural approach brings to our understanding of collective memory. Finally, I highlight the practical implications for education, policy, and society, of the findings, theories, and concepts introduced in this book. What I hope to have shown by then, is how representations of the collective past are constructed, mobilised, and contested, as well as at times, blindly repeated, to understand the complex social world in which we live. And thus, that encouraging reflexive accounts of the past is not, after all, just a fool's errand.

\section{References}

de Saint Laurent, C., Brescó de Luna, I., Awad, S. H., \& Wagoner, B. (2017). Collective memory and social sciences in the post-truth era. Culture \& Psychology, 23(2), 147-155. https://doi.org/10.1177/1354067X17695769

Delori, M. (2011). Le poids de la mémoire sur la politique étrangère. Politique Européenne, 34(2), 231-241. https://doi.org/10.3917/poeu.034.0231

Favero, P. (2010). Italians, the "good people." Reflections on national self-representation in contemporary Italian debates on xenophobia and war. Outlines. Critical Practice Studies, 12(2), 138-153.

Foucault, M. (1993). Surveiller et punir. Naissance de la prison. Gallimard.

Liu, J. H., \& Hilton, D. (2005). How the past weighs on the present. Social representations of history and their role in identity politics. British Journal of Social Psychology, 44, 537-556. https://doi.org/10.1348/014466605X27162

Raudsepp, M., \& Wagner, W. (2012). The essentially other. Representational processes that divide groups. In I. Marková \& A. Gillespie (Eds.), Trust and conflict. Representation, culture and dialogue (pp. 105-122). Routledge.

Rosoux, V.-B. (2001). National identity in France and Germany. From mutual exclusion to negotiation. International Negotiation, 6(2), 175-198. https://doi. org/10.1163/15718060120849035

Tileagă, C. (2013). Political psychology. Critical perspectives. Cambridge University Press. 


\section{Chapter I}

\section{Sociocultural psychology}

Sociocultural psychology is a sub-discipline of psychology better characterised by its theoretical and epistemological foundations than by a specific object of study. Often defined in opposition to "mainstream" approaches to psychology or adjacent fields (Shweder, 1990), it is also more united by the research practices it rejects than by what it shares (Valsiner, 2009). Consequently, trying to provide a coherent and exhaustive presentation of cultural psychology is a nearly impossible task that will not be attempted here. What I introduce here on the main aspects of the sociocultural approach, its brief history, and its main trends of thought is only one of many possible narratives, the one that is the most relevant for the rest of this book. This means that aspects of sociocultural psychology that would be deemed essential by other researchers will be only evoked in passing - most notably Activity theory - simply because they are less relevant to the study of social thinking and collective memory. Of course, that is not to say that these perspectives on cultural psychology are less important, useful, or representative of the field, but simply that they are less central to the theories introduced and ideas developed in this book.

Before introducing the sociocultural approach to psychology, a brief note on the choice of terms is required. Indeed, this perspective has many names: Sociocultural psychology, cultural psychology, social and cultural psychology, or cultural-historical psychology. While they all refer to slightly different groups of researchers and practices, they can all be said to belong, very broadly speaking, to a similar tradition - with the exception, perhaps, of cultural-historical psychology. The term sociocultural psychology has been chosen to emphasise the importance of the social - and not only cultural - aspects of this approach and because of its relative simplicity.

\section{The sociocultural approach}

Sociocultural approaches to psychology share three main assumptions: 1) the interdependence between person and culture; 2) intersubjectivity as constitutive of the self; and 3) the self as a developing agent. First, persons and culture are interdependent. Participation in culture shapes human minds (Bruner, 1990) on two 
levels. On the one hand, it dictates what is possible, acceptable, and expected in social encounters. On the other hand, it offers symbolic and material resources to think, act, and give meaning to the world in ways that are always unique. This double role of culture - as a set of normative practices and representations and as a tool to challenge and create new practices and representations - is well captured, for instance, by the study of autobiographical memory. Indeed, sociocultural approaches to autobiographical memory (Nelson, 2003, 2007; Nelson \& Fivush, 2004) have shown that telling one's life is shaped by the local cultural practices that surround autobiographical narratives - from what types of events should be included to whether personal narratives are encouraged at all - practices that constrain what narratives are considered possible, acceptable, or expected. However, these "constraints" are also used as tools to build narratives that give people's lives meaning and direction and to participate in the construction of a sense of self. This is also what makes mind and culture interdependent (and not a unidirectional relationship): Culture is perpetually renewed every time it is used, and it does not exist outside of the practices and representations that it shapes. As a result, culture is a very difficult term to define (see Jahoda, 2012 for a historical discussion). This is because, in the words of Valsiner (2014, p. 35):

Culture is a process, not an entity. Culture has no agency - the human beings do - yet the power of culture is in the actions of the human agents. Culture does not cause anything, yet human beings operating through culture in goalsoriented ways tore-organize their worlds. In short, it is us, the human beings in any part of the world, who make culture, maintain it, and who destroy it.

Moreover, while the concept of culture is extremely useful, precise definitions of the term are futile and tend to be lists of the types of practices and representations researchers want to study (Jahoda, 2012) or to be constructed with the aim of excluding any non-human behaviour (de Saint Laurent, 2015b; King, 2002). One way around this issue has been to define, instead, what a psychology interested in culture would study, as did Shweder (1990, p. 1):

Cultural psychology is the study of the way cultural traditions and social practices regulate, express, transform, and permute the human psyche, resulting less in psychic unity for humankind than in ethnic divergences in mind, self, and emotion. Cultural psychology is the study of the ways subject and object, self and other, psyche and culture, person and context, figure and ground, practitioner and practice live together, require each other, and dynamically, dialectically, and jointly make each other up.

The second assumption of sociocultural psychology, already hinted at in Shweder's definition, is that of the importance of intersubjectivity. While most approaches in psychology would agree that self-other relations are extremely important, what sets sociocultural psychology apart is that it considers intersubjectivity to be constitutive 
of psychological phenomena: It "understand[s] cognition, emotion, memory, identity, personality, and other psychological constructs as relational entities that emerge out of interactions with others within a sociocultural context" (Kirschner \& Martin, 2010 , p. 1). This assumption can be traced back to the works of two early-twentiethcentury psychologists: Lev Vygotsky and George Herbert Mead. For Vygotsky, social interactions are what allow for the development of children. He argued that the path from the child to the sign passes through the other (Vygotsky \& Luria, 1994); that is, that children learn to use and then understand cultural tools - two different steps for Vygotsky - through interactions with adults who guide the child's participation in various activities (Rogoff, 1990). The development of the use of signs - in the form of language - qualitatively reorganises cognition, allowing the development of what Vygotsky called "higher mental functions" (Van der Veer, 2012; Vygotsky \& Rieber, 1997). These functions also developed over the course of history, leading Vygotsky to argue that in human development two lines are intertwined: Phylogenesis and ontogenesis (Vygotsky, 1978). His approach - "cultural-historical psychology" - is thus central to current sociocultural psychology, as it considers both cultural and social interactions to be constitutive of the human psyche.

George Herbert Mead is less often credited in sociocultural psychology or even in psychology at large (Farr, 1996) than Vygotsky, yet he laid the ground for much of the current sociocultural perspective on the role of social interactions (e.g., Gillespie, 2006). Mead was interested, among other things, in the development of consciousness, which he believed to be the ability to look at oneself as if other, from an outside perspective (Gillespie, 2005, 2006). He argued that this ability develops through participation in "social acts" and the use of oral speech (Mead, 1977). Social acts are activities that require more than one social position, such as teaching/being taught or giving/receiving. In time, we take these different positions, either in imagination (as in children's play) or in reality (through, for instance, reciprocity). In doing so, we learn to look at ourselves from the perspective of others because we have, to a certain extent, been there before. For instance, I can imagine what it would be like for a friend to receive the birthday present I choose for her because I have, in the past, received birthday presents of the same kind. For Mead, oral speech played a similar role, but with an added advantage: Because we can hear ourselves speak, speech allows for being simultaneously in the position of speaker and audience. Telling a moving story, for instance, can affect us as much as it affects our audience. This is because:

Memory is also a performance to the self. This is where the part of the power of many therapeutic practices resides: Retelling one's life is an opportunity to look at the past through the perspective of others, and thus to give it new meanings.

(de Saint Laurent, 2018, p. 158)

It is also through perspective-taking that symbols become significant, because they intertwine "two or more attitudes that belong to the two or more positions 
within a social act" (Gillespie, 2005, p. 32). Thus, for Mead, social interactions are at the roots of both self-consciousness and the symbolic function.

The third assumption of cultural psychology is that of the paramount importance of human development and agency. It considers the person as developing through "irreversible time" (Valsiner, 1994). As already discussed in the first two assumptions, people develop in time through culture and social interactions. However, development, in sociocultural psychology, is not limited to the idea of maturation, but it considers that the self develops throughout the life course (Zittoun, 2012). Through time, people engage in multiple spheres of experience, encounter different systems of values and meanings, and participate in various cultural practices (Zittoun, 2006, 2012; Zittoun et al., 2013). People learn to integrate those into meaningful positions, values, and ideas (Zittoun \& Gillespie, 2015), to use them to create unique trajectories (Zittoun \& de Saint Laurent, 2015). That is, through time, they become intentional agents able to shape their social and cultural environment as much as it shapes them.

This makes of development a central concept for sociocultural psychology, but it has three other main consequences. First, it means that it considers human activity and the environments it constructs to be characterised by intentionality (Shweder, 1990). Conversely to most of psychology, then, it understands the person as a wilful agent interacting in an environment constituted of and by other wilful agents, and not as the result of the blind influence of external variables (Valsiner, 2012). Or, as Kirschner \& Martin (2010, p. 12) explained:

The explicit goal of many psychologists has been (and continues to be) to predict and control behavior, and the existence of human freedom calls into question the viability of such a project. Yet in spite of such a widespread commitment to determinism, many applications of psychological theory and research in education, psychotherapy, and numerous other social institutions and situations tend to assume (at least tacitly) that human beings are capable of making choices and responding in creative and unforeseeable ways, and of asserting themselves in thought and action to improve their own lives and those of others. [...] [Thus] without a viable, nonreductive, yet nonmysterious conception of human agency, psychology lacks the theoretical resources necessary to support not only its claims with respect to application and relevance, but also its status as the social science primarily concerned with an understanding of human experience and action. Even the word "action" denotes a kind of agentive intentionality that seems missing from much contemporary theory and inquiry in the discipline.

The second consequence of the emphasis on agentivity is that human beings need to be studied as developing "wholes" and not as personality traits, neurological reactions, or sum of social influences (Kirschner \& Martin, 2010) that can be isolated in time. Indeed, agency and development presuppose that there is a 
subject who, through time, integrates these elements into "something more": The whole is greater than the sum of the parts because the whole is a conscious, wilful being with a past who thinks, feels, and acts as such and thus can always "override" any part of the sum. While we are not always coherent and unified selves (Hermans, 2002) who hold coherent and unified representations of the world (Jovchelovitch, 2002), studies on identity and autobiographical memory do show that we nonetheless strive for a sense of continuity and coherence, which develops over time (Habermas, 2007), and plays an important part in how we decide to act in the present (de Saint Laurent \& Zittoun, 2017).

The third consequence of considering the subject of psychology as a developing and intentional agent is that it implies a certain degree of self-consciousness. More specifically, people react to the discourses of psychology - and more generally science - and are affected by what it says about them. Indeed, as Shweder (1990, pp. 3-4) puts it:

It is a principle of cultural psychology - the principle of intentional worlds - that nothing real "just is," and that realities are the product of the way things get represented, embedded, implemented, and reacted to in various taxonomic and/or narrative contexts.

And he later adds (Shweder, 1990, p. 31):

It would seem to follow that if realities are not independent of our representations of them and involvement with them, then the raising of questions, even "scientific" questions, is no innocent act. Asking people what they want to do is a way of promoting autonomous decision making. Asking about the potential uses of something is a way of constituting it as instrumental.

The problem of psychology is not just that knowledge is never neutral, and it is always constructed (Berger \& Luckmann, 1966), but that psychological knowledge constructs the very reality it tries to study (Gergen, 1973). A poignant example of this phenomenon is the notion of self-esteem, a concept that was "constructed" by researchers to describe people's representations of their own performances and that now permeates most of Western education. Considering human beings as intentional agents thus has tremendous consequences for psychological research, a point further addressed in Chapter 3 .

In summary, sociocultural psychology studies human beings as intentional agents who develop in irreversible time, and who represent the world, give it meaning, and act within it through the use of symbolic and material tools that are socially introduced, culturally and historically located, and which, in turn, participate in their own construction. In what follows, I briefly summarise its complex, and present three main sociocultural perspectives. I conclude this presentation of sociocultural psychology by introducing its five main epistemological and methodological consequences. 


\section{A brief introduction to a complex history}

Now I have introduced the main theoretical assumptions of sociocultural psychology, a short introduction of the history of the field is due. It was not used as a way of introduction, as is often customary, for one reason: Sociocultural psychology has a complex history that makes it a difficult entry point into the discipline. And indeed, depending on who is writing the history of cultural psychology, it was born four times: With Vico's new science (Shweder et al., 2007), in Wundt's second psychology (Cole, 1996), with Vygotsky's cultural-historical psychology (Van der Veer, 2012), and in the second cognitive revolution (Bruner, 1990). Let us consider each of these "births" in turn, before turning to the "re-birth" of the discipline in the late 1980s.

Vico is often credited as the early father of human sciences; one of the firsts to have defended the idea that the study of man should not employ the same methods as the study of nature (Jahoda, 2012). He defended this idea in The New Science (Vico, 1999), first published in 1725, a regularly rediscovered work. He also believed that imagination was a central human ability (Zittoun, 2015), which was essentially, for him, about giving meaning to the world (Verene, 1981), and which has inspired some scholarship on the topic both in psychology and philosophy. However, globally, the works of Vico are difficult for the modern reader, and most references to The New Science are left as quick mentions at the beginning of longer historical discussions.

A more commonly mentioned date for the birth of cultural psychology is the end of the nineteenth century, in Wundt's Leipzig laboratory (Cole, 1996). Wundt is generally considered to be the father of scientific psychology, yet he did not stop there: While he believed that elementary psycho-physiological phenomena should be studied with basic experiments, he also argued for a second psychology that would study complex human behaviours by "considering successively the main forms of expression of the folk mind" (Wundt, 1916) under the heading of Völkerpsychologie. "The central aims of Völkerpsychologie were to investigate the psychological aspects of groups of people living in communities bound by common language, myths, and customs" (Diriwächter, 2012, p. 45). These two forms of psychology remained separated, although it was not Wundt's aim, as Diriwächter (2012, p. 50) explains:

Wundt felt that creative synthesis was the necessary link between the lower mental processes (i.e., sensory perceptions) and the higher processes that give our life meaning. The higher ones were the foundation of Völkerpsychologie. However, it needed to be understood that Völkerpsychologie was not really a self-standing discipline; rather, it was intimately connected to the lower processes - that is, those connected to physiology (Wundt, 1917), albeit this connection was never truly shown.

But the second psychology of Wundt was forgotten by most, and his experimental work, instead, paved the way for modern scientific psychology - at least in psychology's historical narrative (de Saint Laurent, 2015a; Jahoda, 2007). 
The third possible birth of sociocultural psychology can be found in the works of Lev Vygotsky, Russian psychologist in the early twentieth century, under the name "cultural-historical psychology." The influence of Vygotsky on sociocultural psychology is undisputable, and he has more generally left his mark both on psychology and education. The central idea of Vygotsky's approach was "that the child's naturally given mental processes become transformed by the acquisition of speech and meanings. Through speech the child acquires a worldview that reflects reality in a more adequate way" (Van der Veer, 2012, p. 58). He also believed that speech and meaning are socially transmitted and culturally developed, making of him the author of one of the first fully developed sociocultural theories in psychology. However, it is not until the 1980s that his work became widely known in the West, slowly supplanting the works of more traditional developmental psychologists like Piaget (although they actually shared many ideas now attributed to Vygotsky, see Van der Veer, 2012).

The fourth potential birth of sociocultural psychology followed the cognitive revolution of the 1960s. The cognitive revolution was supposed to bring back the psychological subject that behaviourism had made disappear, yet it lost its way, in particular by relying too much on the computer metaphor (Bruner, 1990). As Shweder (1990, p. 20) puts it:

Ironically, right in the thick of the cognitive revolution, the psyche and the person were nowhere to be found in psychology, as the discipline designed to study the soul, the subjectivity, the person, the rational strivings of human beings for dignity and self-esteem had turned away from those themes and returned to the mechanistic investigation of automatic processes and deep abstract mathematical forms.

Some disappointed psychologists started to propose a second cognitive revolution in the early 1980s, under the name of cultural psychology. As Valsiner explains (2012, p. 4):

Although it began from the educational and developmental concerns in the 1980s that mostly used the ideas of Vygotsky as the center of their new efforts, by 2010s the effort also includes social psychology - both in Europe and the United States - where the generic label "social" becomes frequently taken over by "cultural."

It is this last approach that is often designated "social and cultural psychology."

The history of sociocultural psychology is thus complex and multiple, among other things because while "we know that culture's journey into psychology has already been in the making for over a century" (Valsiner, 2009, p. 7), "culture is a traveller, still negotiating its entrance into the walled city of psychology" (Valsiner, 2009, p. 5). However, if general agreement on the birth of sociocultural psychology is quasi-impossible, it is more generally accepted that it was "reborn" 
in the late 1980 s to early 1990 s - the story of this approach is "ultimately [...] a story of cyclical return" (Shweder, 1990, p. 1), no matter from whose perspective it is told. In the 1990s, many publications defending this return became available, for instance in the form of original books (e.g., Cole, 1996; Rogoff, 1990; Shweder, 1990; Wertsch, 1998), re-editions (e.g., the edition of the complete works of Vygotsky for the first time in English), and scientific journals (Culture \& Psychology, created in 1995 by Jaan Valsiner). Ever since, the field of sociocultural psychology has continuously expanded and been applied to a multitude of topics - from the sociocultural psychology of religion (Belzen, 2010) to that of imagination (Zittoun \& Gillespie, 2016), and creativity (Glăveanu, 2010).

\section{Three sociocultural perspectives}

As sociocultural psychology "re-appeared" in psychology, it took diverse forms. Several attempts have been made to classify them, but no agreement has so far been found. In what follows, I propose to present the main theoretical perspectives that have been developed in sociocultural psychology in the past few decades, selecting and organising them based on two criteria: 1) that they illustrate a central aspect of sociocultural theory and practice; 2) that they fit within the sociocultural tradition as defined in this chapter. Three approaches were thus chosen: Semiotic perspectives, dialogical perspectives, and mediated activity perspectives, which are discussed in turn. Two important candidates were thus removed: Narrative approaches - as they fit under the semiotic and mediation perspectives, and discursive approaches - as they do not fully fit within the frame of sociocultural psychology (see however Chapter 2 for discussions of these approaches).

Each of the perspectives presented below insist more on some sociocultural axioms than others, and the presentation will focus on what aspects are made salient by each perspective. However, it needs to be noted that none of them "ignores" important parts of the sociocultural traditions, and that they are often used in conjunction. They are sometimes used as theories that explain different aspects of the human psyche and can be used with other theories, and sometimes as perspectives that encourage looking at a phenomenon from a specific standpoint.

\section{Semiotic theories and perspectives}

Semiotic theories are interested in how human beings produce meanings about their environment, others, and themselves. In the words of Valsiner $(2014$, p. 1), we are:

... compulsive meaning-makers - whatever we encounter in our lives we need to make sense of, rather than only react or act upon. Or even more precisely, as we react to and act upon the world in the middle of which we live, we construct it as meaningful to ourselves. And it is that meaningful way of living that is central to us. 
Semiotic approaches have thus defended the idea that meaning-making is central to thinking, and that in terms of reasoning, it is on par with formal logic (Bruner, 1990, 2003), if not more important.

Sociocultural semiotic approaches find their roots in the works of Charles Sanders Peirce, more commonly known as the father of pragmatism. Peirce, however, also developed a complex theory of how meaning is made, and in particular, of signs. He considered that the dyadic relation between the sign and the object it referred to was not enough to understand semiosis, and instead proposed a triadic relationship between sign, object, and interpreter (Peirce, 1991), thus making of the subject an essential part of meaning-making. For Peirce (1985, p. 5), a sign:

... is something which stands to somebody for something in some respect or capacity. It addresses somebody, that is, creates in the mind of that person an equivalent sign, or perhaps a more developed sign. That sign which it creates I call the interpretant of the first sign. The sign stands for something, its object.

Because this interpretant is itself a sign, it creates an "infinite chain of interpretation" or thought (Misak, 2004, p. 10).

Peirce's semiotic has inspired many theories in psychology and beyond, following more or less closely his original work, and sociocultural psychology is no exception. On the one side, some researchers have based their theories on Peirce's works and expanded them further. For instance, Jaan Valsiner has proposed a "sociocultural psychology of dynamic semiosis" (Valsiner, 2014, p. 18), arguing, among other things, that we use and construct dynamic hierarchies of signs that allow us to develop a meaningful relation to the world, but also to others and ourselves. On the other side, some sociocultural psychologists have taken inspiration from Peirce but proposed models more distant from his original theory although by no means incompatible. Tania Zittoun, for example, has developed a model of meaning-making based on a semiotic prism, made of the dynamic relations between person, object, shared signification, and personal sense (Abbey \& Zittoun, 2010; Zittoun, 2006, 2017).

Semiotic approaches, globally, have been interested in how signs are produced, shared, and used. As such, they have mainly focused on the "cultural" dimension of sociocultural psychology - while by no means ignoring its social dimension, as Zittoun's work shows - by emphasising the role of shared symbols in psychological processes. They have also opened the grounds for new understandings of higher mental functions, such as imagination (Zittoun \& Gillespie, 2016), and have been at the basis of Bruner's narrative approach (Bruner, 2003, and see also Chapter 2).

\section{Dialogical theories and perspectives}

Dialogical approaches stem from the works of Bakhtin, a mid-twentieth-century Russian literary critic. He argued that speech is always dialogical - it is always 
a reply to something and an anticipation of the next turn - a phenomena he called addressivity (Bakhtin, 1986). He also proposed the notion of heteroglossia (Bakhtin, 1981) to designate the fact that any discourse is made up of the heterogeneous voices of others and borrows from different linguistic genres. Indeed, Bakhtin defended the idea that speech is always a quote from someone else, as we learn language through others' use of it and not through dictionary definitions (Bakhtin, 1986).

His theories have been used in psychology, and more particularly in sociocultural approaches, to argue "that human nature and human life are constituted in interrelations with 'the other,' that is, in other orientation" (Linell, 2009, p. 13). By claiming that discourses are always oriented towards others and borrowing from them, dialogical approaches defend the idea that intersubjectivity - "broadly speaking, [...] the variety of possible relations between people's perspectives" (Gillespie \& Cornish, 2010, p. 19) - is central to the development and use of language, but also more generally of any psychological process. These approaches have very successfully spread in sociocultural psychology, as dialogism is both a theory and a method (e.g., de Saint Laurent, 2014) that allows researchers to take into account the role of social interactions beyond the interactions themselves, that is, beyond face-to-face verbal encounters (although developing truly dialogical methods has proven extremely difficult, see Grossen, 2010).

While dialogism has been a growing field, "peeking under this umbrella term reveals a heterogeneous assemblage of scholars seeking shelter, sometimes more unified by trying to avoid the rain than their choice of umbrella" (Gillespie, 2011, p. ix). However, dialogical approaches do share two common assumptions, as expressed by Grossen \& Salazar Orvig (2011, p. 492):

The first is that language and communication play a central role in human development; the second is that the term "dialogue" does not only refer to face-to-face interaction, but more generally to the fact that any discourse (even a dialogue with oneself) echoes the voices of discourses that were held elsewhere at other times and in other situations.

Two main sociocultural research traditions have emerged out of dialogism in the past few decades. The first, led by the work of Ivana Marková, has focused on the role dialogism - in the form of thematic oppositions called themata (Marková, 2000) - plays in the way we represent alterity and social objects (Marková, 2003, 2016). These dialogical oppositions between and within the representations are what fuel thinking and are at the basis of common sense. From this perspective, knowledge and representations are the product of a dialogue of perspectives that exist in an irreducible tension. Studies in this area have analysed, for instance, the often-latent oppositions between and within social discourses (Léchot et al., 2013) or the different social voices present in one's discourse (Gillespie et al., 2008). 
The second research tradition that emerged in sociocultural psychology, out of Bakhtin's ideas, is Herman's dialogical self theory, that he defined as follows (Hermans, 2002, p. 148):

In a most succinct way, the dialogical self can be described as a dynamic multiplicity of I-positions in the landscape of the mind, intertwined as this mind is with the minds of other people. In a sense the dialogical self is a "society of mind" because there is no essential difference between the positions a person takes as part of the self and the positions people take as members of a heterogeneous society.

In other words, the dialogical self theory posits that since mind is dialogical, and since these dialogical voices represent social positions, we can study minds as dialogues between different positions. While this theory can be criticised on multiple grounds - for example for the fact that it defines these I-positions in a rather static manner, that it tends to overlook the relations between the voices, or that it overly relies on social metaphors - it has also produced very interesting studies. For instance, Aveling \& Gillespie (2008) have used it to analyse the different positions assumed by second-generation Turkish migrants in London, showing the tensions between their British and Turkish I-positions and how they construct hybrid identities.

\section{Mediated activity theories and perspectives}

The third line of research that can be found in sociocultural psychology is centred on the notion of activity. Although research in this field is often grouped under the heading of "Activity theory" or "CHAT" (Cultural-Historical Activity Theory), not all the theories and studies falling within this tradition have adopted this terminology, hence the choice of the terms "mediated activity theories." Most sociocultural psychology approaches have more or less directly claimed to follow a Vygotskian perspective or to be interested in Soviet psychology, but mediated activity theories are probably its most direct descendants (Dafermos, 2014). They follow the works of Vygotsky and his successor Leontiev, and consider that human activity is symbolically, socially, and materially mediated. They have focused, for instance, on how people learn to participate in collective activities (Rogoff, 1993), on the tools they use to do so (Wertsch, 1998), on the effects of the systemic organisation of human activity (Engeström, 1987), or on the historical, social, and ontological development of symbolic action (Boesch, 1997).

Engeström (1999) has distinguished between three generations of activity theory. The first generation corresponds to Vygotsky's work. Vygotsky was interested in how our relation to the world and our actions are mediated by culturalhistorical tools (Wertsch, 2007) in particular signs (Vygotsky \& Luria, 1994). The second generation began with Leontiev, who introduced two major changes to Vygotsky's approach. First, he emphasised the collective nature of human action, 
and proposed a model of activity that "turned the focus on complex interrelations between the individual subject and his or her community" (Engeström, 1999, para. 6). Second, while Vygotsky was more interested in sign mediation - so in language activities - Leontiev's work emphasised the role of social and material mediation and was thus more interested by concrete activities (Van der Veer, 2012). The third generation of mediated activity theories stems from the works of Engeström himself, who argued that activity theory needs "to understand dialogue, multiple perspectives and voices, and networks of interacting activity systems. In this mode of research, the basic model is expanded to include minimally two interacting activity systems" (Engeström, 1999, para. 8). He thus expanded the basic activity triangle he had proposed based on Leontiev's work - a set of triangles putting activity at the intersections between subject, object, and community - and proposed to study activity as the interaction between several activity triangles representing different perspectives, such as professionals/users or teachers/learners (Engeström, 2001, 2009).

While this approach has proved a very useful tool to study action in organisations, in schools, and so on, it can also be criticised for the rather static structure it imposes on activity. Taken to the extreme, it encourages researchers to "fill in" the activity triangles, instead of understanding ever moving, changing, and open systems in their interactions. Moreover, because it focuses primarily on concrete activities, it is adapted for the study of socially, historically, and spatially/ temporally well delimited activities. However, it is quite ill-fitted for the study of complex psychological processes that develop at the intersection of multiple contexts and through participation in a wide range of activities, as is the case for the phenomena studied in this book. The exception here is represented by the first generation of mediated activity, which inspired Wertsch's sociocultural theory of collective memory and will thus be extensively referred to in this book.

\section{Epistemological and methodological implications}

The basic assumptions of sociocultural psychology have important epistemological and methodological consequences, and, at the methodological level, there are at least five main implications. First, sociocultural psychology considers that the unit of analysis should be human beings as wholes and the networks of interdependence in which they develop. Simply put, it means that the main level of analysis in psychology is the person in her context. The notion of context is notoriously difficult to define, but it is here understood as the interactions between the individual under study and the subjects and objects in her environment thus defining context according to what the individual interacts with and not to everything present in the environment (Grossen, 2001). ${ }^{1}$ Sociocultural studies never focus solely on "sub-psychological" elements (e.g., studying personality traits independently of anything else) or on "supra-psychological" elements (e.g., studying groups as super organisms). Of course, this is not to say that 
sociocultural psychology is not interested in any sub- or supra- psychological aspects, but that they are always studied in relation to the person.

Second, it considers that psychological phenomena are by essence qualitative (Valsiner, 2012) and should be studied as such. It is not "against" quantitative methods per se - although many of its advocates are - but considers them to be adapted only on some occasions and not all (Valsiner, 2012). Globally, it adopts an "ideographic" approach - focusing on specific, local meanings and activities instead of the "nomothetic" approach favoured by most of modern psychology which attempts to propose general laws of behaviour (Salvatore \& Valsiner, 2010). Indeed, "the mind, according to cultural psychology, is content-driven, domainspecific, and constructively stimulus-bound; and it cannot be extricated from the historically variable and cross-culturally diverse intentional worlds in which it plays a coconstituting part." (Shweder, 1990, p. 13). Thus, sociocultural psychology is for some a necessarily ideographic science (Salvatore \& Valsiner, 2010), although whether it should lead to generalisations or not is still open to debate, as are many methodological positions in the field (Cole, 1996). Generally, however, it can be said that sociocultural approaches encourage qualitative descriptions and analyses of psychological phenomena, considering them to be always local and unique, in opposition to the natural sciences methods favoured by most of psychology (Valsiner, 1987).

Third, sociocultural psychology tends to adopt methods that include a temporal dimension, usually focusing on development and/or processes. Indeed, considering human beings as developing agents living interdependently from their social, cultural, and material contexts implies understanding psychological phenomena as dynamic (Valsiner, 2014) - unfolding during the activity and in interaction with a non-static environment - and the result of a developmental trajectory (Vygotsky \& Rieber, 1997), where symbolic and material tools are progressively introduced in socially and culturally constrained activities. Whereas most of psychology has been interested in the basic structure of the mind and what externally determines it (Shweder, 1990), sociocultural psychology has been interested in how meanings, representations, and actions are constructed, making of it a "necessarily" developmental science (Zittoun \& Glăveanu, 2017).

Fourth, sociocultural psychology considers the methods of the human and social sciences to be necessarily different to that of the natural sciences (Kirschner \& Martin, 2010). While much of psychology has tried to reproduce the methods of the latter in an attempt to defend its status of "real science" (Valsiner, 2012), sociocultural psychology has adopted a different approach, summarised by Kirschner \& Martin (2010, p. 15):

Rather than seeking to construct cause-and-effect models, to predict and control behaviour, or to "carve nature at its joints" [...], sociocultural theorists are more likely to envision their purpose as the achievement of an increasingly adequate (though never perfect, timeless, or completely unambiguous) understanding of phenomena of interest. 
This is because, in Cole's words (1996, p. 20):

For the cultural-historical sciences the answers to real questions depend upon the particular assumptions and point of view afforded by the culture in question, and both the method of arriving at an answer and what constitutes a problem or an answer are locally contingent, not universal.

While most sociocultural psychologists would agree that we need to go "back to the study of psychological dynamics in all of its complexity," "we are still at a loss about how to do that" (Valsiner, 2012a, p. 5).

As a consequence, and this is the final methodological implication, sociocultural psychology has a preference for "open" methods that adapt to the phenomena being studied, considering that "there are no 'right' (or 'wrong') methods in any science. Instead, the methods emerge from the encounter of the theory and practice with the phenomena. They are tools for new understanding, rather than symbols of "being scientific", (Valsiner, 2014, p. 36). It is thus against the idea that laboratory experiments are the best way to investigate psychological phenomena: While it is not against laboratory experiments in some specific cases - as used, for instance, in some microgenetic studies (Wagoner, 2009) - it considers that "psychological analysis should begin with an analysis of people's everyday activities, rather than with abstract principles embodied in experimental procedures" (Cole, 1996, p. 33). In any case, it is against any method that claims to study human psyche outside of the "noise" of the sociocultural environment, as usually done in quantitative laboratory experiments. As Shweder (1990, pp. 7-8) noted:

The experimental lab is still treated as a privileged space, where, quite fantastically and against much evidence, it is conveniently assumed that one can physically enter a transcendent realm where the effects of context, content, and meaning can be eliminated, standardized, or kept under control, and the central processor observed in the raw.

Globally, it rejects any method that claims to be able to produce an "absolute truth" that transcends contexts; any method that is presented as the most efficient tool for scientific investigation, regardless of what is being investigated.

At an epistemological level, then, most of sociocultural psychology adopts a constructivist perspective, considering all knowledge to be contingent on the context within which it was produced. However, this is not a theoretical necessity deriving from the sociocultural axioms. Generally speaking, it can be said that while sociocultural psychology is built around a constructivist approach, the role given to empirical reality varies immensely, from perspectives that defend the need for a critical but more systematic use of empirical data (Cornish \& Gillespie, 2009) to perspectives that encourage employing and constructing more abstract generalisations (Valsiner, 2014). 
The methodological and epistemological implications of the sociocultural approach can be summarised in two main points. First, by considering that knowledge is socially and culturally located, it invites researchers to continuously question their practices. Objects of study, the way we decide to study them, and the theories we build on are never neutral. This is perhaps the most important lesson sociocultural psychology has to offer to researchers: We should always be self-reflective on the methods we use and the knowledge we are trying to construct. Scientific research is thus a perpetually renewed attempt to produce knowledge that may be useful, transform the way we understand the world, or simply and controversially shake some of our most deep-seated beliefs. The second point, however, is that there is no perfect method: Neither the laboratory experiment nor the most grounded action-research can claim to produce "absolute truth" or the most useful/ beautiful/transformative truth. In conjunction, these two points paint a picture of the social and human sciences quite at odds with the positivist message of modern psychology: Scientific investigation, in sociocultural psychology, is the constant attempt to question, perfect, and adapt methods of investigations to do justice to the elusive nature of psychological phenomena.

\section{Sociocultural psychology in this book}

The approach adopted in this book is located within the field of sociocultural psychology. More specifically, it defends the idea that the object of psychology is the person, as an intentional agent, acting in a specific sociocultural context and interacting with others by using symbolic, social, and material tools. It also considers that three elements play fundamental roles in psychological processes: Meaning-making, as the ability to transcend the here and now, alterity, as the ability to transcend the self, and agency, as the ability to transcend the present conditions.

In consequence, the present work borrows from all three families of theories and perspectives presented above. As they all follow the basic sociocultural axioms, they are globally theoretically, methodologically, and epistemologically compatible. However, this compatibility is often superficial: While all these theories conceptualise human psyche in broadly similar terms and often borrow from each other, they also study it from sometimes widely different angles. Attempting to take them all into account at once is thus an impossible juggling act. In this book, they are thus combined either "locally" (in relation to a very concrete or specific issue), "partially" (only some aspects of the theory are considered), or they are simply used in turn.

This book also takes inspiration from critical psychology, an umbrella term that regroups approaches that consider issues of power to be central to both practices and the construction of knowledge (Teo, 2015). Some attempts have been made to combine critical and sociocultural approaches (Ratner, 2002, 2008), but they have adopted a very macro and sociological perspective. However, as Shi-Xu (2002, p. 72) explains: 
... in doing cultural psychology we must pay attention to power asymmetry and power struggle as an essential and integral part of culture and, therefore, of psychology. We need to realize, in other words, that we are not merely dealing with "culture interacting with psychology," as is usually understood, but perforce encounter the seen but unnoticed political issues of domination, prejudice, exclusion and resistance and, consciously or inadvertently, make our own political choice, that is, take sides.

While the notion of power is largely absent from this book, at an explicit level, it is in the background of this research and stimulated the research questions that will be introduced in Chapter 3 .

Finally, the epistemological perspective adopted in this work is not, contrary to most of sociocultural psychology, constructivist. While I agree that knowledge is always a construction from a certain perspective, I also believe that constructivism runs the risk of making reality disappear by studying the construction of knowledge completely independently from reality (as Berger \& Luckmann, 1966 advocated). Instead, I consider, following Searle (1995), that there are different types of "truth" about which different types of claims can be made. While the significance of World War II is what Searle would call an ontologically subjective claim, the fact that it started in 1939 is ontologically objective: It rests on socially constructed knowledge, such as knowledge of time divisions and what constitutes a war and how it may be started, but it is true within this system of knowledge. ${ }^{2}$ Much of the knowledge produced in psychology is based on ontologically subjective claims - about meanings, values, emotions, and so on - but it should not all be reduced to that. While this distinction is not necessarily major in most psychology studies, it will matter for the subject at hand, for representations of history intertwine both types of claims.

More globally, the epistemology adopted in this book is pragmatist, following in particular the works of James (1922) and Peirce (1955). Pragmatism considers that the "truth value" of an idea does not reside in whether it is a correct representation of reality, but whether it "works;" that is whether it allows human action (Rorty, 1998). This implies that whether an idea is true or false is not an absolute quality of the idea but depends on the interests of the person holding it. In that sense, it is very close to constructivist approaches, as it considers that truth is plural and a matter of perspective, but it differs from constructivism in the sense that it discriminates between ideas based on their pragmatic value. The theories, methods, and data one should use to produce scientific knowledge thus depend on the question asked, not on an absolute hierarchy of research practices (Cornish \& Gillespie, 2009). In the specific context of psychological research, it means that it also values ideas that shed new light on the phenomenon, that have positive consequences for practice, or that question the status quo (Cornish \& Gillespie, 2009), making it an epistemology easily compatible with critical perspectives.

Now that I have set the general theoretical and epistemological grounds for this book, it is time to turn to the construction and use of collective memory. 


\section{Notes}

1 This also means that theories, by making some elements of the environment relevant for the person, participate in the construction of the context.

2 This claim may be open for discussion for historians, but this is because they operate within the system of knowledge of their discipline, which does not fully match that of everyday discourses on history.

\section{References}

Abbey, E., \& Zittoun, T. (2010). The social dynamics of social science research: Between poetry and the conveyer belt. Qualitative Studies, 1(1), 2-17.

Aveling, E.-L., \& Gillespie, A. (2008). Negotiating multiplicity. Adaptive asymmetries within second-generation Turks' "society of mind." Journal of Constructivist Psychology, 21, 200-222. http://dx.doi.org/10.1080/10720530802070635

Bakhtin, M. M. (1981). The dialogic imagination: Four essays. University of Texas Press. Bakhtin, M. M. (1986). Speech genres and other late essays. University of Texas Press.

Belzen, J. A. (2010). Towards cultural psychology of religion. Principles, approaches, applications. Springer.

Berger, P., \& Luckmann, T. (1966). The social construction of reality: A treatise in the sociology of knowledge. Penguin.

Boesch, E. (1997). The sound of the violin. In M. Cole, Y. Engeström \& O. Vasquez (Eds.), Mind, culture and activity: Seminal papers from the laboratory of comparative human cognition (pp. 164-184). Cambridge University Press.

Bruner, J. S. (1990). Acts of meaning. Harvard University Press.

Bruner, J. S. (2003). Making stories. Law, literature, life. Harvard University Press.

Cole, M. (1996). Cultural psychology. A once and future discipline. Harvard University Press.

Cornish, F., \& Gillespie, A. (2009). A pragmatist approach to the problem of knowledge in health psychology. Journal of Health Psychology, 14, 800-809. https://doi.org/ $10.1177 / 1359105309338974$

Dafermos, M. (2014). Soviet psychology. In T. Teo (Ed.), Encyclopedia of critical psychology (pp. 1828-1835). Springer. https://doi.org/10.1007/978-1-4614-5583-7_297

de Saint Laurent, C. (2014). "I would rather be hanged than agree with you!" Collective memory and the definition of the nation in parliamentary debates on immigration. Outlines. Critical Practice Studies, 15(3), 22-53.

de Saint Laurent, C. (2015b). Dialogue and debate in psychology. Commentary on the foundational myth of psychology as a science. In J. Cresswell, A. Haye, A. Larrain, M. Morgan \& G. Sullivan (Eds.), Dialogue and debate in the making of theoretical psychology (pp. 231-239). Captus.

de Saint Laurent, C. (2015c). (No) Empathy for the monkey? Book review of "The cultural origins of human cognition." Europe's Journal of Psychology, 11(2), 363-368. https:// doi.org/10.5964/ejop.v11i2.990

de Saint Laurent, C. (2018a). Memory acts. A theory for the study of collective memory in everyday life. Journal of Constructivist Psychology, 31(2), 148-162. http://dx.doi.org/ 10.1080/10720537.2016.1271375

de Saint Laurent, C., \& Zittoun, T. (2017). Memory in life transitions. In B. Wagoner (Ed.), Handbook of memory and culture (pp. 209-236). Oxford University Press. 
Diriwächter, R. (2012). Völkerpsychologie. In J. Valsiner (Ed.), The Oxford handbook of culture and psychology (pp. 43-57). Oxford University Press.

Engeström, Y. (1987). Learning by expanding. An activity-theorical approach to developmental research. Orienta-Konsultit $\mathrm{Oy}$.

Engeström, Y. (1999). Learning by expanding. Ten years after. Introduction to the German and also Japanese edition of "Learning by expanding," published in 1999. http://lchc. ucsd.edu/MCA/Paper/Engestrom/expanding/intro.htm

Engeström, Y. (2001). Expansive learning at work. Toward an activity-theoretical reconceptualization. Journal of Education and Work, 14(1), 133-156. https://doi. org/10.1080/13639080020028747

Engeström, Y. (2009). Expansive learning. Toward an activity-theoretical reconceptualization. In K. Illeris (Ed.), Contemporary theories of learning (pp. 59-87). Routledge.

Farr, R. M. (1996). The roots of modern social psychology. Blackwell.

Gergen, K. J. (1973). Social psychology as history. Journal of Personality and Social Psychology, 26, 309-320.

Gillespie, A. (2005). G. H. Mead. Theorist of the social act. Journal for the Theory of Social Behaviour, 35(1), 19-39. https://doi.org/10.1111/j.0021-8308.2005.00262.x

Gillespie, A. (2006). Becoming other. From social interaction to self-reflection. Information Age Publishing.

Gillespie, A. (2011). Foreword. In M. Märtsin (Ed.), Dialogicality in focus. Challenges to theory, method and application. Nova Science Publishers.

Gillespie, A., \& Cornish, F. (2010). Intersubjectivity. Towards a dialogical analysis. Journal for the Theory of Social Behaviour, 40, 19-46. https://doi.org/10.1111/j.14685914.2009.00419.x

Gillespie, A., Cornish, F., Aveling, E.-L., \& Zittoun, T. (2008). Conflicting community commitments. A dialogical analysis of a British woman's World War II diaries. Journal of Community Psychology, 36(1), 35-52. https://doi.org/10.1002/jcop.20215

Glăveanu, V. P. (2010). Principles for a cultural psychology of creativity. Culture \& Psychology, 16, 147-164.

Grossen, M. (2001). La notion de contexte. Quelle définition pour quelle psychologie? Un essai de mise au point. In J.-P. Bernié (Ed.), Apprentissage, développement et significations (pp. 59-76). Presses Universitaires de Bordeaux.

Grossen, M. (2010). Interaction analysis and psychology. A dialogical perspective. Integrative Psychological and Behavioral Science, 44, 1-22.

Grossen, M., \& Salazar Orvig, A. (2011). Dialogism and dialogicality in the study of the self. Culture \& Psychology, 17(4), 491-509. https://doi.org/10.1177/1354067X11418541

Habermas, T. (2007). How to tell a life. The development of the cultural concept of biography. Journal of Cognition and Development, 8(1), 1-31. https://doi. org/10.1080/15248370709336991

Hermans, H. (2002). The dialogical self as a society of mind. Introduction. Theory \& Psychology, 12, 147-160. https://doi.org/10.1177/0959354302122001

Jahoda, G. (2007). A history of social psychology. From the eighteenth-century Enlightenment to the Second World War. Cambridge University Press.

Jahoda, G. (2012). Culture and psychology. Words and ideas in history. In J. Valsiner (Ed.), The Oxford handbook of culture and psychology (pp. 25-42). Oxford University Press.

James, W. (1922). Pragmatism. A new name for some old ways of thinking. Longmans, Green and Co. 
Jovchelovitch, S. (2002). Re-thinking the diversity of knowledge. Cognitive polyphasia, belief and representation. Psychologie \& Société, 5, 121-138.

King, B. (2002). On patterned interactions and culture in great apes. In R. Fox \& B. King (Eds.), Anthropology beyond culture (pp. 83-104). Berg.

Kirschner, S. R., \& Martin, J. (Eds.). (2010). The sociocultural turn in psychology: The contextual emergence of mind and self. Columbia University Press.

Léchot, C., Grossen, M., Laufer, D., Ansermet, F., \& Germond, M. (2013). The category "natural" in the discourse of couples who used medically assisted procreation. Journal of Applied Linguistics and Professional Practice, 8(2), 187-208. https://doi.org/10.1558/ japl.v8i2.187

Linell, P. (2009). Rethinking language, mind and world dialogically. Interactional and contextual theories of sense making. Information Age Publishing.

Marková, I. (2000). Amédée or how to get rid of it. Social representations from a dialogical perspective. Culture \& Psychology, 6, 419-460. https://doi.org/10.1177/1354067X0064002

Marková, I. (2003). Dialogicality and social representations. The dynamics of mind. Cambridge University Press.

Marková, I. (2016). The dialogical mind. Common sense and ethics. Cambridge University Press.

Mead, G. H. (1977). On social psychology. The University of Chicago Press.

Misak, C. (2004). Charles Sanders Peirce (1839-1914). In C. Misak (Ed.), The Cambridge companion to Peirce (pp. 1-26). Cambridge University Press. https://doi.org/10.1017/ CCOL0521570069.001

Nelson, K. (2003). Narrative and self, myth and memory. Emergence of the cultural self. In R. Fivush \& C. A. Haden (Eds.), Autobiographical memory and the construction of a narrative self: Developmental and cultural perspectives (pp. 3-28). Lawrence Erlbaum Associates Publishers.

Nelson, K. (2007). Young minds in social worlds. Experience, meaning, and memory. Harvard University Press.

Nelson, K., \& Fivush, R. (2004). The emergence of autobiographical memory. A social cultural developmental theory. Psychological Review, 111(2), 486-511. http://dx.doi. org/10.1037/0033-295X.111.2.486

Peirce, C. S. (1955). Philosophical writings of Peirce (J. Buchler, Ed.). Dover.

Peirce, C. S. (1985). Logic as semiotic. The theory of signs. In R. E. Innis (Ed.), Semiotics. An introductory anthology (pp. 1-23). Indiana University Press.

Peirce, C. S. (1991). Peirce on signs. Writings on semiotic (J. Hoopes, Ed.). University of North Carolina Press.

Ratner,C.(2002).Culturalpsychology. Springer.https://doi.org/10.1007/978-1-4615-0677-5

Ratner, C. (2008). Cultural psychology and qualitative methodology. Scientific and political considerations. Culture \& Psychology, 14(3), 259-288. https://doi. org/10.1177/1354067X08088557

Rogoff, B. (1990). Apprenticeship in thinking. Oxford University Press.

Rogoff, B. (1993). Children's guided participation and participatory appropriation in sociocultural activity. In R. H. Wozniak \& K. W. Fischer (Eds.), Development in context, acting and thinking in specific environments (pp. 121-153). Lawrence Erlbaum Associates Publishers.

Rorty, R. (1998). Truth and progress. Philosophical papers. Cambridge University Press.

Salvatore, S., \& Valsiner, J. (2010). Between the general and the unique. Overcoming the nomothetic versus idiographic opposition. Theory \& Psychology, 20(6), 817-833. https://doi.org/10.1177/0959354310381156 
Searle, J. R. (1995). Construction of social reality. Allen Lane.

Shi-Xu. (2002). The discourse of cultural psychology. Transforming the discourses of self, memory, narrative and culture. Culture \& Psychology, 8(1), 65-78. https://doi. org/10.1177/1354067X0281004

Shweder, R. A. (1990). Cultural psychology. What is it? In J. W. Stigler, R. A. Shweder \& G. Herdt (Eds.), Cultural psychology. Essays on comparative human development (pp. 1-43). Cambridge University Press.

Shweder, R. A., Goodnow, J. J., Hatano, G., LeVine, R. A., Markus, H. R., \& Miller, P. J. (2007). The cultural psychology of development. One mind, many mentalities. In Handbook of child psychology (pp. 1-13). John Wiley \& Sons. https://doi. org/10.1002/9780470147658.chpsy0113

Teo, T. (2015). Critical psychology. A geography of intellectual engagement and resistance. American Psychologist, 70(3), 243-254. https://doi.org/10.1037/a0038727

Valsiner, J. (1987). Culture and the development of the children's action. A cultural-historical theory of developmental psychology. John Wiley \& Sons.

Valsiner, J. (1994). Irreversibility of time and the construction of historical developmental psychology. Mind, Culture, and Activity, 1(1-2), 25-42. https://doi.org/10.1080/107490 39409524655

Valsiner, J. (2009). Cultural psychology today. Innovations and oversights. Culture \& Psychology, 15(1), 5-39. https://doi.org/10.1177/1354067X08101427

Valsiner, J. (2012a). Culture in psychology. A renewed encounter of inquisitive minds. In J. Valsiner (Ed.), The Oxford handbook of culture and psychology (pp. 3-24). Oxford University Press.

Valsiner, J. (2014). An invitation to cultural psychology. Sage Publications.

Van der Veer, R. (2012). Cultural-historical psychology. Contributions of Lev Vygotsky. In J. Valsiner (Ed.), The Oxford handbook of culture and psychology (pp. 58-68). Oxford University Press.

Verene, D. P. (1981). Vico's science of imagination. Cornell University Press.

Vico, G. (1999). New science. Penguin UK.

Vygotsky, L. S. (1978). Mind in society. The development of higher psychological processes. Harvard University Press.

Vygotsky, L. S. (1997). The problem of the development of higher mental functions. In R. W. Rieber (Ed.), The collected works of L. S. Vygotsky: Vol. 4: The history of the development of the higher mental functions. Plenum Press.

Vygotsky, L. S., \& Luria, A. (1994). Tool and symbol in child development. In R. V. de Veer \& J. Valsiner (Eds.), The Vygotsky reader (pp. 99-174). Blackwell.

Wagoner, B. (2009). The experimental methodology of constructive microgenesis. In J. Valsiner, P. Molenaar, N. Chaudhary \& M. Lyra (Eds.), Dynamic process methodology in the social and developmental sciences (pp. 99-121). Springer.

Wertsch, J. (1998). Mind as action. Oxford University Press.

Wertsch, J. (2007). Mediation. In H. Daniels, M. Cole \& J. Wertsch (Eds.), The Cambridge companion to Vygotsky (pp. 178-192). Cambridge University Press. https://doi.org/ 10.1017/CCOL0521831040.008

Wundt, W. (1916). Elements of folk psychology. Outlines of a psychological history of the development of mankind. In K. Thompson (Ed.), The early sociology of culture: Vol. VII. Routledge.

Zittoun, T. (2006). Transitions. Development through symbolic resources. Information Age Publishing. 
Zittoun, T. (2012). Lifecourse. A socio-cultural perspective. In J. Valsiner (Ed.), The handbook of culture and psychology (pp. 513-535). Oxford University Press.

Zittoun, T. (2015). From Vico to the sociocultural imagination. Culture \& Psychology, 21(2), 251-258. https://doi.org/10.1177/1354067X15575796

Zittoun, T. (2017a). Symbolic resources and sense-making in learning and instruction. European Journal of Psychology of Education, 32(1), 1-20. https://doi.org/10.1007/ s10212-016-0310-0

Zittoun, T., \& de Saint Laurent, C. (2015). Life-creativity. Imagining one's life. In V. P. Glăveanu, A. Gillespie \& J. Valsiner (Eds.), Rethinking creativity. Contributions from cultural psychology. (pp. 58-75). Routledge.

Zittoun, T., \& Gillespie, A. (2015). Integrating experiences. Body and mind moving between contexts. In B. Wagoner, N. Chaudhary \& P. Hviid (Eds.), Integrating experiences. Body and mind moving between contexts (pp. 3-49). Information Age Publishing.

Zittoun, T., \& Gillespie, A. (2016). Imagination in human and cultural development. Routledge.

Zittoun, T., \& Glăveanu, V. P. (2017). Imagination at the frontiers of psychology. In T. Zittoun \& V. P. Glăveanu (Eds.), Oxford handbook of imagination and culture. (pp. 1-15). Oxford University Press.

Zittoun, T., Valsiner, J., Vedeler, D., Salgado, J., Gonçalves, M. M., \& Ferring, D. (2013). Human development in the life course. Melodies of living. Cambridge University Press. 


\section{Chapter 2}

\section{Social thinking and collective memory}

\section{Social thinking}

Understanding the role and functioning of democracies (and deciding whether one should vote or not and for whom); Giving meaning to the current refugee crisis (and choosing to welcome refugees or to deter them from coming); Evaluating the potential for change of our economies (and waiting for governments to lead the way towards green economies or taking everyday actions to remove single-use products). These are all part of how we think of our social environment and of others and have very real consequences for how we choose to act in social situations. That is, they all rely on how we understand and represent others (in particular as members of a social group or representants of a social function), social institutions (from governments to the media), and social life and its workings (especially in the form of social norms and expectations).

This is what I propose to group under the term social thinking. It has been, more or less directly, one of the central topics of psychology, especially in social, sociocultural, and some forms of cognitive psychology. By social thinking I mean all forms of psychological processes oriented towards social others, social groups, societies, and communities, and that aim at representing, understanding, evaluating, and giving meaning to them. This has been studied under a large range of headings, from social cognition and social knowledge to categorisation and attribution. Social thinking is thus meant to be a large umbrella term covering a wide array of studies that have investigated and theorised how we relate to the social world.

However, from the sociocultural perspective proposed in the previous chapter, taking these phenomena in isolation is problematic: It decontextualises and separates processes that are profoundly interconnected. Indeed, the way we understand the role and workings of democratically elected governments, for instance, is deeply linked to how we represent different social others - as potential dangers against which we need to protect ourselves, or as allies with whom we should collaborate as well as to the resources that have been made available to us and the reassessments we might have had to do. While taking these in isolation makes sense if they are understood as static mental representations or schemas - then it is a matter of taking stock of their content independently and later connecting the dots - it becomes 
much more problematic when trying to study how people actively engage with these issues and how they think about them, which is the focus of this book.

Instead, what I propose to do in this book is to focus on one of the objects of social thinking: History. Indeed, the way we represent the collective past is a central part of how we understand the world we live in, for three main reasons. First, by offering us a "story of origin" for the societies and communities we are part of, it gives them a raison d'être and a meaning, and provides guidelines as to what behaviours may be acceptable or desirable within them (e.g., de Saint Laurent, 2014). Second, it participates in the construction of social identities (e.g., Bar-Tal, 2014; Kontopodis \& Matera, 2010), giving an "essence" to members of social groups (Raudsepp \& Wagner, 2012). Indeed, the stories told within one's social group about its own past often illustrate a perceived continuity in the psychological characteristics of the members of the group - most commonly bravery and cunning - as well as of its main enemies - usually seen as devious and short-sighted. Third, narratives about the past also speak to how we imagine our future, as stories often indirectly foretell what is to come, a phenomenon known as prolepsis (Brescó de Luna, 2017). Narratives of a golden age and recent decline, for instance, imply that a renaissance may be to come.

As an entry point into the question of how we think about the social environment we live in, I thus propose to explore how people represent, understand, evaluate, and give meaning to the collective past, in particular when they are actively thinking about history - in opposition to simply ventriloquising discourses heard elsewhere. The second part of this chapter will thus focus on the psychological literature on this topic, often grouped under the heading of collective memory, and will specify further how it will be treated in this book.

But first, I propose to review part of the literature that is more generally on social thinking, concentrating particularly on theoretical perspectives and approaches close to sociocultural psychology. Indeed, there are many ways to approach the topic of social thinking, as the literature on the subject is both extremely rich and fragmented. In what follows, I first briefly present the research on social cognition and reasoning, regrouping within it a large range of studies that have made the core of mainstream social psychology. However, because this work is often in contradiction with the principles outlined in the previous chapter, this section focuses more directly on the limits of this approach. I then introduce two theories of social thinking that are more closely linked to sociocultural psychology - social representation theory and discursive approaches to social thinking - as well as the ongoing debate between their proponents. Finally, I outline the perspective on social thinking adopted in this book.

\section{Social cognition and reasoning}

Social cognition refers to the research that is placed at the meeting point between social psychology and cognitive psychology (Fiske \& Taylor, 1991). Globally, it regroups the work done in social psychology that has focused on the cognitive 
processes we use to understand, categorise, and evaluate others (Doise, 1993). In practice, it corresponds mainly to studies done on topics such as attitudes, attribution, and categorisation, and that show the various kinds of cognitive biases hindering everyday social thinking. Indeed, while it "belongs" more to the field of social psychology, it has taken inspiration from cognitive psychology, and in particular from the literature on reasoning (see for instance Carlston, 2013). Actually, most of the research on social thinking in mainstream social psychology have been strongly influenced by cognitive psychology (Fiske \& Taylor, 1991), and a quick detour through the literature on reasoning can shed new light on how they have approached the topic.

The most prominent theory of reasoning in cognitive psychology at the moment remains Evans' dual process theory (Evans, 1989; Evans \& Over, 1996), although some researchers prefer referring to the more recent and popular - yet uncannily similar - system 1 and system 2 theory proposed by Kahneman (2013). According to Evans' theory, we use two different forms of reasoning: The learnt and conventional type of reasoning that follows formal logic, and a more adaptive, personal type of reasoning that is natural logic. This second type of logic is subject to many reasoning biases that make people select, in reasoning tasks, wrong answers because they seem plausible or correct to the participants. While Evans considered this type of logic to be adaptive - allowing people to respond quickly to the demands of everyday situations - this "natural" form of reasoning was meant to explain errors of judgement and was given, even in Evans' theory, a lower status; while formal logic is the educated way to produce a correct answer, natural logic is the instinctive incorrect response to the task.

This perspective permeates much of the research on social cognition. Social psychology research on stereotypes, categorisation, and attribution has consistently shown that we misjudge others even in the face of clear evidence - for instance, even when contact should reduce our prejudice (e.g., Hewstone \& Brown, 1986) or when we have been warned of our own errors of judgement (e.g., Katzev \& Brownstein, 1989). It has also shown that we tend to be kinder in the judgements we make of ourselves than the ones we make of others (e.g., Ross, 1977), and that we are quick to think in terms of "us" versus "them" (e.g., Sherif et al., 1961). Recent research has sometimes called into question the actual prevalence of these phenomena (e.g., see Malle, 2006 for a meta-analysis of attribution studies). However, much of the current research in social cognition has focused on unearthing the conditions under which we use what type of cognitive schema and with what errors, extending rather than challenging traditional social psychology research. The most recent handbook in the field (Carlston, 2013), for instance, shows a particular interest for the role of attention and perception, automatic forms of reasoning, and procedural memory in social cognition - that is, different aspects of how we automatically and subconsciously use biased heuristics to judge social situations. It does demonstrate new interests toward the importance of motivation and affect in how we understand and represent others. These are often seen, however, as blind driving forces and not as sources of agency. 
The view of social thinking offered by social cognition approaches thus suffers multiple limitations. The point here, however, is not to dismiss all the research done in mainstream social psychology, for it has also brought some very interesting findings on group dynamic and how we understand our social environment. The problem with such research, however, is that it presents only a one-sided picture of phenomena it considers universal and essential to human psychology, because it is derived from our "natural" and knee-jerk ways of thinking. In practice, this has resulted in some white supremacists and other racist groups justifying their views by saying that racism is natural. If ethnicities are fundamentally a threat to each other, then they are essentially only defending themselves. It is, for instance, one of the ideas behind the "Great Replacement" conspiracy theory which states that nonwhite and non-Christian populations are actively trying to replace white Christians in Europe, and which has been used as a justification for terrorist attacks, such as the one against a mosque in Christchurch, New Zealand in March 2019.

At a more theoretical level, four main limits can be drawn. First, by adopting a universalistic and deterministic perspective on social thinking, it has constructed human behaviour as such. That is, by understanding social cognition as a natural and instinctive form of reasoning, it has shown little interest in how exactly people think and, for instance, how they reflect and contest the results of scientific research regarding their own behaviour (Gergen, 1973). Instead, it has reified its own representations of social thinking by devising experimental methods that would show, in the "clean" environment of the lab, that people do indeed systematically misjudge others and social situations, and that they are subject to a multitude of biases and influences that determine the responses they give.

Second, the focus on cognitive biases has led researchers to overlook the processes by which people may actively reflect on their representations of their social environment. In a study on the personal trajectories of intellectuals and artists who developed particularly critical representations of history (de Saint Laurent, 2017a, 2017b), for instance, we found that personal and collective events can call into question people's understanding of their social environment. Important ruptures - such as migrating, starting university, or overcoming trauma - can lead people to become actively critical of the representations they had so far, and to look for new sources of information and interpretations of history. Some participants, for instance, became sceptical of any glorifying national narrative, while others adopted a specific ideology - such as communism and used it as a frame to interpret all current events they were confronted with (de Saint Laurent, 2017b). Our personal trajectories, thus, contribute not only to how we understand the world in which we live, but can also lead us to develop particularly complex perspectives on some aspects of our environment while remaining quite uncritical about others.

Third, social cognition research has tended to paint a rather acontextual picture of social thinking. That is, it often overlooks not only the thinking subject and their context - as argued above - but also the cultural context, when evidence has 
shown even the most basic attribution processes to be contingent on the cultural context (see Farr \& Anderson, 1983 for a review and alternative explanation). The way we think of our environment - even in the most unreflective manner - is far from simply being the product of "natural" and universal thinking biases, but is the result of the specific historical and cultural context within which it was developed. Indeed, the way we represent the rule of law or the place of humankind in nature - which has direct consequences for how we understand the meaning of legal and illegal immigration, for instance, or the importance of man-made climate change - is not the product of some universal and natural ways of thinking. It is the product of centuries of intellectual reflection and research on these topics and of how they were appropriated by non-expert audiences.

Finally, social cognition has also encouraged an opposition between the "good" logic of the educated elite against the instinctive reactions of lay people, an opposition already present in Le Bon's (1896) picture of the crowd as a barbarian horde. This has given the impression that the use of formal logic was a more advanced - yet more costly - way to understand one's environment. Everyday social life, however, does require a hefty dose of empathy and perspective taking. Logic might dictate that letting refugees drown in the Mediterranean could be a powerful deterrent and thus prevent future deaths, but it does not make it an appropriate answer to the refugee crisis.

Social cognition research, thus, has painted a one-sided picture of social thinking, and it is exactly this dichotomy between "higher" and "lower" forms of thinking that the next approach aimed to tackle.

\section{Social representation theory}

Social representation theory was developed by Serge Moscovici (1961) in a study on the reception of psychoanalysis in France in the late 1950s. His aim was to understand how groups of people understood psychoanalysis and made sense of it, using a form of logic he called "common sense." More generally, he was interested in the production and communication of social knowledge, and he developed the notion of social representations to designate it, as (Moscovici, 1973, p. xii):

... a system of values, ideas and practices with a twofold function: first to establish an order which will enable individuals to orient themselves in their material and social world and to master it; and secondly, to enable communication to take place among the members of a community by providing them with a code for social exchange and a code for naming and classifying unambiguously the various aspects of their world and their individual and group history.

There are thus two central aspects to social representations. First, they make the unfamiliar familiar: They enable people to grasp new and complex social objects 
by anchoring them into other known objects and by objectifying them - that is, by turning abstract ideas into concrete objects (Moscovici, 1984). Second, they are public and socially shared, by which I mean that they are part of the public discourses (in the media but also in everyday conversations) held by different social groups. In this sense the "social" of social representations and of social thinking are not the same - the latter refers to the object of knowledge, while the former refers to the knowledge itself - although there is a strong overlap between the two. Indeed, social representations participate in the construction of social reality, and as such they are also ideological: They have the potential to impose certain representations of the world, reflecting the unequal distribution of power in the public sphere (Jovchelovitch, 2007b).

Following Moscovici's work, two strong traditions of social representations emerged. The first one, led by Abric (1994) in France, proposed a structuralist model of representations, distinguishing, for instance, between core and peripheral elements. This approach inspired part of the work presented in the section on collected memory - later in this chapter - and will be further discussed there. The second tradition was developed in the UK under the influence of, among others, Ivana Marková, Gerard Duveen, and Robert Farr. It adopted a more dynamic and open understanding of social representation theory (L. Liu, 2004), perhaps closer to what its original author intended. It also furthered Moscovici's theory, for instance by including the dimension of time (Bauer \& Gaskell, 1999), by reflecting on its relation with identity (Duveen, 2001), or by expanding on the symbolic function (Jovchelovitch, 2007b; Zittoun et al., 2003). Ivana Marková (2003) proposed to adopt a dialogical perspective on social representations, considering social representations to be the product of irreducible thematic tensions (Marková, 2000, see also Chapter 1).

\section{Discursive theories}

Discursive psychology was born out of the same discontent with the first cognitive revolution as sociocultural psychology (Harré \& Gillett, 1994), but its main roots are in a different literature: It follows the works of Austin, and Berger and Luckmann. Austin (1975) was a philosopher of language best known for his speech act theory. His idea was that utterances can be statements that are either true or false, but they can also "do" things, such as perform an apology, make a promise, or insult someone. He actually argued that all utterances perform something, even statements, and thus that discourse is a form of action - the succession of speech acts. Berger \& Luckmann (1966), on the other hand, were sociologists who were interested in the sociology of knowledge and how reality is built (Berger \& Luckmann, 1966, p. 15):

... the sociology of knowledge must concern itself with whatever passes for "knowledge" in a society, regardless of the ultimate validity or invalidity (by whatever criteria) of such "knowledge." And in so far as all human 
"knowledge" is developed, transmitted and maintained in social situations, the sociology of knowledge must seek to understand the processes by which this is done in such a way that a taken-for-granted "reality" congeals for the man in the street. In other words, we contend that the sociology of knowledge is concerned with the analysis of the social construction of reality.

Berger and Luckmann actually introduced the term "social construction" to refer to the fact "the worlds in which we all live are not just there, not just natural objective phenomena, but are constructed by a whole range of different social arrangements and practices" (Potter, 1996, p. 12).

Discursive psychology is thus interested in how discourses construct reality. It follows, according to Potter (1996), three main principles. First, it is anticognitivist: It opposes itself to cognitive psychologists on the grounds that they take "for granted that there [are] mental processes 'behind' what people [can] be observed to do" (Harré \& Gillett, 1994, p. 9). For discursive psychology, on the contrary (Harré \& Gillett, 1994, p. 22):

... [the] delineation of the subject matter of psychology has to take account of discourses, significations, subjectivities, and positionings, for it is in these that psychological phenomena actually exist. For example, an attitude should not be seen as a semipermanent mental entity, causing people to say and do certain things. Rather, it comes into existence in displays expressive of decisions and judgments and in the performance of actions.

Discursive psychology thus considers that what psychology should study is what we $d o$ and not what the researcher thinks is in the head of the participants - such as, for instance, mental representations. Second, as its name indicates, it is centred on the idea of discourse, and especially on the idea that psychology should analyse discourses as sequences of acts that are performed (Potter, 1996). This is because it considers that "discursive phenomena, for example, acts of remembering, are not manifestations of hidden subjective, psychological phenomena. They are psychological phenomena" (Harré \& Gillett, 1994, p. 27). Discourse, in this perspective, is where psychological processes take place, and it is thus where they should be studied.

Third, discursive psychology gives an important place to rhetoric. As explained by Billig et al. (1988, p. 3):

Individuals are not to be seen as being fully preprogrammed by neatly systematized plans of action, which are awaiting the appropriate triggering stimulus and which obviate the need for all deliberation. Rather, the contrary themes enable people to discuss and puzzle over their everyday life, and in this respect the rhetorical skills of argument are closely linked to the skills of thinking. 
Indeed, if psychological processes are to be found in discourse, then people's rhetoric abilities become psychological skills. As Harré \& Gillett (1994, p. 27) put it:

The production of psychological phenomena, such as emotions, decisions, attitudes, personality displays, and so on, in discourse depends upon the skill of the actors, their relative moral standing in the community, and the story lines that unfold.

Research in discursive psychology is thereby focused on two questions (Harré \& Gillett, 1994): 1) what resources (systems of signs, mainly) do people have to reach their goals and how do they use them? And 2) how do people construct agreed-upon phenomena (e.g., what it is to produce scientific knowledge, what constitutes a memory, what it is to be creative, and so on) which they can describe using these resources? It has looked, for instance, at how the notion of "false memory" has been constructed, and how it has been used to disqualify certain testimonies (Brown \& Reavey, 2017), or at how the choice of vocabulary in psychology constructs an image of an objective science by removing mentions of the psychological subject (Billig, 1998).

\section{Ongoing debate}

The strong debate between the proponents of social representation theory and discursive psychologists has been going on for more than 30 years, with the latter being one of the most vehement critics of the former (e.g., Potter \& Litton, 1985). On the one hand, discursivists oppose the notion of social representations on the ground that it is a cognitive theory (Potter \& Edwards, 1999), which assumes that people have mental representations of things "stocked" in their heads. While the notion of representation suggests that there is something "in the mind" of the subject, the idea that these representations are shared - for it is often the meaning given to the social component of social representation - does imply that there is a "thing" of which people can "stock a copy." And it is indeed how the theory has been used by some within social psychology.

On the other hand, some researchers working with the theory of social representations have argued that it belongs to a dialogical epistemology, that is "an epistemology of human cognition, communication and, more generally, of the human sciences, which [is] concerned with the study of symbolic thoughts expressed in language" (Marková, 2000, p. 424). From this perspective, thus, social representations are not "static things in the head" but meanings given to social objects through the use of language. These are shared with others because they can be communicated, but more fundamentally because we use shared systems of signs that "promot[e] some - rather than other - interpretations of the current state of affairs" (Valsiner, 2014, p. 100). One fundamental difference is thus that while discursive psychology considers thought to be private speech (Harré \& Gillett, 1994), 
researchers using a dialogical epistemology tend to argue that thought and language are deeply interdependent, but not the same thing.

Proponents of social representation theory have also argued that although there are limits to the notion of representation, one cannot do away with them (Marková, 2000). Doing so would mean doing away with the subject and letting "behaviourism [in] by the back door" (Jovchelovitch, 2007a, p. 128) by reducing psychology to behaviour - this time in the form of discourse. Indeed, while cognitive approaches have created "a mind without history," behaviourism created "a history without a subject" (Jovchelovitch, 2007a, p. 130). By focusing solely on discourse - not necessarily by denying the existence of the rest but by considering it impossible to study and not including it in psychological theories (e.g., Middleton \& Brown, 2005) - discursive psychology replaced agentivity by the intentionality of acts of language: If everything is constructed in discourse, then subjects have no history, no future, and no intentions outside of it. This is why discursive psychology does not fully belong to sociocultural psychology as it has been defined in this book (as mentioned in Chapter 1).

\section{Social thinking for a realist sociocultural perspective}

The first part of this chapter has proposed a brief introduction to the literature on social thinking, focusing more particularly on the theoretical aspects of perspectives globally compatible with the sociocultural approach outlined in Chapter 1. The aim of this book is to investigate how people actively think about social objects, and in particular history; not all the ideas presented above fall within the scope of what we are interested in. Indeed, much of the social representation literature has been focused on the whys of social representations - making the unfamiliar familiar - and how they are communicated - through social exchange and objectification - but less on how they are constructed by individuals trying to make sense of their social environment. That is, this field of study has been more interested in the social aspects of everyday knowledge than on everyday knowledge on social aspects of life. There is of course much overlap between both topics of study: Thinking about social objects is interdependent with the social context within which it occurs, and social representations may be shared; they are still the products of thinking individuals. However, it does mean that social representation theory cannot, alone, explain how people actively think and construct representations of their social environment, simply because it is not its aim.

Discursive approaches to social thinking, on the other hand, do concentrate on how people construct specific understandings of the social world. But by focusing solely on discursive constructions, they suffer two main flaws. As noted above, they tend to make the psychological subject disappear by reducing it to discourses and behaviours constrained by the sociomaterial contexts within which they are displayed. In the case of memory, for instance, it has pushed some authors to declare that individual memories not only do not exist (e.g., Middleton \& Brown, 2005), 
but that it is the setting that does the remembering, not the person (Brown \& Reavey, in press). Some have also argued that memory can never claim to be ontologically true (Brown \& Reavey, 2017), a position deeply problematic from the pragmatic perspective outlined in the previous chapter. While we will return to part of these questions in the next section (see also de Saint Laurent, in press for a critique), for now it suffices to say that discursive approaches can shed light on some aspects of social thinking - in particular the role of discursive constructions and of the social context within which they occur - but cannot constitute, in themselves, a comprehensive approach to social thinking.

Overall, then, what is missing from the theories and perspectives presented here is an account of how individuals actively think about their social environment, often because it is not their overarching aim. By "individuals," I do not mean people taken in isolation from their social and cultural context, a criticism commonly made in sociocultural psychology of researchers using this word. But while thinking always occurs in a given social, cultural, historical, and material context that gives it shape, it does not mean that it is this context that does the thinking or that it is necessarily done collectively. Indeed, sociocultural perspectives cannot and should not do away with cognition: It is the person who thinks, even if she does so by relying on cultural tools and in interaction with others.

The theories presented here are of course only a small part of the literature in psychology on social thinking. They were chosen because of their prominence and/or relevance for a sociocultural perspective, as well as the fact that they concern social thinking in general. In the next section, I explore the literature on collective memory - lay representations of history - and hopefully will deepen our discussion of the processes by which people actively think about their social environment - in opposition to only relaying discourses heard from others.

Temporarily, however, we can conclude that social thinking is the process by which people try to understand and give meaning to others and the social environments they live in. This happens, partially, through discursive practices that contribute to the construction of social reality. The representations produced and used in social thinking can also be socially shared, helping us communicate with others and creating a sense of familiarity in the face of novelty. They are also part of broader and complex systems of knowledge, which are not immune to contradictions. Indeed, thematic oppositions are at the heart of social knowledge, a point upon which we will regularly come back to in this book. What tools and resources do people use, however, to construct these systems of knowledge? How do shared and personal processes become intertwined in social thinking? These questions have been central to collective memory research, towards which we now turn.

\section{Collective memory}

The way we represent the historical past, and the meaning we give to it, is of tremendous importance for collective life: It has the power to shape social identities (Hammack, 2010), to define our future (Brescó de Luna, 2017), to change 
how we relate to others (Delori, 2011), or to give meaning to the present (de Saint Laurent, 2014). As such, historical representations are a central part of social thinking. On the one hand, they provide a wealth of stories and examples that can be used to give meaning to the present or imagine where the future may lead us; on the other hand, they offer a frame from which generalisations can be made about social life and its workings (de Saint Laurent, 2018b).

In psychology, and more generally in the social sciences, these phenomena have been studied under the heading of "collective memory." As a starting point, collective memory can be defined as the representation social groups have of the historical past. It is usually associated with the idea that they adopt biased versions of history, glorifying the actions of local heroes and presenting others as more violent or less civilised than them. As we will see, however, there are many understandings of the concept of collective memory, making of this a heteroclitic field. Moreover, representations of history, as they are studied in this book, fall into the broad category of social thinking that has been defined in the previous section. Psychological research on collective memory thus derives, in large part, from the research on social thinking presented before, although this is not often made explicit.

In the rest of this chapter, I review the literature on collective memory in psychology, looking in particular at how different approaches have conceptualised the psychological processes behind historical representations. However, one of the difficulties one faces when trying to review the field of collective memory, as Olick (1999) noted, is that although a multitude of approaches exist, they are non-paradigmatic and thus there is no clear way to distinguish between them and to "classify" them. Yet, a certain "order," as artificial as it may be, is necessary to be able to discuss more globally the advances and limits of a field. Below, such an attempt is made. It does not follow a chronological order (see for instance de Saint Laurent, 2018a for a chronological account), but rather the theoretical connections between different approaches. And because of the psychological orientation of this book, it is also from this perspective that the field is approached and the literature to be included has been selected. However, our starting point remains its historical origin in sociology - in the work of Maurice Halbwachs $(1950,1992)$.

First, I present the historical roots of the concept of collective memory. Second, I introduce the "collected memory" and "psychosocial memory" approaches, which stem principally from the social cognition and social representations traditions, respectively. I then move on to the sociocultural and discursive approaches that have looked at memory as a discursive practice, a form of mediated action, and as narrative reasoning. I conclude this chapter by presenting the perspective on collective memory that will be adopted in this book.

\section{The historical roots of collective memory}

Collective memory is a concept born in sociology in 1925, in the writings of French sociologist Maurice Halbwachs, a student of Durkheim. It is thus quite 
naturally that it was formulated as a social approach to memory. Actually, Halbwachs' interest was not so much to study how people represent history, but to understand how (small) social groups remember their past (Halbwachs, 1992). He argued that all memory is social memory, and that what we remember about our past is linked to the groups we shared it with: Not only did all of our past take place in social groups - family, friends, co-workers, etc. - but when we part from them we also part from the memories we shared with them (Halbwachs, 1950). To a large extent, then, his work on collective memory would find more resonance today in social approaches to autobiographical memory than in the current understandings of collective memory. However, he also defined collective memory in opposition to history - as the living memory of the group against the dead frame of history - oscillating in his work between a sociological perspective inherited from Durkheim and a very psychological approach to memory (Déloye, 2002).

By the time Halbwachs' work resurfaced, saved from oblivion more than 30 years after its original publication in French, collective memory had taken a decisively more historical and sociological turn. Indeed, it was not until the late 1980s that the concept of collective memory became a topic of research, mainly in history (e.g., Nora, 1997) and anthropology (e.g., Connerton, 1989). There, collective memory became what (large) social groups - primarily the nation remember of their past and how it is embodied in public spaces and oral traditions, in opposition to formal history. As explained above, this distinction was already central to the work of Maurice Halbwachs, but the other aspects of his theory the links with psychology and individual memory - took a back seat. As the concept of collective memory spread to social sciences and humanities, becoming an important object of study in sociology, anthropology, history, political sciences, and literature, the transformation of its meaning became widely accepted - to the point that it is now often ignored by those who use it.

Although almost all the theories presented in this chapter can be grouped under the general heading of collective memory and claim to follow Halbwachs' work, it is usually more because they share a common interest - representations of history and/or socially shared memories - than a certain set of theoretical, methodological, or practical assumptions. To distinguish between these different approaches, new designations are proposed and explained for each category.

\section{Collected memory}

Collected memory is neither the first-born of collective memory, nor even a name scholars would give to their own work. It is, however, the main approach to collective memory in psychology, especially in social psychology, and it is thus a good starting point. The term was coined by sociologist Jeffrey Olick (1999), and aimed at making a distinction between a collective memory that would study social manifestations of history and a collected memory that would simply aggregate individual memory to produce an artificial picture of how the past is collectively remembered (Olick, 1999). Although the critique made may be a bit harsh 
and caricatural, it does not fall far from what is often done in social psychology when studying collective memory. Individual responses are collected, either through interviews or more often questionnaires, and statistically analysed to find the collective memory of the group, under the assumption that societies are simply equal to the sum of their members. This type of research is, nonetheless, quite popular: It has the aura of science only large international samples can provide, and it rests on basic psychological methods easily adaptable to the topic (that is, mainly questionnaires).

Because it is a popular approach, collected memory includes a quite vast spectrum of studies, making the above criticism very fitting in some cases and rather caricatural and simplistic in others. At one end of the spectrum lie large cross-cultural studies, asking hundreds or thousands of participants to fill up questionnaires, to rank historical figures in terms of importance, or to provide a short description of World War II (e.g., J. H. Liu et al., 2005), providing fascinating but often shallow data. On the other end of the spectrum are small(er) scale studies, where members of specific social groups are interviewed about a historical event that is significant to them, asked to tell its story, or explain why it matters to them (e.g., Hewer \& Kut, 2010), often offering a deeper understanding of how the past is remembered. However, what unites the collected memory approach is the underlying assumption that it is the collection of individual memories that produces collective memory. Collective memory is sometimes, in this case, seen as a prolongation of autobiographical memory (Kansteiner, 2002), and is thus simply the product of episodic memory. Because this assumption is shared with collective remembering approaches, presented below, its implications and limits will be discussed there as well.

The majority of collected memory studies, however, do not build on autobiographical or episodic memory, but usually consider, more or less explicitly, that collective memory is a form of social representation (e.g., Haas \& Jodelet, 2000; Jovchelovitch, 2012; J. H. Liu \& Hilton, 2005; Wagoner, 2015). Because social representation theory is (originally) interested in how scientific knowledge is transformed and shared by lay people (Moscovici, 1961), it seems quite selfevident it should be used to study collective memory. From this perspective, then, collected memory is produced by the transformation of historical knowledge into a common-sense representation of the past that fits the needs of the group: Positive self-image, easy communication, anchoring of new information, and so on (e.g., Psaltis, 2012; Wertsch \& Batiashvili, 2012). The process of collected memory is a process of deformation and diffusion, but not of (knowledge) construction: It is a common-sense appropriation of the knowledge produced by others, experts in the subject matter. This is also because, generally, collected memory studies use a static and structuralist version of social representations that understands them as something that can be collected in a questionnaire and then aggregated in a unified picture that characterises the collective memory of a specific group.

Studies in this area have yielded, nonetheless, very interesting findings. They have shown, for instance, that the collective memory of nation groups often takes 
the form of a myth of origins that is deeply linked to national identity (J. H. Liu \& Hilton, 2005), as it defines on what basis the group was created and around what values. Other studies have demonstrated that groups which are in conflict will often hold widely opposed versions of the same past, presenting the ingroup as heroic or victimised and the outgroup as the villain or the oppressor (Bar-Tal, 2014). These narratives are not just deeply linked to the identity of the group, they also define how others are seen. Indeed, collective memory is often used to justify stereotypes about others, on the grounds that if they have consistently behaved in a particular way throughout history then it must be "in their nature" to do such things (Raudsepp \& Wagner, 2012). As a result, representations of the past can play a prominent role in conflicts, and participate in their intractability by presenting the other group as the author of unforgivable wrongs or as essentially different from the ingroup, both in terms of values and behaviours (Licata et al., 2007).

As may be apparent from above, not only have collected memory approaches used social representation theory, but so has the work done on social cognition. This area of research has indeed been strongly influenced by mainstream social psychology studies on stereotypes, group dynamic, attribution, categorisation, and so on. As such, it has also created a picture of collective memory as ruled by the same principles, ignoring how historical narratives can also participate in reconciliation (Nicholson, 2017) and resistance (Awad, 2017), and setting up studies that would only confirm this evaluation (de Saint Laurent et al., 2017). Consequently, although collected memory research has presented a very interesting picture of collective memory, it should be approached cautiously. In particular, one should guard against overly generalising these findings and limiting the role of historical representations to questions of identity and intergroup conflict.

\section{Psychosocial memory}

Another perspective on collective memory has emerged from social psychology in the past few years, although from slightly different roots. It did not start, as collective and collected memory did, out of an interest for how people remember history and other collective events, but was born out of autobiographical and episodic memory studies, where the importance of social interactions in individual memory quickly became clear (Fivush, 2011; Nelson, 2007). As a result, some started applying the methods - especially experiments - and theories - mainly concerning group dynamics - of social psychology to memory. Studies were made, for instance, on reminiscence of major events in groups, showing how what people choose to include or omit is influenced by the stories told by others, and will have a long-term effect on what is actually remembered afterwards (Hirst \& Echterhoff, 2012). Other studies, more closely linked to autobiographical memory, have looked at the family transmission of memories. They have showed, for instance, how it contributes to a sense of continuity with one's family (Fivush et al., 2008), or how family narratives can be transformed over several generations to show one's ancestors in a better light (Welzer et al., 2013). 
In many ways, this approach is closer to Halbwachs' original work than any other presented here, as it is a truly social and psychological approach to memory. However, it also means that it is further away from our topic of interest: Because it focuses on how people remember in groups, it usually does not cover historical events but only recent collective events. Theoretically, and although most proponents of this approach claim that they belong to the wider field of collective memory studies (e.g., Coman et al., 2009), their interest lies more in psychosocial memory than in representations of the historical past. Methodologically, however, it is easier to study how people discuss major events that will soon be part of history, because it allows researchers to bring together in the lab participants who do not know each other and yet will have a common event to discuss.

In terms of processes, the psychosocial approach is quite similar to collected memory, although social representation theory is usually left out in favour of work done on memory. Indeed, because it is interested in social influence, its main objects of study are the transformations - most often in the form of biases - of memory. Although this time the deformation goes from individual souvenirs to a collective and homogeneous story, instead of from scientific knowledge to lay representations, the basic mechanism remains the same: Collective memory is the product of the distortion social groups operate on the (more accurate) accounts of past provided by experts, actors, and eye-witnesses. There is, of course, much to learn from these processes, and social psychological approaches to collective memory have a lot to add to the debate - although its object of study is rather different from the one in this book. Considering everyday thinking about history primarily in terms of loss of information, biases, and conformism with others, however, is giving quite a narrow picture of how people construct representations of the past; one that tends to cast a rather large shadow on people's ability to speak and act as reasonable, thinking beings. This is exactly what the approaches discussed next aimed to overcome.

\section{Collective remembering}

The term collective remembering made its first noticeable entrance in memory studies in the eponymic book edited by Middleton \& Edwards in 1990. However, the idea to replace "memory" with "remembering" dates back from Frederic Bartlett's work in the early twentieth century. Bartlett's (1932) argument for this change of terminology was that memory is not about "storing" static (and in experiments at the time, often meaningless) content for later retrieval, but about being able to reconstruct past experience to adapt to present challenges. In particular, he showed how people who were asked to repeat, at different intervals, a story that makes little sense to them would progressively rationalise and conventionalise their version of the story more at each recall. This is what he called "an effort after meaning." He also introduced to psychology the notion of schema, which he considered to be generalisations of past experiences. He believed that schemas organise remembering, and he was very interested in people's ability to 
"turn upon their schema;" that is, to reflect not just on what they remembered but also on the processes through which they remembered.

The change of terminology from collective memory to collective remembering thus implied moving from understanding it as the ability to store information to conceiving it as an action oriented toward an aim (Wertsch, 2002). This resulted in a renewed interest for the environment in which the person remembers, from the social groups one belongs to, to the cultural context that shapes how and what actions should be carried out. It also meant considering the main process of collective memory to be memory - a sometimes problematic assumption, as we will see. However, beyond the original interest for collective memory as (a mnemonic) activity and for contextualisation, there is not always much else that unites collective remembering approaches. Indeed, in the three main approaches presented below, the first one stems from the works of discursive psychology, the second is more closely linked to the sociocultural mediated action perspective, and the third follows Bruner's narrative approach.

\section{Discursive approach}

Middleton \& Edwards (1990) were the first to claim the name of collective remembering-although others soon followed-to designate the activity of constructing discourses on the historical past. In fact, discursive approaches to collective memory have conceptualised it as a social and discursive activity that makes certain claims about the past and thereby constructs a certain social reality (Edwards et al., 1992). Because this is a social activity, cultural and social norms, values, and practices play a central role in the construction of collective remembering, prescribing what counts as memory and how it should be presented. However, the scope of this approach is not limited to discourses, as it considers non-discursive forms of memory to be social activities regulated in a similar manner (Brown et al., 2001). Thus, discursive approaches to collective memory have also looked at the role of memorials (Poulter, 2017), museums (Katriel, 1994), and more globally at the materiality of commemorative practices (Murakami \& Middleton, 2006). But the field has tended more and more to be mainly interested in collective practices of memory - as in court cases (Brown \& Reavey, 2017), archives (Brown et al., 2001), or professional settings (Middleton, 1997) - and not in collective memory per se, often with the assumption that these two are actually the same (Middleton \& Brown, 2005).

Discursive approaches have looked at the production of discourses on the past in everyday life and have been especially interested in how they are produced in specific cultural contexts and through specific social interactions. This has been done by considering collective remembering as a performance (Brown et al., 2001) and by focusing on the cultural, social, and material conditions that make such discourses possible, but far less by looking at how people actually think about the past, in part because of the disappearance of the subject in discursive psychology, discussed earlier in this chapter. Moreover, pushing discursive approaches to their extreme has led to two main drawbacks. First, understanding 
collective memory primarily as discursive performance can be deeply problematic from an epistemological and ontological standpoint. Indeed, it takes talking about the past to be a discursive action that must follow a certain number of norms to be properly executed - which often involves using a coherent narrative and where judgements of truth and falsity are procedural and normative, but not about ontological truth (Brown \& Reavey, 2017). Although this is an interesting perspective on how truthfulness is assessed in social settings (much research has indeed shown that we tend to value form over content, e.g., Herlihy et al., 2012), and memory is never a "copy" of the past, it does not mean that it cannot be true or false: I can say as much as I want that I won an Olympic medal, I can even believe it, it will never mean that it happened nor that this distinction should not matter for memory research.

Second, by emphasising that collective memory is a discursive performance, this approach to collective memory has had a tendency to reduce its aims to that of persuasion and argumentation, overlooking the construction of meaning that was so important to Bartlett (1932). On the one hand, it has made discursive approaches very efficient in analysing how the past is mobilised in public settings, for what purpose, and with what consequences. For instance, Billig (1995) showed how our discourses on our own country's history tend to legitimise nationalism, presenting it as "banal" and making it largely invisible, while our discourses on the past of other countries construct their nationalism as irrational and dangerous. On the other hand, however, it has pushed issues of power, social struggle, identity, etc., so much to the forefront that it gives a picture of collective memory where everything that is said about the past is either the product of a calculation or coerced by social structures. While it offered a welcome criticism to overly individual and cognitive theories of both personal and collective memory, discursive memory has also, however, sometimes taken a step too far, for instance, claiming that any impression we may have that our memories and the way we understand the past is personal is nothing more than an illusion (Middleton \& Brown, 2005).

\section{Mediated approach}

Around the same period as the discursive approach, James Wertsch proposed a mediated perspective on collective memory - also borrowing from dialogical approaches and summarised in the book Voices of Collective Remembering (Wertsch, 2002). Wertsch was originally interested in Vygotsky's work, and in particular, in the idea that human activity is mediated by cultural tools (see Chapter 1). During a stay in Russia, he was confronted with a very different collective memory, where a widely different narrative of World War II, for instance, is defended. He thus started applying his theory on the role of action and mediation (Wertsch, 1998) to the study of collective memory. As he explains (Wertsch, 2002, p. 13):

... remembering is a form of mediated action, which entails the involvement of active agents and cultural tools. It is not something done by an isolated 
agent, but it is also not something that is somehow carried out solely by a cultural tool. Both must be involved in an irreducible tension. This has several implications, perhaps the most important being that because cultural tools reflect particular sociocultural settings, mediated remembering is also inherently situated in a sociocultural context.

Wertsch conceptualised collective remembering as an action done by an agent, using cultural resources, and in interaction with the voices of others - although he did very little to theorise the last point, in spite of the title of his book - that exist in an irreducible tension. He considered, in particular, that memory relies both on material tools, such as computers and notebooks, and on cultural resources - for instance how to tell a story - that make remembering possible. But because these tools do not in themselves remember, it means that remembering is located at the intersection between agents and the tools they use.

Wertsch used this approach to study collective memory primarily in Russia, which led him to three main theoretical propositions. First, he proposed to distinguish between the production of collective memory and its consumption (Wertsch, 1997). Indeed, he noticed that while states and other official institutions tried to produce a representation of history that would fit their best interest, people did not blindly repeat these stories, but consumed them according to their own agenda. Hence, in spite of the colossal Soviet propaganda about its own history, which changed with the political flavour of the moment, a widespread expression in the population at the time was "we never know of what yesterday will be made." This led Wertsch to a second distinction, between the mastery and the appropriation of historical narratives (Wertsch, 2002). While historical representations can be mastered - that is, known and understood by people - they may not be appropriated that is, they do not become part of the people's representation of the past. In the case of the USSR, it meant that while people mastered very well the official narratives and could repeat them in public as a matter of safety, they would not believe them, and they would discuss the past in a very different way in private. Both of these conceptual distinctions give the impression that Wertsch's understanding of collective memory is more positive and less caricatural than what was seen in the collected memory and discursive memory approaches, giving room for people to contest historical representations and presenting them as "agents." However, as with the social and interactional dimensions of collective remembering, Wertsch's position on this remained more a declaration of intention than a real theoretical inclusion and, in more recent works, he simply defined collective memory as the biased representations of the past that aim at showing one's group in the best of lights (Wertsch \& Batiashvili, 2012).

One of Wertsch's latest theoretical contributions to collective remembering is the idea of "narrative templates" (Wertsch, 2008). Narrative templates are cultural tools that offer a schematic narrative organisation of events and meanings and that shape how the past is remembered. They are used to organise multiple historical events, giving an impression of historical continuity and consistency. For 
instance, Wertsch observed that the stories he collected in Russia often followed the same pattern: 1) an initial situation where Russians live in peace; 2) aggression by an outsider; 3 ) crisis; 4) resolution of crisis by the heroic actions of Russia, acting alone (Wertsch, 2002). Narrative templates are thus something widely spread within a national culture, and that play a primordial role in the content and organisation of collective memory. It is exactly this narrative aspect of historical representations that is at the heart of the next approach.

\section{Narrative approach}

Narrative approaches to collective memory appeared in the late 1990s and were fathered by at least two different fields - making it a less unified area than the two previous ones. On the one hand, they are the product of the appropriation of the topic by cultural psychologists following Bruner, who had argued for the importance of narrative reasoning as a way to think about the world (Bruner, 1987, 1991). On the other hand, they are the result of the emerging interest for narratives and life stories in autobiographical memory and identity research (McAdams, 1988, 1993; Nelson, 2006), applied to collective memory. This approach emphasises the narrative structure of memory and the role of narrative schemas in the construction of representations of the past, and some of Wertsch's work thus also belongs to this category. Although most of collective memory research today shows some interest in one way or another in narratives, narrative memory approaches are characterised by the central role they give to storytelling, seen both as the canonical form for memory (Brockmeier, 2002) and the way cultural contexts shape recall (Wertsch, 2008).

This approach therefore links the processes through which people remember the collective past to narrative reasoning. This offers the advantage of highlighting the importance of meaning-making in memory - an important part of Bartlett's criticism - while making the study of collective memory quite straightforward. Indeed, if its canonical form is a story, then one needs only to find the plot and the protagonists to have all the information necessary to study how people understand the past. And it was indeed, most of the time, what happened in narrative studies of collective remembering: They focused far more on the content of the stories told than on the processes through which they were produced - often out of a far greater interest for the effects of narrative construction on identity (e.g., Gómez-Estern \& de la Mata Benítez, 2013; Kulyk, 2011). Moreover, most of the research on the processes through which historical narratives are constructed has disregarded the idea of narrative reasoning - at the centre of Bruner's work and instead focused on the normative role of culture in the way stories are told (in the form, for instance, of Wertsch's narrative templates).

Narrative approaches have offered rich descriptions of collective memory in specific contexts but have also proposed theoretical contributions and contributed to a better understanding of how it shapes identity. For instance, Brescó de Luna (2017) has argued that historical narratives use prolepsis, "the narrative 
manoeuver consisting of narrating or evoking a future event in advance" (Brescó de Luna, 2017, p. 280). By doing so, they implicitly defend a certain vision of the future, embedded in the representation of the past: Narratives of golden ages and declines, for example, imply that a regrowth is to come. Hammack (2010), on the other hand, showed how shared narratives participate in the construction of identity, and how collective stories are nonetheless adapted to create a unique identity, by analysing the discourses of Palestinian youths who built their identities by using the shared theme of loss and dispossession.

However, the narrative approach has two important flaws. First, it has not been fully able to provide an account of how people actively produce meaning about the past in cultural contexts where myriads of narratives are available and when cultures are always multiple, contradictory, and open to alternatives (Billig, 1987), and thus where stories, however shared as they may seem, are always contested. Second, it has had a tendency to collapse all memory into the idea of "narratives on the past," often neglecting other forms it may take. At best, it has led researchers to overlook memory that does not take a narrative form. At worst, it has led them to commit the psychologist's fallacy (James, 1890) of assuming that for any reference to the past there is a story underlying, waiting to be discovered - hidden in the head of the research participant (de Saint Laurent, 2018a).

How, then, can we theorise the ways in which we think about history, while keeping sight of the subject as an intentional agent and the context within which collective memory occurs? This is what the next chapter aims to do.

\section{References}

Abric, J.-C. (1994). Les représentations sociales: Aspects théoriques. In J.-C. Abric (Ed.), Pratiques sociales et représentations (pp. 11-35). Presses Universitaires de France.

Austin, J. (1975). How to do things with words (2nd ed.). Harvard University Press.

Awad, S. H. (2017). Documenting a contested memory: Symbols in the changing city space of Cairo. Culture \& Psychology, 23(2), 234-254. https://doi.org/10.1177/1354067X17695760

Bar-Tal, D. (2014). Collective memory as social representations. Papers on Social Representations, 23, 5.1-5.26.

Bartlett, F. C. (1932). Remembering. A study in experimental and social psychology. Cambridge University Press.

Bauer, M. W., \& Gaskell, G. D. (1999). Towards a paradigm for research on social representations. Journal for the Theory of Social Behaviour, 29, 163-186. https://doi. org/10.1111/1468-5914.00096

Berger, P., \& Luckmann, T. (1966). The social construction of reality: A treatise in the sociology of knowledge. Penguin.

Billig, M. (1987). Arguing and thinking. A rhetorical approach to social psychology. Cambridge University Press.

Billig, M. (1995). Banal nationalism. Sage Publications.

Billig, M. (1998). Repopulating social psychology. A revised version of events. In B. Bayer \& J. Shotter (Eds.), Reconstructing the psychological subject: Bodies, practices and technologies (pp. 126-152). Sage Publications. 
Billig, M., Candor, S., Edwards, D., Gane, M., Middleton, D. J., \& Radley, A. (1988). Ideological dilemmas. A social psychology for everyday thinking. Sage Publications.

Brescó de Luna, I. (2017). The end into the beginning. Prolepsis and the reconstruction of the collective past. Culture \& Psychology, 23(2), 280-294. https://doi.org/ 10.1177/1354067X17695761

Brockmeier, J. (2002). Remembering and forgetting. Narrative as cultural memory. Culture \& Psychology, 8(1), 15-43. https://doi.org/10.1177/1354067X0281002

Brown, S. D., Middleton, D. J., \& Lightfoot, G. (2001). Performing the past in electronic archives: Interdependencies in the discursive and non-discursive ordering of institutional rememberings. Culture \& Psychology, 7(2), 123-144. https://doi.org/10.1177/ $1354067 X 0172001$

Brown, S. D., \& Reavey, P. (2017). False memories and real epistemic problems. Culture \& Psychology, 23(2), 171-185. https://doi.org/10.1177/1354067X17695764

Brown, S. D., \& Reavey, P. (in press). Memory in the wild. In B. Wagoner (Ed.), Memory in the wild. Information Age.

Bruner, J. S. (1987). Life as narrative. Social Research, 54, 11-32.

Bruner, J. S. (1991). The narrative construction of reality. Critical Inquiry, 18, 1-21.

Carlston, D. (Ed.). (2013). The Oxford handbook of social cognition. Oxford University Press. https://doi.org/10.1093/oxfordhb/9780199730018.001.0001

Coman, A., Brown, A. D., Koppel, J., \& Hirst, W. (2009). Collective memory from a psychological perspective. International Journal of Politics, Culture, and Society, 22(2), 125-141. https://doi.org/10.1007/s10767-009-9057-9

Connerton, P. (1989). How societies remember. Cambridge University Press.

de Saint Laurent, C. (2014). "I would rather be hanged than agree with you!" Collective memory and the definition of the nation in parliamentary debates on immigration. Outlines. Critical Practice Studies, 15(3), 22-53.

de Saint Laurent, C. (2017a). Personal trajectories, collective memories. Remembering and the life-course. Culture \& Psychology, 23(2), 263-279.

de Saint Laurent, C. (2017b). Trajectories of resistance and historical reflections. In N. Chaudhary, G. Marsico, P. Hviid \& J. Villadsen (Eds.), Resistance in everyday life: Constructing cultural experiences (pp. 49-63). Springer.

de Saint Laurent, C. (2018a). Memory acts. A theory for the study of collective memory in everyday life. Journal of Constructivist Psychology, 31(2), 148-162. http://dx.doi.org/ 10.1080/10720537.2016.1271375

de Saint Laurent, C. (2018b). Thinking through time. From collective memory to collective imagination. In C. de Saint Laurent, S. Obradović \& K. Carriere (Eds.), Imagining collective futures. Perspectives from social, cultural and political psychology. Palgrave Macmillan.

de Saint Laurent, C. (in press). Setting specificity and memory: A perspective from sociocultural psychology. In B. Wagoner (Ed.), Memory in the wild. Information Age. www.researchgate.net/publication/334508407_Setting_specificity_and_memory_A_ perspective_from_sociocultural_psychology

de Saint Laurent, C., Brescó de Luna, I., Awad, S. H., \& Wagoner, B. (2017). Collective memory and social sciences in the post-truth era. Culture \& Psychology, 23(2), 147-155. https://doi.org/10.1177/1354067X17695769

Delori, M. (2011). Le poids de la mémoire sur la politique étrangère. Politique Européenne, 34(2), 231-241. https://doi.org/10.3917/poeu.034.0231 
Déloye, Y. (2002). Halbwachs Maurice (1877-1945). In J. Barus-Michel, E. Enriquez \& A. Lévy (Eds.), Vocabulaire de psychosociologie (pp. 498-500). Eres.

Doise, W. (1993). La double dynamique sociale dans le développement cognitif. Bulletin de Psychologie, 412, 653-661.

Duveen, G. (2001). Representations, identities, resistance. In K. Deaux \& G. Philogene (Eds.), Representations of the social (pp. 257-270). Blackwell.

Edwards, D., Middleton, D. J., \& Potter, J. (1992). Remembering as a discursive phenomenon. The Psychologist, 15, 441-446.

Evans, J. (1989). Bias in human reasoning. Causes and consequences. Erlbaum.

Evans, J., \& Over, D. E. (1996). Rationality and reasoning. Psychology Press.

Farr, R. M., \& Anderson, T. (1983). Beyond actor-observer differences in perspective. Extensions and applications. In M. Hewstone (Ed.), Attribution theory: Social and functional extensions (pp. 45-64). Blackwell.

Fiske, S. T., \& Taylor, S. E. (1991). Social cognition. McGraw-Hill.

Fivush, R. (2011). The development of autobiographical memory. Annual Review of Psychology, 62(1), 559-582. https://doi.org/10.1146/annurev.psych.121208.131702

Fivush, R., Bohanek, J. G., \& Duke, M. (2008). The intergenerational self. Subjective perspective and family history. In F. Sani (Ed.), Self continuity. Individual and collective perspectives (pp. 131-143). Psychology Press.

Gergen, K. J. (1973). Social psychology as history. Journal of Personality and Social Psychology, 26, 309-320.

Gómez-Estern, B. M., \& de la Mata Benítez, M. L. (2013). Narratives of migration. Emotions and the interweaving of personal and cultural identity through narrative. Culture \& Psychology, 19(3), 348-368. https://doi.org/10.1177/1354067X13489316

Haas, V., \& Jodelet, D. (2000). La mémoire, ses aspects sociaux et collectifs. In N. Roussiau (Ed.), Manuel de psychologie sociale (pp. 121-134). Editions In Press.

Halbwachs, M. (1950). La mémoire collective. Albin Michel.

Halbwachs, M. (1992). On collective memory. The University of Chicago Press.

Hammack, P. L. (2010). The cultural psychology of Palestinian youth. A narrative approach. Culture \& Psychology, 16(4), 507-537. https://doi.org/10.1177/1354067X10380159

Harré, R., \& Gillett, G. (1994). The discursive mind. Sage Publications. https://doi. org/10.4135/9781452243788

Herlihy, J., Jobson, L., \& Turner, S. (2012). Just tell us what happened to you. Autobiographical memory and seeking asylum. Applied Cognitive Psychology, 26(5), 661-676. https://doi.org/10.1002/acp.2852

Hewer, C. J., \& Kut, M. (2010). Historical legacy, social memory and representations of the past within a Polish community. Memory Studies, 3(1), 18-32. https://doi. org/10.1177/1750698009348292

Hewstone, M., \& Brown, R. (1986). Contact is not enough. An intergroup perspective on the "contact hypothesis." In M. Hewstone \& R. Brown (Eds.), Contact and conflict in intergroup encounters (pp. 1-41). Basil Blackwell.

Hirst, W., \& Echterhoff, G. (2012). Remembering in conversations: The social sharing and reshaping of memories. Annual Review of Psychology, 63, 55-79. https://doi.org/ 10.1146/annurev-psych-120710-100340

James, W. (1890). The principles of psychology: Vol. I. Dover Publications.

Jovchelovitch, S. (2007a). In defence of representations. Journal for the Theory of Social Behaviour, 26, 121-135. https://doi.org/10.1111/j.1468-5914.1996.tb00525.x 
Jovchelovitch, S. (2007b). Knowledge in context. Representations, community and culture. Routledge.

Jovchelovitch, S. (2012). Narrative, memory and social representations. A conversation between history and social psychology. Integrative Psychological \& Behavioral Science, 46(4), 440-456. https://doi.org/10.1007/s12124-012-9217-8

Kahneman, D. (2013). Thinking, fast and slow (1st ed.). Farrar, Straus and Giroux.

Kansteiner, W. (2002). Finding meaning in memory. A methodological critique of collective memory studies. History and Theory, 41(2), 179-197. https://doi.org/10.1111/ 0018-2656.00198

Katriel, T. (1994). Sites of memory. Discourses of the past in Israeli pioneering settlement museums. Quarterly Journal of Speech, 80, 1-20. https://doi.org/10.1080/ 00335639409384052

Katzev, R., \& Brownstein, R. (1989). The influence of enlightenment on compliance. The Journal of Social Psychology, 129, 335-347.

Kontopodis, M., \& Matera, V. (2010). Doing memory, doing identity: Politics of the everyday in contemporary global communities. Outlines. Critical Practice Studies, 12(2), 1-14.

Kulyk, V. (2011). The media, history and identity. Competing narratives of the past in the Ukrainian popular press. National Identities, 13, 287-303. http://dx.doi.org/10.1080/14 608944.2011 .591373

Le Bon, G. (1896). Psychologie des foules. Alcan.

Licata, L., Klein, O., \& Gély, R. (2007). Mémoire des conflits, conflits de mémoires. Une approche psychosociale et philosophique du rôle de la mémoire collective dans les processus de réconciliation intergroupe. Social Science Information, 46(4), 563-589. https://doi.org/10.1177/0539018407082593

Liu, L. (2004). Sensitising concept, themata and shareness. A dialogical perspective of social representations. Journal for the Theory of Social Behaviour, 34, 249-264. https:// doi.org/10.1111/j.0021-8308.2004.00247.x

Liu, J. H., Goldstein-Hawes, R., Hilton, D., Huang, L.-L., Gastardo-Conaco, C., DreslerHawke, E., Pittolo, F., Hong, Y.-Y., Ward, C., Abraham, S., Kashima, Y., Kashima, E., Ohashi, M. M., Yuki, M., \& Hidaka, Y. (2005). Social representations of events and people in world history across 12 cultures. Journal of Cross-Cultural Psychology, 36(2), 171-191. https://doi.org/10.1177/0022022104272900

Liu, J. H., \& Hilton, D. (2005). How the past weighs on the present. Social representations of history and their role in identity politics. British Journal of Social Psychology, 44, 537-556. https://doi.org/10.1348/014466605X27162

Malle,B.F.(2006). The actor-observer asymmetry in attribution:A(surprising)meta-analysis. Psychological Bulletin, 132(6), 895-919. https://doi.org/10.1037/0033-2909.132.6.895

Marková, I. (2000). Amédée or how to get rid of it. Social representations from a dialogical perspective. Culture \& Psychology, 6, 419-460. https://doi.org/10.1177/1354067X0064002

Marková, I. (2003). Dialogicality and social representations. The dynamics of mind. Cambridge University Press.

McAdams, D. P. (1988). Biography, narrative, and lives. An introduction. Journal of Personality, 56(1), 1-18. https://doi.org/10.1111/j.1467-6494.1988.tb00460.x

McAdams, D. P. (1993). The stories we live by. Personal myths and the making of the self. William Morrow.

Middleton, D. J. (1997). The social organization of conversational remembering: Experience as individual and collective concerns. Mind, Culture and Activity, 4, 71-85. 
Middleton, D. J., \& Brown, S. D. (2005). The social psychology of experience. Studies in remembering and forgetting. Sage Publications.

Middleton, D. J., \& Edwards, D. (1990). Collective remembering. Sage Publications.

Moscovici, S. (1961). La psychanalyse, son image et son public. Presses Universitaires de France.

Moscovici, S. (1973). Foreword. In C. Herzlich (Ed.), Health and illness. A social psychological analysis (pp. ix-xiv). Academic Press.

Moscovici, S. (1984). The phenomenon of social representations. In R. Farr \& S. Moscovici (Eds.), Social representations (pp. 3-69). Cambridge University Press.

Murakami, K., \& Middleton, D. J. (2006). Grave matters. Emergent networks and summation in remembering and reconciliation. Ethos, 34(2), 273-296. https://doi.org/10.1525/ eth.2006.34.2.273

Nelson, K. (2006). Narratives from the crib. Harvard University Press.

Nelson, K. (2007). Young minds in social worlds. Experience, meaning, and memory. Harvard University Press.

Nicholson, C. (2017). The role of collective memory in protracted conflict. Culture \& Psychology, 23(2), 217-233. https://doi.org/10.1177/1354067X17695762

Nora, P. (1997). Les lieux de mémoire. Gallimard.

Olick, J. K. (1999). Collective memory. The two cultures. Sociological Theory, 17(3), 333-348. https://doi.org/10.1111/0735-2751.00083

Potter, J. (1996). Representing reality. Discourse, rhetoric and social construction. Sage Publications.

Potter, J., \& Edwards, D. (1999). Social representations and discursive psychology. From cognition to action. Culture \& Psychology, 5(4), 447-458. https://doi.org/10.1177/ 1354067 X9954004

Potter, J., \& Litton, I. (1985). Some problems underlying the theory of social representations. British Journal of Social Psychology, 24, 81-90. https://doi.org/10.1111/ j.2044-8309.1985.tb00664.x

Poulter, J. (2017). The discursive reconstruction of memory and national identity. The antiwar memorial the Island of Ireland Peace Park. Memory Studies, 1750698016688240. https://doi.org/10.1177/1750698016688240

Psaltis, C. (2012). Intergroup trust and contact in transition. A social representations perspective on the Cyprus conflict. In I. Marková \& A. Gillespie (Eds.), Trust and conflict. Representation, culture and dialogue (pp. 83-104). Routledge.

Raudsepp, M., \& Wagner, W. (2012). The essentially other. Representational processes that divide groups. In I. Marková \& A. Gillespie (Eds.), Trust and conflict. Representation, culture and dialogue (pp. 105-122). Routledge.

Ross, L. (1977). The intuitive psychologist and his shortcomings: Distortions in the attribution process. Advances in Experimental Social Psychology, 10, 173-220. https://doi. org/10.1016/S0065-2601(08)60357-3

Sherif, M., Harvey, O. J., White, B. J., Hood, W. R., \& Sherif, C. W. (1961). Intergroup conflict and cooperation. The Robbers Cave experiment. The University Book Exchange.

Valsiner, J. (2014). An invitation to cultural psychology. Sage Publications.

Wagoner, B. (2015). Collective remembering as a process of social representation. In G. Sammut, E. Andreouli, G. Gaskell \& J. Valsiner (Eds.), The Cambridge handbook of social representations (pp. 143-162). Cambridge University Press.

Welzer, H., Moller, S., \& Tschuggnall, K. (2013). Grand Père n'était pas un nazi. Nationalsocialisme et Shoah dans la mémoire familiale. Editions Gallimard. 
Wertsch, J. (1997). Narrative tools of history and identity. Culture \& Psychology, 3(1), 5-20. https://doi.org/10.1177/1354067X9700300101

Wertsch, J. (1998). Mind as action. Oxford University Press.

Wertsch, J. (2002). Voices of collective remembering. Cambridge University Press.

Wertsch, J. (2008). The narrative organization of collective memory. Ethos, 36, 120-135. https://doi.org/10.1111/j.1548-1352.2008.00007.x

Wertsch, J., \& Batiashvili, N. (2012). Mnemonic communities and conflict. Georgia's narrative template. In I. Marková \& A. Gillespie (Eds.), Trust and conflict. Representation, culture and dialogue (pp. 37-48). Routledge.

Zittoun, T., Duveen, G., Gillespie, A., Ivinson, G., \& Psaltis, C. (2003). The use of symbolic resources in developmental transitions. Culture \& Psychology, 9, 415-448. https://doi. org/10.1177/1354067X0394006 


\section{Thinking about the collective past}

\section{Beyond collective memory}

\section{Moving beyond collective memory}

\section{The problem with collective memory}

The aim of this book is to study how people actively think about history, to understand, evaluate, represent, and give meaning to the collective past. As such, part of the literature presented in the previous chapter, although able to bring interesting insights into the questions that will be considered, is a bit outside of our scope. In particular, the literature on collective memory that considers it to be the result of memory processes is not especially adapted to the study of historical representations: Not only does it solely cover recent events - the ones we lived through - but it supposes a fundamental difference between these and the representations of the historical past. This position is hard to justify, as it means making a difference in terms of processes that we assume to be taking place but that may not show in practice or that are too deeply intertwined (de Saint Laurent, 2018). How to know, more than 70 years after it took place, if my grandmother is remembering World War II, or relying on what she has heard about it ever since?

Similarly, studies that focus on collective memory as a collective phenomenon mainly collected approaches - are partly off the topic of this book. If this may sound a bit confusing, this is because the word "collective" has a double meaning in this context. On the one hand, it means "the memory of collective events," but on the other, it designates "the memory of the collective." This second meaning does not fit within the scope of this book; because I am interested in how historical representations are constructed - and not how they are shared - the phenomena that interest me are at the limit of social representations, where they appear, disappear, and stop being "social." This is not to say, of course, that I do not take psychological phenomena to be deeply social, as we will see. It simply means that the present book focuses on processes and practices that are outside the full scope of social representations.

What I propose, then, is to move beyond the term of collective memory, for two main reasons. First, as has been seen in the non-exhaustive literature review of the previous chapter, it is a polysemantic term that covers a multitude of interrelated yet different phenomena. It is thus necessary to move beyond the term of collective memory to be able to avoid confusion and propose further theoretical 
advances that take the differences between the phenomena into account. Second, and as has been argued above, a large part of what is designated by the term collective memory is not "memory" in the psychological sense. Moving beyond this term thus means moving beyond the idea that everything that is said about the past is the result of a single process - memory.

At a more "political" level, however, it implies questioning who has expertise on the topic, beyond the researchers investigating the phenomenon. If representations of the past are the memory of someone, then this person, however biased, has a strong legitimacy over what can be said about that past. No matter how flawed my memory may be, I do have more legitimacy in claiming that some events took place or not in my childhood than anyone who did not witness them or know me as child. However, if representations of the past are not a person's memory, then she does not have a particular legitimacy in talking about it. I may have grown up in France, for instance, but I am not more legitimate when I talk about the Revolution than, say, a person who has read extensively on the topic. This distinction is particularly important in an era where claims based on "feelings" and "impressions" are gaining more and more traction (de Saint Laurent et al., 2017; Keyes, 2004): Talking about collective memory does imply, to a certain extent, that the French, the Polish, or the British have more legitimacy in discussing their past - because it is theirs - than anyone else, including the "others" who may have suffered from it. Moving beyond the term of collective memory, then, also means questioning such problematic consequences.

\section{A (not so) new vocabulary}

I propose, thus, to use in this book a "new" vocabulary: New in the sense that it creates new delimitations within the field of collective memory, but not so new insofar as it uses quite commonsensical terms. Indeed, I will prefer, in the rest of this book, the expressions collective past, representations of the collective past, and thinking about the collective past. First, I will use the term collective past (CP), in place of history or collective memory, to designate the object of this type of social thinking. It avoids mixing together the content of what is represented (Historical facts? Memories of our social life?), by whom (Historians? Lay people?), and how (Scientific deliberation? Biased narration?), to cover more broadly past events that belong to the realm of collective life. It does so by bypassing the questions raised by the terms collective memory and history that are not directly relevant to this book. In particular, these terms pose the question of whether the difference between history and collective memory is a matter of temporality (i.e., living memory vs. dead history), expertise (i.e., historians vs. lay people), or processes (i.e., remembering vs. representing), which, as seen above, is not pertinent here; in fact, quite the contrary.

Second, the term representation of the collective past ( $R C P$ or representation of $C P$ ) will be used when referring to the way this collective past is represented. More specifically, adapting from the concept of social representations, I propose to define representations of the collective past (RCPS) as a system of values, ideas, 
and practices about the collective past that enables people to give meaning to it and to communicate about it. Finally, thinking about the collective past (TCP or thinking about $\mathrm{CP}$ ) refers to how these representations are used, constructed, maintained, contested, and challenged. Exploring the construction of $R C P s$ and the processes underlying $T C P$ will be the central object of the rest of this book.

These three terms do not aim at replacing the one of collective memory - especially as large areas of collective memory are not covered here; in particular, those concerned with the psychosocial processes of memory. On the contrary, they offer a more specific vocabulary to study phenomena that have been designated as a single broad term: collective memory or collective remembering. It thus allows us to focus on one particular aspect of collective memory; that is, the construction of RCPs. In the rest of this chapter, I will first propose a sociocultural model of RCPs and TCP based on the literature reviewed in the previous chapter. I will then discuss the questions raised by this model and introduce the three studies that were developed in response.

\section{Thinking about the collective past}

\section{A model of how we think about the collective past}

How do we think about the collective past, using and constructing specific representations of it? Based on the literature on social thinking and collective memory reviewed in Chapter 2, and the pragmatist sociocultural approach presented in Chapter 1, we can propose the preliminary model presented in Figure 3.1.

The "self" pole of the model refers to the agent who is thinking about the collective past. Indeed, understanding the past is always done from a subjective point of view. That is not to say that objective facts about the collective past do not exist, but that their meaning and significance is always interpreted from a specific perspective. This also emphasises the intentionality of TCP: While some references to the collective past may be unreflexive or unconscious - I do not knowingly refer to Admiral Horatio Nelson when I say I turn a blind eye to something, even

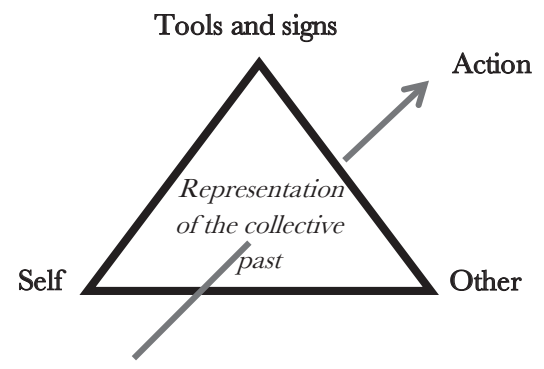

Figure 3.I Thinking about the collective past (TCP) as oriented, culturally mediated, and dialogical action.

Source: adapted from de Saint Laurent, 20I7a. 
if the expression does come from him looking through a telescope with his blind eye during a battle - thinking about the collective past is an intentional activity. For instance, choosing to compare the current political situation in Europe and the US with the 1930s, as many have done in the past few years, is a very intentional action. Doing so not only reflects an active effort towards understanding the past - in order to draw a comparison with the present - but it is also done from a specific perspective, often one of deep concern for the current rise of nationalist discourses. It is also, in many cases, the product of a quite personal understanding of World War II, often linked to one's family history.

The "other" pole of the model highlights the dialogical orientation of RCPs, at two levels. First, it refers to how representations of the past are produced and used in interactions with others. That is, talking about the past is always done against the backdrop of what others have to say about it, and what we imagine them to know or believe. For instance, comparing the present with the 1930s implies imagining that the other shares a representation of World War II as a nadir of humanity to be avoided at all cost - unfortunately, not a given - for the comparison to conserve its power. Second, defending certain representations of the past positions us towards others, and as proponents of specific ideologies or members of particular social groups. To continue with our example, equating Trump's election or the rise of farright parties in Europe with the beginning of Nazism quite clearly positions one within the social field, most often as rather leftist and pro-immigration.

The "tools and signs" pole corresponds to the resources one can use to think about the collective past. This is a bit of a catch-all term, but it can be divided into three broad categories. First, framing or structuring tools, such as narratives frames, allow people to organise and structure RCPs. The general narrative of unforeseen yet predictable shift from democracy to dictatorship, for instance, is often used to describe the pre-war period, but it is not specific to it - it is also, funnily enough, the plot of the Star Wars prequels. This narrative frame, however, can be used to organise our representations of the 1930s. Second, symbols and signs can help give meaning to the past. In the previous example, the narrative frame used is associated with particular symbols: Around democracy and dictatorship, most notably, but also around the Cassandra archetype - the one able to foresee the future but who cannot do anything to prevent it. Third, other accounts of the collective past - in the form of texts, movies, political discourses, museum exhibits, etc. - are a major resource for RCPs and TCP, providing content both to construct new accounts and to challenge them. Our representations of the pre-war era, for instance, are often fuelled by how it has been presented in movies, most often as a dangerously carefree period.

The final pole of this model, "action," emphasises the action orientation of TCP. It highlights two main aspects. First, thinking about the collective past is an activity oriented towards an aim, whether it is, for instance, to give meaning to the past, convince others, or imagine where the future may lead us. Comparing the present to the pre-war period can help one understand the current political climate, imagine how it might turn out, and what could be done, as well as argue with others about whether political action is required or not. Second, it highlights 
the fact that TCP is part of a broader activity that orients how the past will be represented. Discussing the 1930s in a political discourse, for instance, in order to characterise one's opponent as dangerous, will necessarily yield very different results than doing it in a conversation with one's partner in an attempt to imagine where you might be in ten years.

This model thus considers TCP to be an oriented action - an "effort after meaning" to use Bartlett's expression - done by intentional agents, in interactions with others, and through the use of cultural tools. It thereby builds on the different literatures presented in the previous chapters. First, it follows the basic assumptions of sociocultural psychology, considering psychological processes to be characterised by agentivity, an orientation towards others, and cultural mediation. The triangle self-other-tools and signs indeed stems from Vygotsky's work, who posited that all human activities are mediated by the use of cultural tools and/or signs (Vygotsky, 1978) and that they exist in a triangular relation including self and others, through which such tools and signs come to be mastered (Vygotsky \& Luria, 1994). It also borrows from Wertsch's adaptation of it to collective memory (Wertsch, 2002, see Chapter 2). Moreover, this model is dialogical, putting the relation self-other at the heart of human cognition (Fernyhough, 2008).

Second, it uses the discursive approach, understanding representations of CP as intentional constructions, although it does not limit it to discourse. That is, it sees TCP as a process oriented towards an action. Finally, it borrows from social representations theory, conceptualising RCP as a symbolic representation of the collective past. It hereby highlights the importance of meanings, considering that one of the central aims pursued by people when they remember the collective is to give it meaning, in line with Bruner's work, Bartlett's ideas, and semiotic perspectives on sociocultural psychology.

However, this model does leave open multiple questions: If the past is constructed from a specific subjective perspective, how does that perspective emerge in time? If RCPs are oriented towards others and constructed in interactions with them, how do we come to share some aspects of them and not others? If different cultural elements - from historical concepts to movies - can be used to think about the collective past, how do we choose which ones to use and how do we use such a broad range of resources? Finally, if TCP is an activity oriented towards an aim, how do we construct different representations of the past in different contexts, and yet conserve a sense of coherence? In order to propose tentative answers to these questions, let us consider each pole of the model in more detail.

\section{Going further}

\section{Action}

Action, in the model presented above, refers to both the intentionality of the person thinking about the collective past - what she is trying to do by using or constructing RCPs - and the broader activity context within which TCP is taking place. 
Reviewing all the intentions one may be pursuing when thinking about the collective past, or all the activities within which it could take place, would only result in an inexhaustive laundry list of situations: Representations of the collective past are both pervasive and, as we will see, very flexible tools. Nonetheless, at a quite general and abstract level, RCPs can be used for two main purposes: Meaningmaking and argumentation.

Meaning-making refers to how we make sense of things, to "the process by which human beings make the world readable, valuable and actionable, through the use of semiotic means" (Dahinden \& Zittoun, 2013, p. 187). It is thus a very broad term, encompassing the multitude of ways through which we attempt to understand the world around us. In the case of RCPs, meaning-making has two main dimensions. First, representations of the collective past can be used to give meaning to the present, or what we imagine might come in the future. In other words, thinking about the collective past may be a tool to understand present aspects of collective life. This is, for instance, what intellectuals like Foucault help us do: By constructing a new representation of the history of mental illness, for example, or of crime, Foucault's work gives new meaning to the ways in which our societies presently deal with these issues in psychiatric hospitals and prisons.

Second, thinking about the collective past, by constructing a symbolic representation of it, also involves giving it meaning. On the one hand, if RCPs can be used as a resource to understand other events, it is because they have for us a certain signification: If people are comparing the present to the pre-war period, it is because it represents a period of relative carelessness in the face of imminent doom, a situation some are paralleling with how the election of Donald Trump has not always been taken very seriously by the media. On the other hand, understanding the past in itself requires giving it meaning: Comprehending something as monumental as World War II implies attempting to make sense of how it could have happened and of what it signifies for human societies.

If RCPs are both a resource to make sense of the world and themselves the result of a semiotic process, one interesting implication is that the relation between the meaning given to the collective past and how it is used to give meaning to the present can be bidirectional. In other words, the past can give sense to the present, but the present can also give sense to the past, a phenomenon sometimes refered to as presentism (Brescó de Luna, 2018). There is no reason to think, however, that this two-way relationship is limited to the past/present: The meaning given to an historical event could very well be used to make sense of others, and representations of the past, therefore, may constitute a quite flexible system of knowledge.

Thinking about the collective past can also be done with another general purpose: To argue with others in order to convince them of a certain state of affairs or of the validity of a certain course of action. Because of the power social knowledge has in (at least partially) creating social reality, it is constantly negotiated, making argumentation a central aspect of social life (Billig, 1987). References to the 1930s in discussions about the current political context, for instance, are 
usually used to argue that Trump's actions or the general rise of the far right need to be taken seriously, before it is too late. RCP, thus, are also rhetorical devices that can be very consciously employed to convince others - or even oneself - by drawing, for instance, analogies with the present.

The way representations of the collective past can be used in argumentation does, of course, depend on the meaning that is given to them. The two general aims outlined in this section are thus interrelated, and it may be difficult - and perhaps pointless - to separate them in practice. Taken together, two aims of TCP outlined here have two main consequences. First, the way people think about the collective past will depend on what they are trying to make sense of or to argue for. This does not necessarily mean that we defend widely different versions of RCPs, constantly changing our minds to fit our current needs, but that different aims and interlocutors may afford using particular aspects of RCPs or giving it different - yet not incompatible - meanings. Referring to the 1930s to discuss politics, for instance, will make some aspects of it more salient than if one uses it to review how governments should react to financial crises. Second, it implies that RCPs cannot be taken in isolation from each other, for they are part of broader systems of knowledge, and relate more globally to how we understand the world we live in.

\section{Other}

Because dialogism stands on "the assumption that human nature and human life are constituted in interrelations with 'the other', that is, in other orientation" (Linell, 2009 , p. 13), it offers us several concepts that can help us unpack the "other" dimension of the model proposed in this chapter. In particular, the notions of addressivity, I-positions, and themata - introduced in chapters 1 and 2 - are especially useful here. As a reminder, addressivity is the idea, proposed by Bakhtin (1986), that all speech is always a reply to someone and that it anticipates what might be said next. I-positions, a term introduced by Hermans (2001), refer to the fact that the self can speak from different (internalised) social positions that may enter into dialogue with each other. Finally, themeta - a concept developed by Marková (2000) and originally proposed by Moscovici (Moscovici \& Vignaux, 1994) - are the thematic oppositions that structure and fuel social thinking. What do these notions bring to the study of RCPs and TCP?

First, addressivity implies that what is said about the past is always a reply to someone else: It is the response to the - real or imagined - discourses held by others. This extends beyond the situation within which TCP takes place, as conversations can extend over time (e.g., reacting hours or days later to something the other has said) and interlocutors (e.g., "taking out" our frustration on someone other than the person who originally angered us), or can even be entirely imagined (e.g., rehearsing a conversation in our head). Narrating the history of one's country in a research interview, thus, means addressing the researcher asking the questions - and what she is imagined to want - but also what we think she might 
hear elsewhere, what we have discussed with others, and what we may have said about it in the past. This might be one of the reasons why collective memory research has found that we tend to reduce discourses to a single voice by downplaying "ambiguity and doubt" (Wertsch \& Batiashvili, 2012, p. 38), because it focuses on only one part of a multi-sided conversation.

Second, the concept of I-positions entails that people speak from different, internalised, social positions. Indeed, discourses are never neutral but always the product of a specific social position. This goes beyond claims about the social construction of social reality: Even the most objective of facts are described using a certain vocabulary and a certain genre that is associated with its use by specific people in the past - we do not learn to talk from dictionaries but from the speech of others - in specific context - scientific articles and storytelling, for instance, call for a very different style (Bakhtin, 1986). We come to take, in time, a myriad of such I-positions (Hermans, 2001). Not only do we come to assume multiple social positions, but we also come to belong to numerous social groups. Indeed, social memberships are neither static nor mutually exclusive (Gillespie et al., 2012). As a result, the way we talk about the collective past socially positions us towards others and towards ourselves (de Saint Laurent, 2017a). Most notably, the accounts we give of the collective past can signal to others which social groups we would like to be associated with, and where we locate ourselves on the political spectrum. During the Brexit campaign, for instance, the different interpretations given to the end of World War II and the construction of the European Union were clearly associated with different identities and voting choices. On one side, World War II was seen as proof of the strength of the "British spirit" and the EU as a successor of the USSR - as illustrated in the introduction of this book. On the other, the EU was portrayed as the guardian of peace, warding us against the nationalisms of World War II.

Finally, themata relies on the notion that social knowledge is structured by thematic oppositions (Marková, 2003) between different aspects of social life, that correspond to fundamentally antinomic ideas. The opposition between democracy and authoritarianism, for instance, fuels much of our representations of how modern states are working. While one side is often seen as more desirable than the other, Billig (1987) argued that it is actually because we are attracted to both poles that debate exists. Although most would indeed agree that dictatorship is to be avoided, debates about whether we should prefer "strong statesmen" - seen as strong by flirting with authoritarianism - regularly flair up, usually in relation to the recent electoral success of such statesmen. And indeed, defending a certain representation of the world means that we can imagine the alternative to be possible, or that we have heard others argue for it. Thus, representations always exist in tension with their alternative (Gillespie, 2008).

These dialogical theories paint an interesting picture of the role of alterity in RCPs and TCP. They entail that discourses on the collective past are not just constructed in dialogue with others, but that they are fully co-constructed. Indeed, while the former implies that what we say is shaped by whom we are addressing, 
the latter means that what others are imagined-thinking about the past participate to the content of RCPs themselves. Moreover, if thematic oppositions are at the heart of social thinking, and thus of TCP, it means that what is said about the past activates a web of alternative representations, potentially making RCPs a lot more flexible than what the literature has suggested so far.

\section{Self}

How to explain that, in the same context, people who share a similar sociocultural background may produce widely different accounts of the past? In other words, where is the person, in her uniqueness, in our understanding of TCP? In fact, what has often been missing in theories of collective memory, but also more generally social thinking, is the psychological subject who does said thinking. But how to bring back the person at the centre of these processes, without losing sight of her social and cultural dimensions by reducing her to a series of discrete and decontextualised personality traits? One way to do this, proposed by Zittoun (2006), has been to adopt a developmental perspective. And indeed, collective memory theories have tended to present it as an "amnesic" phenomenon, where the person representing the past is deprived of the past that makes her who she is. Overlooking the temporal dimension of TCP has, as a result, disconnected it from the subject that uses and constructs RCP.

Sociocultural developmental perspectives consider that because human life takes place in irreversible time (Valsiner, 1994), it creates unique trajectories (Zittoun et al., 2013). In time, we become familiar with different values and systems of meaning, through the various spheres of experience we find ourselves in (Zittoun \& Gillespie, 2015). Our lives are also marked by ruptures, where "the obvious suddenly comes into question" (Zittoun, 2006, p. 6), as when we start a new job, have a child, migrate, or lose a loved one. These ruptures may lead to transitions, where the way we understand the world and our life irremediably changes (Zittoun, 2012). These ruptures and transitions may be general and concern socially marked events - like starting a family - but they can also be very local and personal: Discovering that a beloved childhood figure committed wrongdoings, for instance, can lead one to reinterpret parts of their youth. As such, trajectories are subjective and dynamic: What may be experienced by some as life-shattering may not be questioned much by others. As we go through ruptures and navigate various spheres of experience - like work, family life, or our hobbies - we appropriate different systems of meaning or, by generalising from what we have experienced, produce new ones. Thus, our trajectories can account for how we relate to the world and give it meaning (Zittoun, 2006, 2008, 2012).

Adapting this literature to the topic at hand, it would mean that people have a "history in front of history," forming a trajectory - what I have called elsewhere, for simplicity, a trajectory of remembering (de Saint Laurent, in press, 2017a, 2017b; de Saint Laurent \& Zittoun, 2017). It implies that the way we think about the collective past is the result, on the one hand, of the meanings, ideas, and values 
we become exposed to throughout our lives, and, on the other hand, of how we have thought about it in past situations. It is indeed rarely the first time we think about a specific past event, and we do not start anew with every conversation we have. If you have come to the conclusion, for instance, that comparing the present with the 1930s is inappropriate because we now live in a much more globalised and urbanised world than we did almost a century ago, you are not going to forget this conclusion next time you discuss it, even if it is in a widely different context, with a completely different aim. And, similarly, the way you feel about globalisation and urbanisation is probably not disconnected to the values you have come across throughout your life.

While the concept of trajectories refers, in Zittoun's work, to personal life events, I believe that we can extend it to social thinking and TCP for two reasons. First, ideas, meanings, and representations do evolve in time, potentially forming trajectories in one's life. Second, the events that make up the collective past - and so the significations given to them - can influence one's trajectory as much as private events do and similarly provoke ruptures. The rise of far-right sympathisers in recent electoral results, for instance, has been experienced by some as a rupture that goes beyond the day-to-day consequences it may have, leading them to question how they have so far represented the society in which they live. Discovering that what you have always believed about the history of your country is false may provoke similar results - as it did, for instance, when I discovered that France had not been, since the Revolution, the champion of human rights I had learnt it in school to be, but instead a quite merciless colonial force. As such, our trajectories of remembering contribute to how we think today about the collective past, how we give it meaning, and the tools we might have to do so. It is through them that our unique and subjective perspectives on the collective past are forged.

\section{Tools and signs}

The last pole of the model corresponds to the tools and signs one may use to think about the collective past. As explained earlier in this chapter, as well as in chapters 1 and 2, this stems from Vygotsky's work, in particular on mediation, and its adaptation to collective memory by Wertsch. While Vygotsky was interested in how tools and signs are introduced to children, Wertsch's work focused on how we use resources to produce accounts of the past, especially texts. As a result, "tools and signs" is a bit of a catch-all expression, referring both to an abstract theoretical idea - the role of mediation in learning - and an extremely specific empirical reality - that existing texts about the collective past contribute to our RCPs. What is needed here is thus, at the same time, more concreteness - to apply Vygotsky's theory to TCP - and less specificity - to extend Wertsch's idea beyond textual resources. As a starting point, I thus propose to define tools and signs, in this model, as the set of resources one has access to in order to construct representations of the past, and that may give content, meaning, or structure to these representations. Indeed, based on the literature reviewed earlier, we can outline 
three broad categories of resources used for each of these purposes - content, meaning, and structure.

First, what Wertsch referred to as "text" can be extended to include, more generally, all the sources of content one may use for TCP. Movies, commemorations, and museum exhibits, but also conversations, artwork, etc., can and do provide some form of knowledge about the past. No matter how biased or interpretative our representations of the collective past are, they rely on what we believe to be at least partially accurate facts from the perspectives of those who experienced it. These act as potential resources - and not as unavoidable facts to be made sense of - because we are not passive in front of them. On the one hand, people can go to extreme lengths to reject or validate information depending on their own worldview and interest, even in the face of what would look to others damning evidence. On the other hand, we often actively seek knowledge that we consider to be trustworthy, for the very purpose of constructing a representation of a world that we believe to be as accurate as possible.

Second, we dispose of a multitude of semiotic resources that can help us give meaning to the past. That is, stories, symbols, concepts, values, and ideas can help us understand the past by connecting them to other areas of life or to more general interpretations. Cultures abound with such resources, which are either designed for this purpose - such as maxims, which offer meaningful generalisations about life - or can be diverted from their original aim - such as movies, often written to be entertaining and yet sometimes used to shed a new light on one's life (Zittoun \& Grossen, 2013). Given that one of the aims of TCP is to give meaning to the past, we can suppose that semiotic resources are particularly important for representations of the collective past. And because almost any cultural element can be used to produce meaning - even when it is not its original aim (Zittoun et al., 2003) semiotic resources may be quite pervasive.

Finally, we can use resources that provide a structure to our RCP, such as when we use a narrative template (Wertsch, 2008) to create an account of the past. This is what Bartlett (1932) referred to as schemas, which he explained as follows (p. 200):

An active organization of past reactions, or of past experiences, which must always be supposed to be operating in any well-adapted organic response. That is, whenever there is any order or regularity of behavior, a particular response is possible only because it is related to other similar responses which have been serially organised, yet which operate, not simply as individual members coming one after another, but as a unitary mass.

Schemas, from this perspective, are both the product of the organisation of past experiences and a resource to think about them. They are flexible, open-ended processes that allow people to generate new knowledge from the information available to them (McVee et al., 2005). While for Bartlett these were produced by generalising from past experiences - in a way rather similar to the processes that can be at play in life transitions - there is no reason to believe that schemas cannot 
be learnt from others - which is, in the case of RCP, one of the aims of history education (e.g., van Drie et al., 2005).

To use, one last time, our example comparing the present to the 1930s thus requires using specific information about the past (e.g., about the 1929 economic crash), giving it meaning (e.g., as the cause of the rise of nationalism), and a structure (e.g., through a narrative where economic desperation drives people towards nationalism) that can be used to draw an analogy with the present (e.g., the current rise of far-right parties is the result of the 2008 financial crisis). This example does highlight, however, the limits of the difference between RCPs and TCP: Representations of the collective past are both a resource to think about the past - they give meaning, content, and structure to how we understand past events - and the result of how we, and others, have thought about it. In our example, a representation of the past (the 1930s) is constructed to give meaning to another past event (the 2008 economic crisis). As such, the distinction between TCP and RCP is artificial. Yet, it has some practical interest: It allows us to distinguish between process and product, no matter how intertwined they are, and it is for this purpose that it will be used in the rest of this book.

\section{Studying how we think about the collective past}

\section{Research questions}

I have proposed, so far, a model of how we think about the collective past based on the literature on collective memory, social thinking, and sociocultural psychology. I have also tried, in the previous section, to theoretically extend this model. It is now time to empirically put these ideas to the test, and hopefully thereby enrich them, by addressing four general questions:

1) In what contexts are representations of the collective past used, and for what purposes?

2) How are representations of the collective past constructed and mobilised in interactions?

3) How do people come to develop specific or unique representations of the collective past?

4) What resources are used to construct representations of the collective past, and how are they employed?

Each one of these questions could be, in itself, the subject of an entire research programme, yet there is tremendous interest in studying them together. The research presented here is thus, in many aspects, exploratory. As such, it cannot directly address question 1: As discussed above, there is multitude of aims that one may pursue when thinking about the collective past, and a very wide array of studies would be required to answer this question. Instead, it will be addressed 
transversally (see also de Saint Laurent \& Obradović, 2019 for an overview). That is, each of the other three questions will be investigated in a specific fieldwork, and, in each of them, the issue of purpose will be included.

Three studies have thus been conducted, looking at the role of interactions, development, and resources in the construction of representations of the collective past. While they each focus on one aspect of the model presented in this chapter, they do not do so in isolation. Instead, each fieldwork builds on the previous one, integrating its findings and, so to speak, adding a layer to this complex phenomenon. Each study is presented in a separate chapter, over the next three chapters.

\section{Methodological note}

Before presenting the studies that were conducted to answer these questions, however, it is important to consider the methodological standpoint from which they were developed. As we have seen in Chapter 1, sociocultural psychology is not only characterised by a set of theoretical assumptions, but also by their epistemological and methodological consequences. In particular, five main consequences were identified, that I propose to summarise here alongside their practical results.

First, sociocultural approaches consider that the basic unit of analysis for psychological phenomena is the person as a whole, living interdependently with her social, material, and cultural context (Valsiner, 2014). This is not to say that, at a practical level, one needs to include "everything" that makes a person and her environment, or that no references can be made to other levels of analysis, which would be both impossible and pointless. But it means, on the one hand, that researchers need to study psychological phenomena as part of this whole and, on the other, that they must be sensitive to the fact that various elements of the context may become extremely relevant. Practically, this implies that research protocols and analyses must take the subject as a unique meaning-making agent into account, and that both the method and the data recorded must be able to account for the context within which the person is inscribed (Brinkmann, 2013). This includes a wide range of practices, depending on what phenomena is investigated and how, going from collecting supplementary data on both persons and contexts in order to include it in the analysis, to devising methods that reflect on how the tasks were understood by participants.

Second, sociocultural psychology is interested in local meanings and activities, and not in the development of universal laws predicting behaviour, considering the latter a vain endeavour. This is not to say that it is against generalisations - with some of its proponents actually advocating that this is the only way for sociocultural psychology to be scientific (Valsiner, 2014) - but it defends a very different perspective on how to produce them. Indeed, because humans, the activities they carry out, and the contexts within which they live are always unique, generalisation cannot be obtained through the statistical analysis of "representative" data - as it is the norm in mainstream quantitative psychology studies - which often only reflect how WEIRD (Western, Educated, Industrialised, Rich, and Democratic) 
people behave in lab experiments. On the contrary, sociocultural psychology considers that generalisations can be made even from single case studies (Zittoun, 2017b), in particular through the use of abduction, by using the inference to the best explanation (Evers \& Wu, 2006). On the one hand, focusing on the psychological processes of people living interdependently from their social, cultural, and material context means that such processes can be generalised as long as one does not lose sight of how the expression of said processes will always be unique and context-bound. On the other hand, because sociocultural psychology is not a predictive science, it gives a different meaning to the idea of generalisation: It is not about concluding that all/most individuals, under certain conditions or displaying certain characteristics will behave in a certain way, but about understanding what, in specific contexts, will participate in the meaning people give to the situation and how they react to it, as well as what psychological processes may be involved. As a consequence, sociocultural psychology favours rich qualitative analyses over quantitative research.

Third, sociocultural approaches consider that psychological processes unfold in time (Valsiner, 1994), and that people develop throughout the life course (Zittoun, 2012). Thus, the best way to study the human psyche is to adopt a developmental perspective. Moreover, as this field of research is interested in how psychological processes take place - and not in linear causal relations or the quantification of specific behaviours or states - it is necessary to use a dynamic perspective that can capture these processes as they unfold. In practice, this has taken place at a variety of levels, from phylogenesis to microgenesis (see Boesch, 1997 for a cross-level analysis). Globally, however, it can be said to have encouraged three types of studies: Historical studies, focusing on how a(n often social) phenomenon has evolved across time (e.g., Danziger, 2008); life-course and developmental studies, using longitudinal or trajectory analyses to investigate the development of psychological processes during the course of living (e.g., Hviid, 2008; Zittoun, 2017a); and microgenetic or interactional studies, concentrating on the moment-tomoment changes in interactions or in textual data (e.g., Wagoner, 2009). These studies do not just attempt to capture changes between different periods of time, but also how such changes unfold. Sociocultural research thus tries to investigate the dynamic nature of psychological phenomena, and not just to compare changes between static "recordings" of different stages of development.

Fourth, sociocultural psychology considers that the methods of the human sciences should necessarily be different than that of the natural sciences (Kirschner \& Martin, 2010). Many of the reasons for this difference have already been highlighted in the previous paragraphs, from the fact that psychology is not a predictive science to the importance it gives to time and contexts, which are not well captured by traditional quantitative experimental studies. One additional reason is that sociocultural psychology considers all knowledge to be constructed from a specific perspective. As a result, the objectivity towards which natural sciences methods are oriented is impossible, and in the social sciences it often leads to the normalisation of certain perspectives over others (Valsiner, 2012), either because 
they are left unquestioned by scientists and policymakers or because they serve their own interests. At a practical level, it means that the methods used in sociocultural studies try to capture, as best as possible, the phenomena under investigation, but do not consider that some methods are inherently better than others (Cornish \& Gillespie, 2009). This branch of psychology does tend to prefer, however, methods that allow researchers to analyse people's understanding of the world they live in and how they act within it; for instance through qualitative interviews, participant observations, or multi-method case studies.

This leads us to the fifth methodological consequence of the sociocultural approach: Methods should adapt to phenomena and research questions and should thus be innovative, open-ended, and developed reflexively. Because the perspective adopted in this thesis is pragmatist, and not only constructivist, I also consider that in the face of a specific question and specific phenomenon, not all methods are "equal," especially in the face of the "broader" objective one is pursuing. It is thus important to clarify, beyond the research question, what type of knowledge one is seeking, for it changes how it can be reached. In the case of this thesis, the aim is not to test specific hypotheses or to analyse particular settings, but to shed new light on the processes behind the construction and uses of collective memory, among other things, by proposing new theoretical perspectives on these phenomena. That is, one of my general objectives is to propose alternative ways to understand, conceptualise, and analyse collective memory that could allow us to appreciate how it is constructed and used beyond one-sided, hegemonic, and often nationalist accounts of the past. Following the principles of sociocultural psychology, my aim, at a methodological level, is thus to develop qualitative methods that can help us understand how this phenomenon takes place, while taking into account the cultural, social, and situated nature of human activity. Doing so means building on a wide range of existing practices of data collection and analysis to build tools adapted to my specific research questions and objectives. This is what I have attempted to do in the following three chapters.

\section{References}

Bakhtin, M. M. (1986). Speech genres and other late essays. University of Texas Press.

Bartlett, F. C. (1932). Remembering. A study in experimental and social psychology. Cambridge University Press.

Billig, M. (1987). Arguing and thinking. A rhetorical approach to social psychology. Cambridge University Press.

Boesch, E. (1997). The sound of the violin. In M. Cole, Y. Engeström \& O. Vasquez (Eds.), Mind, culture and activity: Seminal papers from the laboratory of comparative human cognition (pp. 164-184). Cambridge University Press.

Brescó de Luna, I. (2018). How the future weights on the past. Prolepsis and other ways of reconstructing the past in relation to different imagined futures. In C. de Saint Laurent, S. Obradović \& K. Carriere (Eds.), Imagining collective futures. Perspectives from social, cultural and political psychology (pp. 109-128). Palgrave Macmillan.

Brinkmann, S. (2013). Qualitative interviewing. Oxford University Press. 
Cornish, F., \& Gillespie, A. (2009). A pragmatist approach to the problem of knowledge in health psychology. Journal of Health Psychology, 14, 800-809. https://doi.org/10.1177/ 1359105309338974

Dahinden, J., \& Zittoun, T. (2013). Religion in meaning making and boundary work. Theoretical explorations. Integrative Psychological and Behavioral Science, 47(2), 185-206. https://doi.org/10.1007/s12124-013-9233-3

Danziger, K. (2008). Marking the mind. A history of memory. Cambridge University Press. de Saint Laurent, C. (2017a). Personal trajectories, collective memories. Remembering and the life-course. Culture \& Psychology, 23(2), 263-279.

de Saint Laurent, C. (2017b). Trajectories of resistance and historical reflections. In N. Chaudhary, G. Marsico, P. Hviid \& J. Villadsen (Eds.), Resistance in everyday life: Constructing cultural experiences (pp. 49-63). Springer.

de Saint Laurent, C. (2018a). Memory acts. A theory for the study of collective memory in everyday life. Journal of Constructivist Psychology, 31(2), 148-162. http://dx.doi.org/ 10.1080/10720537.2016.1271375

deSaintLaurent,C.(inpress). Setting specificityandmemory:Aperspectivefromsociocultural psychology. In B. Wagoner(Ed.), Memory in the wild. Information Age. www.researchgate. net/publication/334508407_Setting_specificity_and_memory_A_perspective_ from_sociocultural_psychology

de Saint Laurent, C., Brescó de Luna, I., Awad, S. H., \& Wagoner, B. (2017). Collective memory and social sciences in the post-truth era. Culture \& Psychology, 23(2), 147-155. https://doi.org/10.1177/1354067X17695769

de Saint Laurent, C., \& Obradović, S. (2019). Uses of the past: History as a resource for the present. Integrative Psychological \& Behavioral Science, 53(1), 1-13. https://doi. org/10.1007/s12124-018-9463-5

de Saint Laurent, C., \& Zittoun, T. (2017). Memory in life transitions. In B. Wagoner (Ed.), Handbook of memory and culture (pp. 209-236). Oxford University Press.

Evers, C. W., \& Wu, E. H. (2006). On generalising from single case studies. Epistemological reflections. Journal of Philosophy of Education, 40(4), 511-526. https://doi. org/10.1111/j.1467-9752.2006.00519.x

Fernyhough, C. (2008). Getting Vygotskian about theory of mind. Mediation, dialogue, and the development of social understanding. Developmental Review, 28(2), 225-262. https://doi.org/10.1016/j.dr.2007.03.001

Gillespie, A. (2008). Social representations, alternative representations and semantic barriers. Journal for the Theory of Social Behaviour, 38, 375-391. https://doi.org/10.1111/ j.1468-5914.2008.00376.x

Gillespie,A., Howarth, C., \& Cornish, F. (2012). Four problems for researchers using social categories. Culture \& Psychology, 18, 391-402. https://doi.org/10.1177/1354067X12446236

Hermans, H. J. M. (2001). The dialogical self: Toward a theory of personal and cultural positioning. Culture \& Psychology, 7, 243-281. http://cap.sagepub.com/content/7/3/243.abstract.

Hviid, P. (2008). "Next year we are small right?" Different times in children's development. European Journal of Psychology of Education, 23, 183-198. https://doi.org/10.1007/ BF03172744

Keyes, R. (2004). The post-truth era. Dishonesty and deception in contemporary life. St. Martin's Press; Macmillan.

Kirschner, S. R., \& Martin, J. (2010). The sociocultural turn in psychology. An introduction and an invitation. In S. R. Kirschner \& J. Martin (Eds.), The sociocultural turn in psychology. The contextual emergence of mind and self (pp. 3-27). Columbia University Press. 
Linell, P. (2009). Rethinking language, mind and world dialogically. Interactional and contextual theories of sense making. Information Age Publishing.

Marková,I. (2000). Amédée or how to getrid of it. Social representations from a dialogical perspective. Culture \& Psychology, 6, 419-460. https://doi.org/10.1177/1354067X0064002

Marková, I. (2003). Dialogicality and social representations. The dynamics of mind. Cambridge University Press.

McVee, M. B., Dunsmore, K., \& Gavelek, J. R. (2005). Schema theory revisited. Review of Educational Research, 75(4), 531-566. https://doi.org/10.3102/00346543075004531

Moscovici, S., \& Vignaux, G. (1994). Le concept de thêmata. Structures et Transformations Des Représentations Sociales, 25-72.

Valsiner, J. (1994). Irreversibility of time and the construction of historical developmental psychology. Mind, Culture, and Activity, 1(1-2), 25-42. https://doi.org/10.1080/ 10749039409524655

Valsiner, J. (2012b). Psychology courting culture. Future directions and their implications. In J. Valsiner (Ed.), The Oxford handbook of culture and psychology (pp. 1092-1104). Oxford University Press.

Valsiner, J. (2014). An invitation to cultural psychology. Sage Publications.

van Drie, J., van Boxtel, C., Erkens, G., \& Kanselaar, G. (2005). Using representational tools to support historical reasoning in computer-supported collaborative learning. Technology, Pedagogy and Education, 14(1), 25-41. https://doi.org/10.1080/14759390500200191

Vygotsky, L. S. (1978). Mind in society. The development of higher psychological processes. Harvard University Press.

Vygotsky, L. S., \& Luria, A. (1994). Tool and symbol in child development. In R. V. de Veer \& J. Valsiner (Eds.), The Vygotsky reader (pp. 99-174). Blackwell.

Wagoner, B. (2009). The experimental methodology of constructive microgenesis. In J. Valsiner, P. Molenaar, N. Chaudhary \& M. Lyra (Eds.), Dynamic process methodology in the social and developmental sciences (pp. 99-121). Springer.

Wertsch, J. (2002). Voices of collective remembering. Cambridge University Press.

Wertsch, J. (2008). The narrative organization of collective memory. Ethos, 36, 120-135. https://doi.org/10.1111/j.1548-1352.2008.00007.x

Wertsch, J., \& Batiashvili, N. (2012). Mnemonic communities and conflict. Georgia's narrative template. In I. Marková \& A. Gillespie (Eds.), Trust and conflict. Representation, culture and dialogue (pp. 37-48). Routledge.

Zittoun, T. (2006). Transitions. Development through symbolic resources. Information Age Publishing.

Zittoun, T. (2008). Learning through transitions. The role of institutions. European Journal of Psychology of Education, 23, 165-181. https://doi.org/10.1007/BF03172743

Zittoun, T. (2012). Lifecourse. A socio-cultural perspective. In J. Valsiner (Ed.), The handbook of culture and psychology (pp. 513-535). Oxford University Press.

Zittoun, T. (2017a). Symbolic resources and sense-making in learning and instruction. European Journal of Psychology of Education, 32(1), 1-20. https://doi.org/10.1007/ s10212-016-0310-0

Zittoun, T. (2017b). Modalities of generalization through single case studies. Integrative Psychological and Behavioral Science, 51(2), 171-194. https://doi.org/10.1007/ s12124-016-9367-1

Zittoun, T., Duveen, G., Gillespie, A., Ivinson, G., \& Psaltis, C. (2003). The use of symbolic resources in developmental transitions. Culture \& Psychology, 9, 415-448. https://doi. org/10.1177/1354067X0394006 
Zittoun, T., \& Gillespie, A. (2015). Integrating experiences. Body and mind moving between contexts. In B. Wagoner, N. Chaudhary \& P. Hviid (Eds.), Integrating experiences. Body and mind moving between contexts (pp. 3-49). Information Age Publishing.

Zittoun, T., \& Grossen, M. (2013). Cultural elements as means of constructing the continuity of the self across various spheres of experience. In M. B. Ligorio \& M. César (Eds.), Interplays between dialogical learning and dialogical self (pp. 99-126). Information Age Publishing.

Zittoun, T., Valsiner, J., Vedeler, D., Salgado, J., Gonçalves, M. M., \& Ferring, D. (2013). Human development in the life course. Melodies of living. Cambridge University Press. 


\section{Chapter 4}

\section{The collective past in interactions ${ }^{\prime}$}

One of the most studied aspects of collective memory has been its role in group identity (e.g., Liu et al., 1999; Liu \& Hilton, 2005), and especially how narratives defended by state institutions, such as schools or public museums, participate in the construction of national identities (e.g., Gavriely-Nuri, 2013). Indeed, foundation myths can give meaning to the actions and the existence of the group (Wertsch, 2002, 2008; Wertsch \& Batiashvili, 2012), by providing it a raison d'être. It may illustrate what is believed to be the "essence" of the national group (Raudsepp \& Wagner, 2012), showing that fellow members have always displayed similar qualities - usually courageousness, righteousness, or cunningness - as the ones that characterise it today. National narratives, as a result, also contribute to how we interact with other groups (Delori, 2011), in particular with the ones against whom our ancestors have shown that they were indeed courageous, righteous, or cunning. This has led some researchers (e.g., Bar-Tal, 2014) to argue that representations of the collective past defend one-sided glorifications of the past to the group - where one's group has been, time and time again, heroic in the face of adversity.

However, we have seen in the previous chapter that representations of the collective past (RCPs) are constructed in interaction with the discourses of others, and in the relation with their alternative. How, then, to account both for the role of RCPs in national identity and their dialogical nature? In other words, how do we construct representations of the collective past in interaction with others, and use them to give meaning to the groups to which we belong - in particular nations? In order to answer these questions, I propose in this chapter to analyse how the collective past is discussed in a series of parliamentary debates on immigration, looking both at the role of interactions and the meaning given to the nation through the use of RCPs. Indeed, parliamentary debates offer the opportunity to look at how different public discourses interact. And because "it is impossible to create a meaning without actually creating the boundary between that meaning and what differs from it, and reversely" (Dahinden \& Zittoun, 2013, p. 202), debates on immigration - where the boundaries of the group are debated - are an interesting place to investigate how meaning is given to the national group. 
These kinds of debates also give us the chance to look at how national groups are made more or less salient categories to organise the social world - being, for some, the most important organiser, while for others, they are nothing more than something which determines the colour of your passport. Indeed, group memberships, as with the groups themselves, are multiple, dynamic, historical, and contextual (Gillespie et al., 2012). However, it seems that some of them "stick," whether in time (becoming part of history) or for those who hold them (becoming part of their identity). Looking at how we give meaning to the group to which we belong also has the potential, then, to help us understand why some memberships unleash passions, sometimes to the point of violence, either physically or in discourse.

In what follows, I first introduce the data that was collected - French parliamentary debates on immigration from 2006 - and how it was analysed. I then present the two main aspects of French history that are mobilised in the debates to give meaning to the nation: The history of immigration, and the history of the construction of the French Republic. The analysis focuses more particularly on how the meanings are constructed by each side of the political spectrum and how they reply to each other. Finally, I discuss how the collective past is used to give meaning to the national group and to immigration, but also to the parliament itself, and how the interactions between the parliamentary groups shape what they say about the collective past.

\section{Parliamentary debates on immigration}

The aim of this study was to look at how RCPs are constructed and used in interactions, and it thus focused on political discourses in parliamentary debates, as they represent a unique opportunity to observe the interactions between perspectives that make up most of the public discourses on an issue. And as political discourses frequently use representations of the collective past, it is likely to come up several times over the course of a parliamentary debate. Moreover, this does not only allow for the study of RCPs, but also their use as it "naturally" occurs both in interactions and through time. "Naturally" here refers to the type of data used, not to an assumption about the genesis of the phenomenon. Indeed, parliamentary debates are a form of "naturally occurring data," which designates any data that would have occurred in the same way independently of the researcher's intervention (Potter, 2016). It is particularly favoured by discursive psychologists (Flick, 2014), on the ground that data collection that requires an intervention from the researcher produces data about the research process and how participants react to it, more than about the phenomena under study.

Another advantage of this type of data is that it is public. In the words of Zittoun \& Gillespie (2011, p. 5):

Using $[\ldots]$ publicly available data, can $[\ldots]$ work against fragmentation $[\ldots]$ by enabling other researchers, through access to the data that we analyzed, 
to deepen, extend, critique or complete our analyses. If other researchers can access the primary data on which our analyses are based, we enhance transparency and possibly the quality of research.

Indeed, there have been many pledges, in recent years, for transparency through sharing research data. However, this is often difficult in practice, especially in psychology where it raises important ethical questions: While analyses can be anonymised by removing information that would permit the identification of the participants, it is difficult (and often impossible) to do so with interview transcripts where removing all concerned information would denature the interview. Public data, such as the one used in this study, solves this problem, all the more when it concerns public figures who know that their interventions will be analysed - if not by researchers, at the very least by journalists and fellow politicians.

The specific parliamentary debates to be analysed were chosen following the principles of corpus construction, where sources of data are not selected through randomisation or with the aim of being generally representative, but by choosing data that can best answer the research questions (Gaskell \& Bauer, 2000). This process necessarily includes some arbitrariness, especially as corpora are selected before the analysis (Barthes, 1977). However, it has the advantage of focusing resources where they theoretically and methodologically should matter the most, and it is thus very adapted to qualitative research (Gaskell \& Bauer, 2000). In the case of this study, it involved first selecting what type of political debate to focus on. I chose to analyse parliamentary debates on immigration, for two reasons. First, collective memory has been shown to be linked to national identity, and it was thus likely to be discussed in this context and to be largely mobilised. Second, work done on thematic oppositions has highlighted how the need to choose a path for action - such as voting on a bill - forces people to choose between the contradictory positions they often hold on an object (Billig et al., 1988). Parliamentary debates on immigration thus have the potential to lead to interesting interactions and position statements on national identity, and in some cases on the collective past.

The data used consists of the official transcripts of 15 sessions of parliamentary debates, which took place in France between 2 May 2006 and 17 May 2006, as well as the vote session of 30 June 2006. This constitutes the whole of the examination of the bill number 2986 on "Immigration and Integration" by the National Assembly, one of the two organs of the legislative power in France and, here, the first one to officially discuss the bill, for a total of 107 hours of debates. These debates were chosen for two main reasons. First, political discourses can be layered with more or less implicit references to a multitude of social and cultural elements, especially when they are, as is the case for parliamentary debates, addressed to several audiences - the media, electors, other politicians, and the direct interlocutors in the assembly. As a result, I preferred selecting French debates, given that it is where I grew up and had been living, at the time of the debates, for 18 years, in order to have available a sufficient cultural background to analyse the data. 
Second, the bill number 2986 on "Immigration and Integration" was chosen for its political significance. Indeed, the context of the bill was one of great political tension and this law - the second one proposed by Nicolas Sarkozy on immigration polarised the French public sphere and became a symbol of the ideas defended by its author during the following campaign for the presidential elections (Girier, 2007). The aim of the bill, proposed by the right-wing majority, was to drastically reduce the number of long-term visas accorded to foreigners through a tightening of the delivery conditions for illegal migrants, migrant's families, and those married to EU citizens. It was also to impose the signature of an "Integration Charter" asking immigrants to adhere to a series of values presented as specifically French. As a result, the parliamentary groups were, in the debates, mostly organised around the notion of majority (Right) - following Sarkozy and supporting the bill - and opposition (Left) (de Saint Laurent, 2012). However, the deep clivage between Right and Left - so central to the French political life that it shapes "the individual political identifications and the processes of politicisation which underlie them" (Haegel, 2005, p. 46, my translation) - started much earlier to these debates (Rose \& Urwin, 1970).

The transcripts were collected on the parliament's official website and contain the participants' whole interventions and interruptions from the opening to the end of the sessions, as well as general reactions of the assembly - such as laughter or exclamations - which are usually attributed to a whole parliamentary group. These groups are central to the assembly's structure, as speaking times and turns, seats, places in commissions, etc., are allocated to a parliamentary group and not to specific members. Furthermore, the allegiance to one's group is necessary to run for the next elections, and therefore taken very seriously by the MPs (Abélès, 2001). The Right side of the hemicycle, author of the bill and constituting the majority, was represented by one parliamentary group, the Union for Popular Movement, whereas the Left was represented by the Socialists (Socialist Party, second group of the parliament) and the Radical Left (Communist and Republican Deputies), although both groups defended a very similar line. ${ }^{2}$

Parliamentary days are usually organised into three sessions - morning, afternoon, and evening - lasting around four to six hours, and often finish in the middle of the night. For these reasons, and because an impressive number of bills are discussed every year, only a limited number of deputies - the members of the National Assembly - participate in the discussion of a bill. As a result, out of the 577 deputies in the French parliament, around 20 MPs actively took part in the debates analysed here.

\section{Analysing references to the collective past in interactions}

The aim of the analysis was to look at the use of RCP in interactions by analysing the references made to the collective past in these debates, how they were shaped by the interactions within which they took place, and how they were used 
to give meaning to the nation and its present immigration situation. In order to achieve this, I first gathered all the references to history made in the debates, be they in the form of direct mentions of historical events or actors, or indirectly, by citing historical figures or documents, such as the French Déclaration des Droits de l'Homme et du Citoyen from 1789. To define what would constitute historical time without entering into a debate only remotely relevant to this work, it was decided to stop at the most recent events among those mentioned that would conventionally be considered as part of history in France, namely decolonisation. It amounted to 65 intercepts, all of which were rather short (between 15 and 1 lines, with no more than 3 participants, excluding general reactions from the assembly) except for a lengthy (and heated) conversation on World War II (around 250 lines, with 12 participants).

The extracts thereby obtained were then coded along two axes. First, the events referred to were thematically coded (do they talk about World War II, the French Revolution, colonisation, etc.?), trying to map out the historical periods represented and regroup similar references. Second, the groups the speakers belonged to were coded, with two categories: Political party and side of the political spectrum. The references were then organised chronologically, according to the events they mention, and by political orientation of the speaker (left or right). Finally, I gathered background information on the events and actors mentioned - primarily in books dedicated to French history and newspaper articles where politicians had discussed them in the past - as well as on the members of parliament who made use of historical references - mainly their official profile on the National Assembly website, Wikipedia page, and other mentions of history they had made in newspapers or on personal blogs.

Two further analyses were conducted: One focusing on the narratives underlying the MPs' interventions (de Saint Laurent, 2014), and one looking at the relational templates found in the references made to history, and how they echo present-day interactions (de Saint Laurent, 2015). In what follows, I mainly focus on the content of the references made to the collective past, as well as how they are used and how the interventions reply to each other. The figures that resulted from the analysis - depicting the references made to the collective past by both sides of the parliament and how they reply to each other - are included, alongside the two lines of discussion surrounding the collective past.

\section{Results}

The key to the subsequent figures is presented in Figure 4.1, while Figure 4.2 shows the events discussed by the members of parliament and the reactions they led to, grouped by side of the hemicycle. Figure 4.2 only presents events evoked at least twice, given that those mentioned only once were all isolated references that did not provoke a response or become part of a broader narrative. Indeed, two broad storylines emerged: One led by the left, on the historical roots of immigration; and one led by the right, on the construction of the French Republic. 


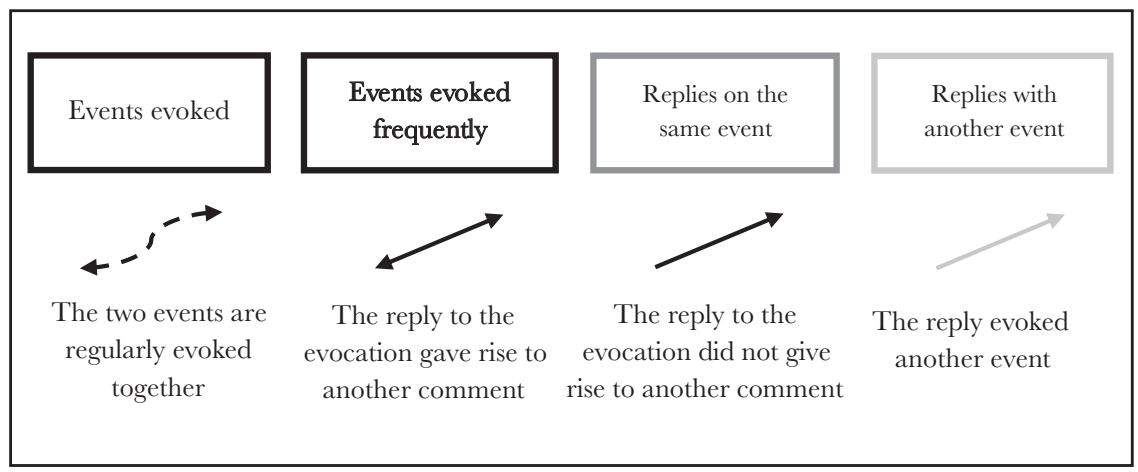

Figure 4.I Key to the figures.

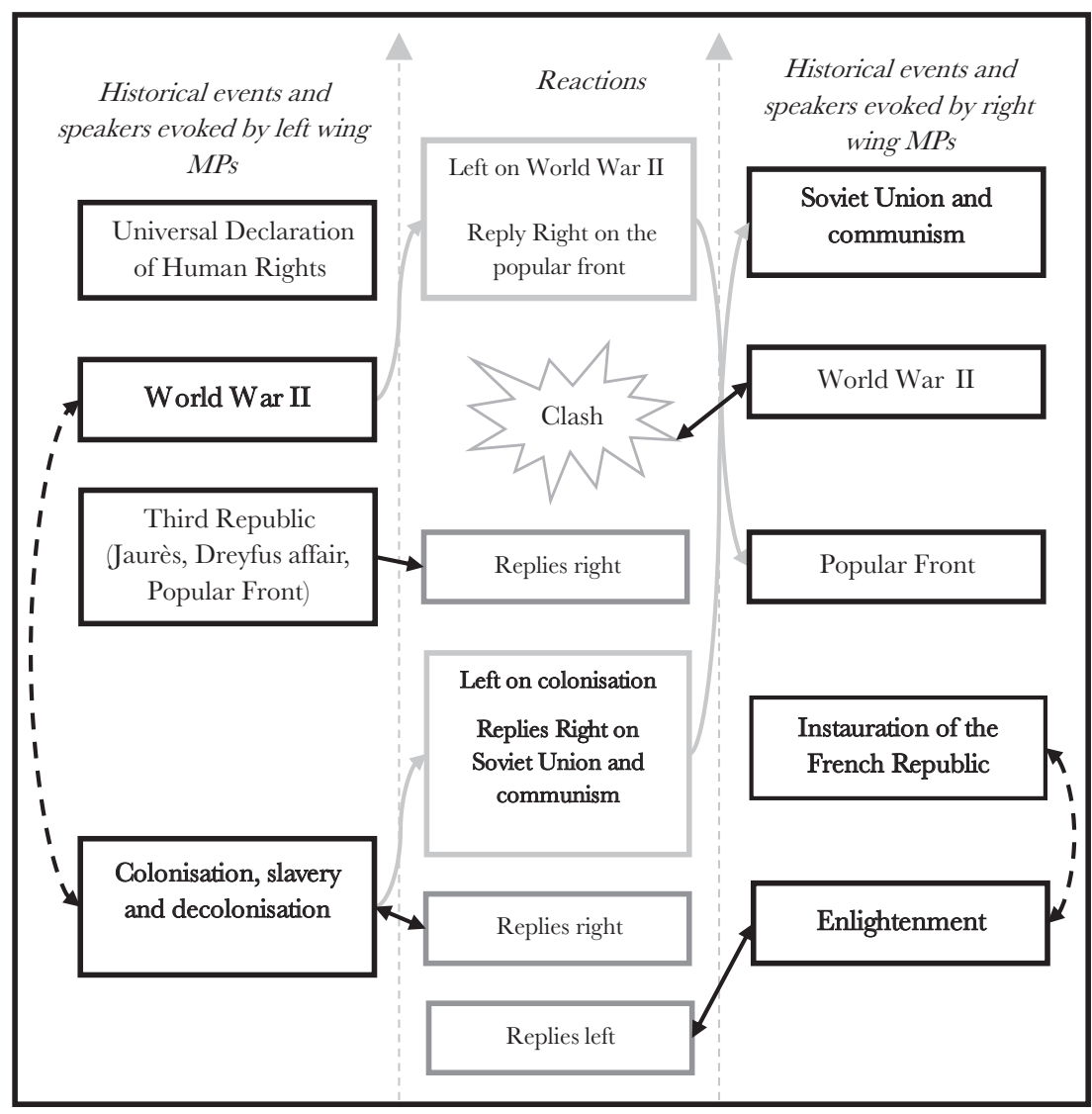

Figure 4.2 References to the collective past in the parliamentary debates. 


\section{History of immigration}

The first line of discussion around the collective past in the debates concerns the historical roots of immigration in France, both in terms of populations (i.e., immigrants from ex-French colonies) and treatment (i.e., how France has treated foreigners in the past). It is mainly carried out by the Left, primarily with references to World War II and/or colonisation (17 spontaneous references by Left-wing deputies), and it is within this storyline that most of the mentions of history in the debates fall. These references are used to defend two arguments. First, most of the people trying to migrate to France come from ex-French colonies, and the country "owes" them, both for the treatment they and their ancestors received in the colonies and the fact that their ancestors were often forced to fight for France during World War II. This is, for instance, what a Socialist MP replied to his Right-wing colleague asking why people from ex-French colonies should be more welcome than others:

RENÉ DOISIÈRE (SOCIALIST): Because, Mister Vanneste, the colonised came in the cold, mud and rain to fight and often die so that France could live!

(3 May 2006, second session ${ }^{3}$ )

Second, the Left uses references to colonisation and World War II to defend the idea that the treatment of immigration by the Right resembles the logic of these periods, as one of the aims of the bill was to increase the number of qualified immigrants and restrict access to the country to unqualified immigrants. This is how MPs reacted to it:

JEAN-PIERRE BRARD (RADICAL LEFT): I can very well picture him, filling up his basket on the international market $[\ldots]$ plundering the developing countries of their life forces! You want to plunder them today like the colonial troops did yesterday!

(3 May 2006, first session)

ARNAUD MONTEBOURG (SOCIALIST): An immigration that you decided to abuse by making resurface the shadows of a neo-vichyssoise ideology of sorting men out.

(3 May 2006, third session)

In the last excerpt, "neo-vichyssoise" refers to the Vichy Regime, Petain's regime in Southern France which collaborated with the Nazis. While most of these references concerned World War II and colonisation, they were not limited to it:

JEAN-PIERRE BRARD (RADICAL LEFT): Really, two France are in confrontation, as throughout History: the one of Coblence ${ }^{4}$ against the one of the Revolution; the one of Paul Reynaud against the one of the Popular Front; the one of Napoleon and Josephine against the one of Toussaint Louverture and Victor Schoelcher [...] The one that supported Franco, 
Salazar, Mobutu (protestations on the Right's benches) against the one that defended Grimau, Cunhal, Lumumba, ...

SEVERAL RIGHT-WING DEPUTIES: And Stalin! And Stalin!

JEAN-PIERRE BRARD (RADICAL LEFT): ... the France that supported the colonial wars against the France in solidarity with the oppressed populations! [...] We will fight you with every fibre and ounce of strength we have!

(2 May 2013, third session)

This excerpt illustrates quite well the general storyline proposed by the Left: That throughout history, they have defended oppressed populations - by colonisation, slavery, or antisemitism - against the Right, who have often supported their oppressors - like the colonial troops, the Vichy regime, or Napoleon. Being cast out as the eternal villain does, of course, provoke quite strong reactions from the Right. Their main counter argument in this regard - used 14 times - can be found already in the excerpt above: The Left has supported the USSR, an oppressive regime that also had colonies.

JEAN-PIERRE BRARD (RADICAL LEFT): When I fight against your bill, I am faithful to my anti-colonial tradition. [...]

CHRISTIAN VANNESTE (RIGHT): You are talking about the Soviet colonies?

(3 May 2006, first session)

A second argument put forward by the Right is that the Vichy regime was made possible by the Popular Front, an interwar Left-wing movement that resulted in several social reforms and that is still championed by the Left. It has been frequently accused of destabilising France and causing the defeat in 1940, an accusation that started with Petain himself and that is echoed by several Right-wing MPs in the debates. Their third and most questionable argument is that colonisation not only had drawbacks, but it is not clear in the debates whether for them it implies that their political family was not wrong for supporting it or that France does not owe much to its ex-colonies. A last line of counter argument is attempted once in the debates, referring to World War II. After a Right-wing MP is accused by his Left-wing counterpart of not being present enough in the debates - by telling him to go back to his constituency - one of his Right-wing colleagues comes to his defence and says:

CLAUDE GOASGUEN (RIGHT): I would like to remind my colleague that, in this Chamber, there is no deputy of Levallois, Saint-Denis or the 16th arrondissement ("Yes, there is" on the benches of the Socialists and Radical Left). Here are only representatives of the national sovereignty. Therefore, you do not have to assign yellow stars to one or another! (Exclamations on the Socialists'benches.)

(5 May 2006, second session) 
This reference to World War II, comparing implicitly a Left-wing MP to the Nazis, led to a lengthy and heated argument between several deputies. The session had to be suspended twice and the usher had to intervene, while Goasguen (author of the quote above) and Dray (to whom the quote is addressed) accused each other of being anti-Semites multiple times. Surprisingly enough, not only do both MPs know each other very well - one was the student of the other and they admittedly remained friends since - but one is Jewish and the other the head of the parliamentary group dedicated to the friendship between France and Israel. It thus appears the issue might have had more to do with the fact that the Right was using an event and comparison normally "reserved" for the Left, than with the possibility that either MP really thought the other was being antisemitic. Moreover, much of the Resistance during World War II was associated with the French communist party, while the Vichy regime had its roots in the traditionalist Right.

The Left references to the collective past, summarised in Figure 4.3, thus construct a representation of history as the long repetition of a struggle between those defending an oppressed population - primarily the Left itself - and those supporting their oppressors - the Right. Each event is seen as analogous to those that preceded it, and the current discussion of the bill is just another illustration of this struggle. As a result, the most significant boundary for the Left is not between who is French and who is not, but between those who defend humanist values and those who do not - that is, between them and the parliamentary majority. It is important to note, however, that this boundary only indirectly concerns immigrants: They are not presented by the Left as part of the group, but as victims that members of the group should protect, in a rather paternalistic fashion. And the Right, thereby presented as the eternal villain the Left must fight, does not directly attempt to deny their relationship with colonisation, slavery, or the Vichy regime. Instead, they accuse the Left of having been similarly associated with dictatorships, in particular the USSR - but doing so with the Nazis led to a substantial backlash. However, the Right does not stop there, as they also put forward a competing narrative, centred around the history of the French Republic.

\section{History of the French Republic}

The second storyline, primarily carried by the Right, concerns the history of the French Republic. It was most often discussed through references to the Revolution, spontaneously mentioned 14 times by Right-wing MPs, and presented as the foundation of the modern French state. Two other aspects of French history, deeply linked to the Revolution, are also frequently mentioned: The Enlightenment and the Declarations of the Rights of Man and of the Citizen. The former is principally referenced through discussion of Rousseau, a philosopher more traditionally associated with the Left. And indeed, the Right most often uses Rousseau to argue that, as their bill is in agreement with his ideas, the Left should accept it. The Right's position towards Rousseau actually changed throughout the debates: While he is presented as a "naïve" philosopher at first, later references to his ideas resemble the following: 


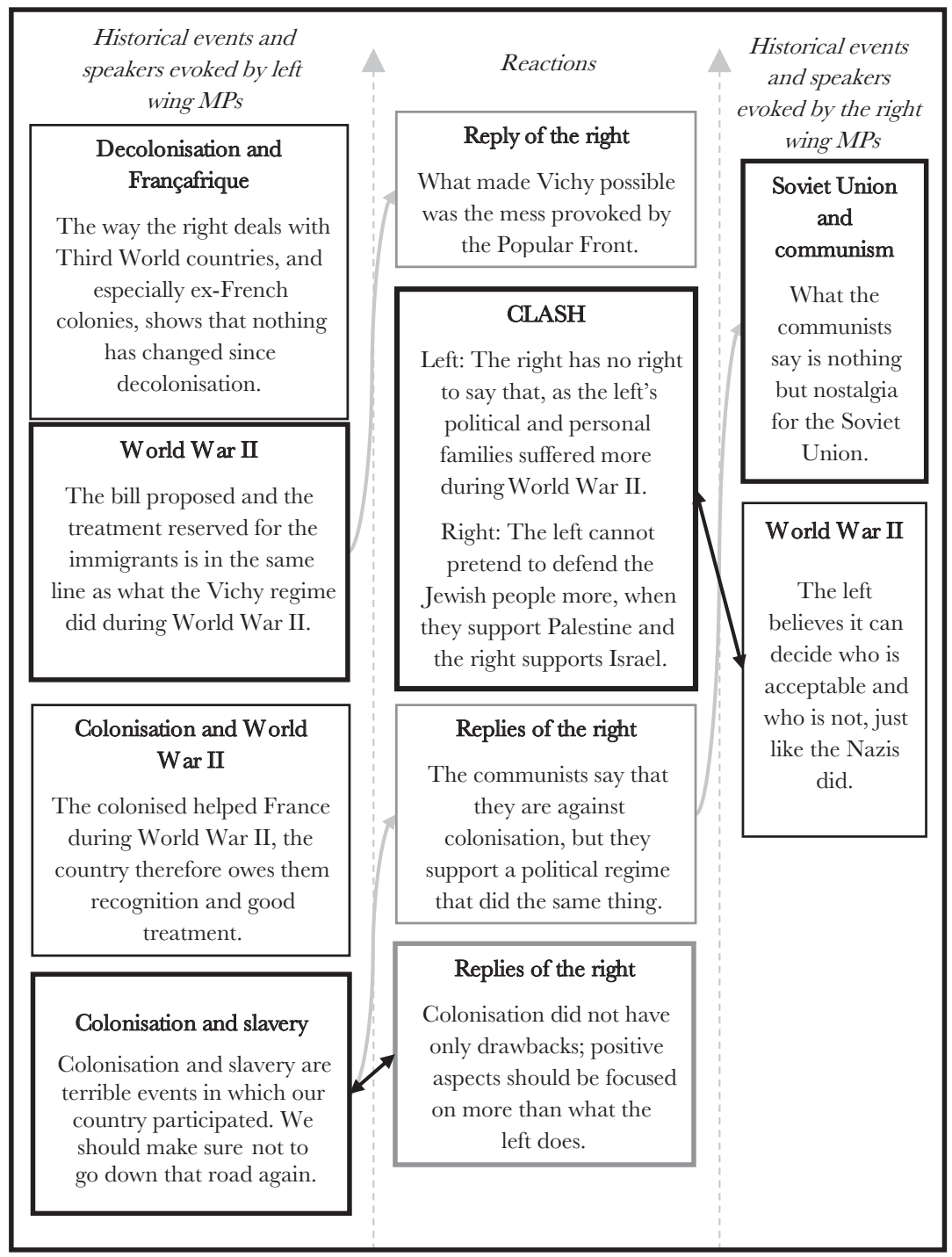

Figure 4.3 References to events linked to immigration.

CHRISTIAN VANNESTE (RIGHT): You say that immigration is a fact. But a fact does not make a right.

JÉRÔME RIVIÈRE (RIGHT): Very good!

CHRISTIAN VANNESTE: And you know who said that? Jean-Jacques Rousseau! 
THIERRY MARIANI (RIGHT): Very good!

(4 May 2006, first session)

Rousseau's idea that society is founded by a "civil pact" is also referenced several times and presented as a common-sense principle foundational for communities:

RICHARD MALLIÉ (RIGHT): There is no need to go back as far as Rousseau's civil pact to understand that living together comes with rights, but also duties. This common sense principle is all the more true when it concerns the foreign nationals that we welcome.

(4 May 2006, first session)

Another set of references from the Right is linked, indirectly, to the French Revolution, and specifies the grounds for this pact: It consists of quotations from the Declarations of the Rights of Man and of the Citizen. The idea defended here by the Right-wing MPs is that the bill needs to respect those principles, only those, and that it does. Human rights are evoked frequently in the debates, but only the Right refers to "the Rights of Man and of the Citizen," a direct product of the French Revolution, while the Left always refers to its "Universal" or "European" versions. Such a difference in point of view is best illustrated in the following extract. It is a reply to the Right-wing MP Christian Vanneste, who defended the idea of establishing a contract with newly arrived immigrants that includes their obligation to respect and follow "the French principles."

PATRICK BRAOUEZEC (RADICAL LEFT): When Mister Vanneste affirms that the French law needs to be obeyed, nobody is saying the contrary, but let's not ask more from foreigners, not matter what their situation is, than from the French.

SERGE BLISKO (SOCIALIST): Equality!

CHRISTIAN VANNESTE (RIGHT): The Rights of the Citizen are not just the Human Rights!

PATRICK BRAOUEZEC (RADICAL LEFT): To obey to the Republican principles, nobody in this hemicycle would think of questioning this principle. However, obeying "French principles," I admit that I don't know what this mean. I know universal values, but I don't know French values. I know some Republican principles, I know the French law, but I don't see why France would have specific values.

JACQUES MYARD (RIGHT): French specificity does not exist?

(4 May 2006, first session)

It thus seems that for the Right, what made France is a pact that followed the Revolution. It is the central event in the history of the country - the only national 
event lengthily referred to - whose associated political ideology, seen as its origin, refers to a "civil pact." The content of this pact, presented in the excerpt above as "specific" to France, is taken from the Declaration of the Rights of Man and of the Citizen, a direct product of the French Revolution. This understanding of the creation of the French Republic affects how the Right represents both who should be allowed to immigrate to France and the role of the National Assembly they are part of. On the one hand, foreigners are seen as fundamentally different, when it comes to communal living, because they are not yet part of the "French specificity." In order to be welcomed in, they must first agree to be part of France's civil pact by formally agreeing to follow "French values" and signing up to them. On the other hand, it presents the National Assembly as the legislative guardian of this pact. As a result, Right-wing MPs implied several times that political parties who do not follow the principles of the French Republic do not have a place in the parliament. In the debates, they indeed reject any alliance with the Front National, an anti-immigration party seen at the time as also anti-Republican (a position that has changed as it started attracting more voters), and are critical of the Socialist (at the time the main opposition party) alliance with the Radical Left, a parliamentary group including the Communists:

JEAN-PIERRE BRARD (RADICAL LEFT): Le Pen doesn't need to have a seat here: he is represented by his adepts!

CHRISTIAN VANNESTE (RIGHT): So is Stalin!

(3 May 2006, first session)

The Left opposed this representation of French history in three ways. First, they argued several times against the Right's interpretation of Rousseau - although it did not amount to much more than a few protestations each time Right-wing speakers were quoting the philosopher. Second, they proposed an alternative story for the foundation of the modern French state, in the social struggle of the Popular Front. Third, they opposed the Declaration of the Rights of Man and of the Citizen in favour of the European Convention on Human Rights. As shown in the excerpt above with Patrick Braouezec, Left-wing MPs systematically refuse the Right's references to the French post-Revolution declaration - and the idea that it is specific to France - and prefer their international version, that aims at being more universal.

The references made to the history of France and its political institutions is summarised in Figure 4.4. They paint a representation of France, for the Right, as the product of the French Revolution, which made it a unique country. The Revolution then becomes the most important event, and the one against which to judge the importance of others (de Saint Laurent, 2014). Where the Left presented history as the eternal repetition of the same story, for the Right it is the result of a general organising event that serves a grand narrative to organise how the rest of history is understood. It also makes the national group one of the most relevant 


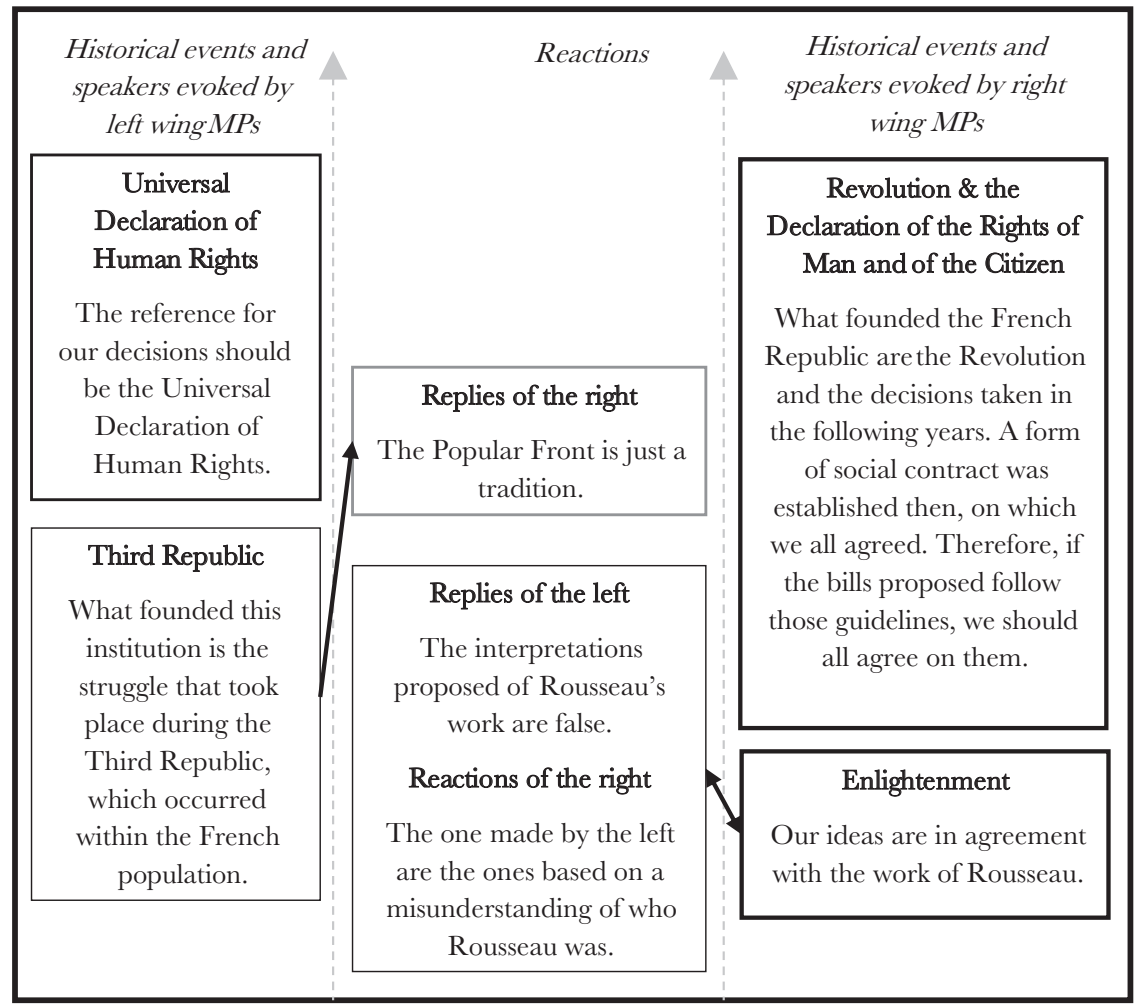

Figure 4.4 References to events linked to the French Republic.

social categories, along with one's adherence to the "Republican principles" as they were proposed after the French Revolution.

\section{Discussion}

Going back to our original question, how do we construct representations of the collective past in interaction with others, and use them to give meaning to the groups we belong to? Based on the analysis presented above, I first look at how meanings about the collective past are constructed and used to make sense of the nation by each side of the political spectrum, and then focus on how these may respond to each other.

\section{Constructing meanings}

It appears that some of the stories told about the past are indeed used to produce meaning about the nation, as well as about other historical events. For the Left, 
the numerous fights for human rights that took place in the history of the country give to its existence the sense of an ongoing struggle for the implementation of a humanistic ideology, perpetually endangered by the ideologies of oppressing others, of which the Right is a representative. What matters about the past are the various actors' intentions - oppressing, defending - and how they made the different groups relate to each other. For the Right, the past, read as the establishment of an exclusive contract between equal citizens, makes of the nation a place where civic life can go on, on the basis of a mutual agreement, one that only its members are legitimately able to negotiate. Here, the past is used to define a starting point where the rules have been laid down and that gives legitimacy to the group's existence. Stepping out of such rules would imply creating "something else," something that would not be the French nation anymore.

These representations of the collective past are mobilised in the debates to give meaning to the nation, as well as its boundaries. Defining the group as united by a Republican pact signed several hundred years ago, that ensures that a set of values is respected by all, allows limiting access to the group to those who accept the pact and its values. It presents "being French" as the access to specific rights and makes of the inclusion into the national group an honour that implies respecting the duties defined by the original group. On the contrary, defining the group as the place where a constant struggle between defenders of the oppressed and collaborators of the oppressors takes place renders another boundary more salient: That between humanists and non-humanists. It is not only the nation who cannot be reduced to the desired group - for some of its historical members would then be left out - but this new group includes members far outside the national group. In that case, the nation is not a relevant group to organise the social world.

These divergent visions also produce different separations in the National Assembly: Between Right and Left and between Republican parties and the "extremes." And it is indeed the two separations that can be found in the discourses of politicians and the political media in France. Thus, it is not only the boundaries of the group that are negotiated here, but the very possibility of imposing some inside the national group. The stories told and the meaning they produce also seem to attribute legitimacy to the various groups. Where the Right recognises the place of the Socialists in the "national representation," the various "extremists" have no right to speak. For the Left, the Right seems to be legitimate only as an adversary of its ideologies. However, perhaps more interesting are the groups whose voices are not delegitimised - which implies considering the possibility of the alternative - but who remain silent in the stories of the MPs. The immigrants are notably silent in these stories, if not completely absent. Even in the case of the Left, where they are presented as a group to be protected, they do not appear as full characters, but as the object over which the "heroes" and the "villains" fight. The Right and the Left discourses about immigration may often be deeply opposed, but paternalism and discrimination are two faces of the same token that essentialises differences (Costa-Lascoux, 2001, p. 129). 
Interestingly, however, RCP are not only used to give meaning to the present, but also to other past events. This transfer of meaning from one event to the other seems to be done, in the case of the Left, by analogies, where the meaning of one event is transferred to another because they are seen as similar. It allows the organisation of multiple events along a single line, shown by the rather wide array of historical periods to which they refer, thus offering a sense of continuity. For the Right, a historical event is turned into a founding act, creating a form of "grand meaning" that organises how other events are going to be understood. Thus, in both cases, it appears that RCPs are not simply used to give meaning to the present but may also be considered as the product of such a meaning-making process themselves. As a result, their meaning can always be renegotiated as they are used - as, for instance, when the Right changes from using Rousseau to mock their opponents as naïve, to referring to him to show that they actually all agree.

Moreover, organising the past along a meaningful line is one of the functions of storytelling (Bruner, 2003). One of their characteristics, pointed out by Aristotle (quoted in Bruner, 2003), is that they are always based on the structure "familiarrupture of the familiar by a peripetia" or there would not be a story (a peripetia being an incident or turning point usually taking place in a dramatic story). Then, if symbolic resources are cultural elements used to make sense of ruptures, and if stories are themselves about such ruptures and how life-like characters reacted to them, they are especially fitted for such a role. It may thus be because stories are themselves the product of a symbolisation of the unexpected that they can in turn help us to produce meaning around present ruptures (see Zittoun et al., 2008 for an illustration of a similar case).

The stories told here are indeed about ruptures: With the monarchy, with the ideologies previously defended, with an "other" that threatens the life of the group or its ideology, etc. Therefore, it is possible to see representations of the collective past as constructions in a specific situation that aim at giving meaning (Bartlett, 1932) by inscribing it into an ongoing chain of events that would go beyond the experienced rupture (de Saint Laurent, 2014). The way meaning is produced may also change how collective memory is used as a symbolic resource, by attributing a different "momentum" to the flow of historical time. Indeed, using analogies seems to provide meaning for a rather wide range of events. However, it does not open up new possibilities for the future, as it is the eternal replay of the same story. As for the use of a "grand meaning," it seems on the contrary to allow the production of a range of meanings, provided that they fit with the original one. However, it excludes elements that do not seem to fit with the general storyline.

\section{Negotiation of meanings}

Although each side of the political spectrum seems to organise the past around its own specific narrative, the groups also seem to reply to each other through a series of oppositions. To a founding act (Right) is opposed the idea of a fight that seems never to end (Left); to a unifying contract (Right), incompatible ideologies 
(Left); to French specificities (Right), universal values (Left) ... The stories told by each political group may call for such oppositions. In the case of the Right, the other's views, perspectives, and voices are considered as either similar to those of the rest of the group or they are illegitimate, limiting recognition to similarity and leaving no space for the expression of the other's singularity. As for the Left, the dichotomy operated does not go without judgement on the validity of the other's knowledge: What differentiates the opposed sides of the conflict is here judged in terms of respect for desirable values, as expressed in the various human rights declarations. For the other, the only options are either to agree, or to be cast out as the "bad guy" in the conflict.

What we have here are also two types of discourse that may reinforce each other: One may react to the tentative to turn the debate into a monologue, such as the Right does, by insisting on what makes them profoundly different, which seems indeed to be the reply of the Left. And the other may try to demonstrate that they believe in the same things - and therefore think similarly, as is done by the Right through references to Rousseau - as a way to refuse to be considered the "villain" of the story, a position in which the Left is casting out its opponents. Such an opposition can also be understood through the different aims pursued by the majority and opposition in parliamentary debates. For the Right, representing the majority at the time, the aim seemed to be to persuade the other of the validity of its position, which is after all often the purpose of a debate, parliamentary or not.

For the Left, the situation is rather different: It represents the opposition, and the overwhelming majority of Right-wing MPs in the parliament who are very attached to this bill makes persuasion an unrealistic aim. The objective that the Left seems to pursue is in line with its official name in the parliament: The opposition. Indeed, in the stories they tell, the Republican pact and the Revolution are quite left out, and an important number of events are highlighted instead. However, in many other circumstances, these events were made central by Left-wing politicians. For instance, the socialist education minister and former member of parliament, Vincent Peillon, proposed shortly after taking his post, the creation of "moral and civic teaching" classes in every high school where the principles emanating from the French Revolution would be taught. ${ }^{5}$ Where in other circumstances both sides could agree on the importance of these principles, ${ }^{6}$ in the debates the Left oppose them by insisting on other principles and other events.

However, in spite of the profound oppositions between the two main parliamentary groups, common symbols exist, making communication possible between them. Indeed, the emergence of signs and meaning in the triangular relation selfother-object allows for a distinction to be drawn between what they mean for the person and what is assumed to be common in relation to the other; that is, between the socially shared meaning of a sign (signification), and a personal one taken when it is associated with experience and given an emotional tonality (sense) (Abbey \& Zittoun, 2010). Here, the different groups share common signs - the "yellow star" as a symbol of discrimination, the French Revolution as the creation 
of modern France, etc. - that enable communication by ensuring the existence of a common ground. But the sense given to them may widely differ. For instance, the Revolution may be presented by both sides as the act that founded the French Republic, but the particular sense given by the Right is that of a contract making life in common possible. As for the Left, it is the beginning of a "humanist fight" which is yet to be won.

If "by establishing some shared semiotic systems, groups of people can also agree on certain interpretations of the world and then generalise them into values or full Weltanschaugen which then ground the organisation of the civil society" (Dahinden \& Zittoun, 2013, pp. 187-188), this discrepancy between the meanings given to the nation goes hand-in-hand with a different vision of the world and of the future of the group. However, the common sign may give the MPs the impression that this is not the case, and it gives them a place for grounding their opposition. This opposition may also be a product of the French political organisation. The cleavage between Right and Left, accentuated by an electoral system privileging the bipartisanship (Rose \& Urwin, 1970), rests on this paradox: To be on a "side" implies the existence of another side, which at the same time belongs to a unique "whole." The parliament then becomes more than an "electoral show," and is also the place where differences can be re-enacted to justify the existence of such an opposition. In this game of "who am I?" each side is defined as much by what its members say than by what it refutes in the other. That is, parliamentary debates and the references made to the collective past allow politicians to perform, once more, what sets them apart from each other.

\section{Conclusion}

The aim of this chapter has been to look at how representations of the collective past are co-constructed in interactions and used to give meaning to one's national group. By analysing the references made to history in a set of parliamentary debates on immigration, we have shown how the stories told and the arguments defended by the politicians respond to each other. Indeed, what each side says about the past defends a competing narrative that fits its own interests and its own understanding of the present, in particular, around the bill that is discussed. It is also a reply to what the other has said before and what is anticipated to be said next, as the inclusion of each of their interventions in a long chain of arguments shows (see Figures 4.2, 4.3, and 4.4). Taking each side of the debate in isolation, as is often done in collective memory research, can make us overlook this dynamic. Looking only at the Left's interventions on the Revolution and the Declaration of the Rights of Man and the Citizen, for instance, could give the impression that they are resolutely pro-European and anti-nationalist in this regard, when it is in fact a response to the Right's position in the debates - they have, when themselves in power, defended a quite different point of view.

This brings us to one of the uses of RCPs highlighted by these debates: They allow speakers to position themselves in the social field, both through the stories 
they champion and the historical figures they identify themselves with. Indeed, stories are always expressed from a specific perspective. Choosing to defend one version of the past over another means choosing a perspective on it - corresponding to past actors with whom one identifies to a certain degree - at least enough to consider it more "valid" than others. And because it presents a certain vision of the status quo, it positions the speaker within the social field, as well as those holding an opposing view. In the case of the debates, presenting the history of France as an ongoing struggle between those supporting oppressed populations and those championing their oppressors, for instance, positions the Left as a humanitarian hero and the Right as the villain against whom vulnerable populations need to be protected.

The other use of RCPs in these debates is to give meaning to the national group, by rooting it as a foundational myth - either in the Revolution or in the political struggles that ensued - as well as by determining its significance in organising the social world. In the multiplicity of memberships displayed here - parliamentary group, side of the political spectrum, national institution, country - it indeed appears that the meaning given to the groups may determine how important they are for those who hold them. If, for the Right, the nation allowed the existence of all the other groups, for the Left, it made the political oppositions more salient than the nation. For the former, then, national boundaries are what matter most, while for the latter, ideological orientation is presented as more meaningful.

In spite of these differences in perspective, both sides are still able to debate through the discussion of common benchmarks, such as World War II or the construction of the French Republic. These events are shown as extremely significant for all the parties involved, and their foundational meaning is in part shared. They do have, however, a different sense for each political family. World War II, for instance, is a central event in the narratives of both the Right and the Left and presented as a tragedy whose repetition should be avoided at all costs. But while for the Left it is the illustration of the dangers of oppressive ideologies that "sort men out," for the Right it symbolises more the last time France lost sovereignty over its territory (see de Saint Laurent, 2014).

The existence of common benchmarks, then, might be necessary for a dialogue to take place. Interactions thus not only shape what is said about past events, but also which events are going to be part of the discussion and which events are going to be overlooked. It is particularly striking, for instance, that decolonisation is only indirectly evoked in the debates. And in spite of a growing interest in the remembrance of the independence wars, it often leads, in official discourses (e.g., Lang, 2001), to a certain paralysis (Blanchard \& Veyrat-Masson, 2008). But retribution and the recognition of past crimes are not all that is at stake in the construction of a common narrative of colonisation and decolonisation between the French population and the immigrants from its former colonies. To invent a common future, in a multicultural society marred neither with discrimination nor with paternalism, may require writing a common past and producing a meaningful narrative. 


\section{Notes}

1 Parts of this chapter are reproduced from de Saint Laurent, C. (2014). "I would rather be hanged than agree with you!": Collective memory and the definition of the nation in parliamentary debates on immigration. Outlines. Critical Practices Studies, 15(3), 22-53.

2 In the interest of clarity, the organisation of the French political groups, the parliaments and the French political system as a whole have been simplified here. The original analysis was however made without these truncations.

3 All quotes from the debates are designated by author, date, and parliamentary session. The transcripts do not contain page or paragraph numbers. The political affiliations of the participants were added in brackets for clarity, [...] replaces the parts of the interventions that were removed. Comments about the reactions of the assembly, in italics and in brackets, are part of the original transcripts. All translations were made by the author.

4 All the historical figures evoked here work in opposing couples: 1) Coblence was the city where many noble men, accompanied by the king's brothers, took refuge during the Revolution; 2) Reynaud was a French politician known for his economically liberal positions during the social movement of the Popular Front; 3) Toussaint Louverture and Victor Schoelcher are important figures of the anti-slavery political fight, during the eighteenth century in the French colonies for the former, and in nineteenth-century metropolitan France for the latter. Napoleon I (evoked here with his wife Josephine) reinstituted slavery in the French colonies by the end of the eighteenth century; 4) Franco, Salazar, and Mobutu, twentieth-century dictators in Spain, Portugal, and the Republic of Congo, were opposed by Grimau (Spanish politician executed during Franco's dictatorship), Cunhal (Portuguese politician, major opponent of the Estado Novo, Salazar's party), and Lumumba (Congolese independence leader, executed shortly after Mobutu's putsch).

5 Proposition made in September 2012, with a first application in September 2013 (see Le Monde, dated 9 September 2013, "Vincent Peillon présente sa 'charte de la laïcité"').

6 Research in the French newspapers Le Monde (centre left) and Le Figaro (centre right) for the period between 1 January 2013 and 1 September 2013 showed that it had been defended by both Left-wing and Right-wing politicians, but that it concerned the latter more than 70 per cent of the time.

\section{References}

Abbey, E., \& Zittoun, T. (2010). The social dynamics of social science research: Between poetry and the conveyer belt. Qualitative Studies, 1(1), 2-17.

Abélès, M. (2001). Un ethnologue à l'Assemblée. Odile Jacob.

Bar-Tal, D. (2014). Collective memory as social representations. Papers on Social Representations, 23, 5.1-5.26.

Barthes, R. (1977). Elements of semiology. Farrar, Straus and Giroux.

Bartlett, F. C. (1932). Remembering. A study in experimental and social psychology. Cambridge University Press.

Billig, M., Candor, S., Edwards, D., Gane, M., Middleton, D. J., \& Radley, A. (1988). Ideological dilemmas. A social psychology for everyday thinking. Sage Publications.

Blanchard, P., \& Veyrat-Masson, I. (2008). Les guerres de mémoires. La France et son histoire. La Découverte.

Bruner, J. S. (2003). Making stories. Law, literature, life. Harvard University Press. 
Costa-Lascoux, J. (2001). L'ethnicisation du lien social dans les banlieues françaises. Revue Européenne de Migrations Internationales, 17(2), 123-138. https://doi.org/10.3406/remi. 2001.1781

Dahinden, J., \& Zittoun, T. (2013). Religion in meaning making and boundary work. Theoretical explorations. Integrative Psychological and Behavioral Science, 47(2), 185-206. https://doi.org/10.1007/s12124-013-9233-3.

de Saint Laurent, C. (2012). Dialogue in democratic institutions. A dialogical analysis of the French parliamentary debates on immigration of 2006 [Unpublished dissertation]. London School of Economics.

de Saint Laurent, C. (2014). "I would rather be hanged than agree with you!" Collective memory and the definition of the nation in parliamentary debates on immigration. Outlines. Critical Practice Studies, 15(3), 22-53.

de Saint Laurent, C. (2015). Collective memory and alterity: Remembering as a dialogical process. In L. M. Simao \& D. Guimarães (Eds.), Knowledge and otherness: Disquieting experiences in the dynamics of cultural psychology (pp. 145-160). Library Dante Moreira Leite.

Delori, M. (2011). Le poids de la mémoire sur la politique étrangère. Politique Européenne, 34(2), 231-241. https://doi.org/10.3917/poeu.034.0231

Flick, U. (2014). An introduction to qualitative research. Sage Publications.

Gaskell, G. D., \& Bauer, M. W. (2000). Towards public accountability. Beyond sampling, reliability and validity. In M. W. Bauer \& G. D. Gaskell (Eds.), Qualitative researching with text, image and sound (pp. 337-350). Sage Publications. https://doi.org/10.4135/ 9781849209731.n19

Gavriely-Nuri, D. (2013). Collective memory as a metaphor. The case of speeches by Israeli prime ministers 2001-2009. Memory Studies, 7(1), 46-60. https://doi.org/ $10.1177 / 1750698013497953$

Gillespie, A., Howarth, C., \& Cornish, F. (2012). Four problems for researchers using social categories. Culture \& Psychology, 18, 391-402. https://doi.org/10.1177/13540 $67 \mathrm{X} 12446236$

Girier, J.-M. (2007). L'identité en debat. Representations et ideologies dans les discours sur l'immigration au sein de l'espace public. [Unpublished master's dissertation]. Université de Lyon II. www.memoireonline.com/09/07/590/identite-en-debat-representationset-ideologies.html

Haegel, F. (2005). Pertinence, déplacement et renouvellement des analyses en termes de clivage en France. Revue Internationale de Politique Comparée, 12, 35-45. https://doi. org/10.3917/ripc. 121.0035

Lang, J. (2001). Ouverture des travaux. In D. Borne, J.-L. Nembrini \& J.-P. Rioux (Eds.), Actes de la DESCO Université d'été octobre 2001 (pp. 3-7). CRDP.

Liu, J. H., \& Hilton, D. (2005). How the past weighs on the present. Social representations of history and their role in identity politics. British Journal of Social Psychology, 44, 537-556. https://doi.org/10.1348/014466605X27162

Liu, J. H., Wilson, M. S., McClure, J., \& Higgins, T. R. (1999). Social identity and the perception of history. Cultural representations of Aotearoa/New Zealand. European Journal of Social Psychology, 29, 1021-1047. https://doi.org/10.1002/(SICI)10990992(199912)29:81021::AID-EJSP9753.0.CO;2-4

Potter, J. (2016). Discursive psychology and the study of naturally occurring talk. In D. Silverman (Ed.), Qualitative research (4th ed., pp. 189-206). Sage Publications. 
Raudsepp, M., \& Wagner, W. (2012). The essentially other. Representational processes that divide groups. In I. Marková \& A. Gillespie (Eds.), Trust and conflict. Representation, culture and dialogue (pp. 105-122). Routledge.

Rose, R., \& Urwin, D. W. (1970). Persistence and change in Western party systems since 1945. Political Studies, 18, 287-319.

Wertsch, J. (2002). Voices of collective remembering. Cambridge University Press.

Wertsch, J. (2008). The narrative organization of collective memory. Ethos, 36, 120-135. https://doi.org/10.1111/j.1548-1352.2008.00007.x

Wertsch, J., \& Batiashvili, N. (2012). Mnemonic communities and conflict. Georgia's narrative template. In I. Marková \& A. Gillespie (Eds.), Trust and conflict. Representation, culture and dialogue (pp. 37-48). Routledge.

Zittoun, T., Cornish, F., Gillespie, A., \& Aveling, E.-L. (2008). Using social knowledge. A case study of a diarist's meaning making during World War II. In T. Sugiman, J.-K. Gergen, W. Wagner \& Y. Yamada (Eds.), Meaning in action. Constructions, narratives, and representations (pp. 163-179). Springer.

Zittoun, T., \& Gillespie, A. (2011). Using diaries and self-writings as data in psychological research. In E. Abbey \& S. E. Surgan (Eds.), Developing methods in psychology (pp. 1-26). Transaction Publishers. 


\section{Trajectories of remembering}

We have seen in the previous chapters that the way we think about the collective past is shaped by the context in which we are - both in terms of interactions and of the aims the situation might afford - as well as the resources that are available to us. Yet, even within similar circumstances and between people who globally share a similar background, as was the case of most of the politicians taking part in the debates analysed in Chapter 4, each may defend quite different representations of the collective past (RCPs). In particular, while some may repeat rather unreflexively the stories they have heard at school or in movies, or seen displayed in museums and memorials, others become immensely critical of these accounts. Without going as far as seeing official historical narratives as the product of conspiracies - a tendency that has been on the rise in the past couple of decades - being able to critically appraise them is central to how we think about the collective past. It is, indeed, by reflecting on how RCP are constructed that we can distance ourselves from their content and learn to actively think about the collective past, instead of ventriloquising discourses heard elsewhere.

But why does learning to reflect on RCPs and to sometimes resist them matter so much? It is because by adopting specific narratives about the past of our social groups and, just as importantly, by forgetting other elements (Brockmeier, 2002), we position ourselves towards the present situation. Is it an injustice? The apogee of a centurylong battle for our rights? The end of a golden age? The answers to these questions give meaning to our present situation and a direction for the future. If the past matters, then, it is not only in itself, but also because of what it reveals about us and our future (Dudai \& Carruthers, 2005). Research on representations of history has, so far, mainly concluded that groups transform and deform history to show themselves in the best light possible (Wertsch \& Batiashvili, 2012). But how to understand, then, the processes by which some come to question history and doubt the greatness of the past actions of their group? If many do indeed defend and repeat narratives that serve the interests of their countrymen and their own - a quick look at any country's extreme right party discourses illustrates this - others do become critical.

In this chapter, I first argue that in order to understand how unique and/or critical accounts of the past are forged, we need to include, in our models of RCPs and TCP (thinking about the collective past), their temporal dimension. I will thus 
propose to look at how RCPs and TCP develop in time and introduce the notion of trajectory of remembering. I then present the study that was constructed to explore the development of how we think and represent the collective past: A series of qualitative interviews with intellectuals and artists who have a critical relation to the collective past. We will look in more detail at the trajectory of two women who came to resist hegemonic discourses on the pasts of their group. Finally, I will discuss the three main ways in which our trajectories of remembering shape, in the long run, how we think about the collective past - namely, through the development of social ties sustained by RCPs, of a metamemory, and of a personal philosophy of the world.

\section{Trajectories of remembering}

\section{Explaining differences}

As we have seen in the previous chapters, the way we represent the collective past is, at least in part, shaped by the stories we have heard and the social groups to which we belong. For example, as a French person, I share with my fellow citizens certain representations, often historically dubious, of who Napoleon was. Much of the research on collective memory has thus focused on collective manifestations of representations of the past, as displayed in memorials, school history textbooks, commemorative practices, movies, and political discourses (Beim, 2007). Although this has made the discovery of extremely interesting mechanisms possible - for instance, how historical events tend to be systematically deformed by groups to fit their existing cultural narratives (Liu \& Hilton, 2005; Wertsch, 2008) - it has also occulted how the person locally produces discourses on the past.

For instance, I do not talk about Napoleon in the same way when I am back home, conversing about current politics with my family, or where I live in a Swiss Canton that was invaded and occupied by Napoleon's army. And, perhaps more importantly, I would probably not have chosen him as an example if I had not been writing this chapter just after reading a newspaper article on the topic. Indeed, as seen in Chapter 4, interactions with others - present, distant, or imagined - play an important role in TCP. As with any other human activity, thinking about the collective past is not done in a vacuum, and even less in a social vacuum. That is, talking about history and the way it is done locates people in the social field - as members of a specific group, proponents of a specific worldview, etc. - and is a reply to what has been said by others.

Continuing with the example of Napoleon, it means that I produce different discourses with my family or with my colleagues at work because these are shaped in my interactions with them. When talking about Napoleon with my family, I am reacting to the comparisons they might make between him and current politicians, as well as prolonging a long public debate about whether he should be remembered as a military genius or a dictator. What I say about him positions me on the political spectrum and towards my own family's political orientations. However, 
when I talk about Napoleon with my Swiss colleagues, I am responding to a very different debate: The question is not whether he was a good or a bad leader - it is commonly accepted that he was a tyrannical invader - but whether I, as a French person, will attempt to defend him or side with the people he attacked. What I say about him in this context positions me as either a blind patriot or defender of my country (and in some ways as an ungrateful immigrant), or as enlightened enough to see the ills of my country of origin and the goods of the one I live in (and thus as a good immigrant).

That is not to say that I hold almost schizophrenic discourses on history: I do not defend Napoleon in one case and bash him in another. But the ways in which I talk about him and defend my opinion will be deeply different because I am addressing a very different audience, with whom I share very different resources and pursue different aims. In order to account for these variations in how people represent the collective past, Wertsch proposed to make the distinction between the production and the consumption of narratives (Wertsch, 1997). For him, the production of narratives is primarily the prerogative of the state, that puts forward a certain understanding of what happened. But when people, in turn, use these narratives, they do not do so passively. Instead, as consumers, they choose what to use and when. To go back to the example of Napoleon, being exposed to stories about him in history classes as a child and reading an article about him today does not mean that I blindly repeat these discourses. However, they are resources that I use to talk about the past and advance, or resist, a certain representation of it.

While the distinction between production and consumption of RCP can help us account for why people do not simply reproduce official narratives, it does not quite explain how people create their own understanding of the collective past and will, in a similar context, say very different things about history. How come my sister and I - sharing the same culture, broadly the same education and being from the same generation - will tell, in the same conversation, extremely different stories about Napoleon? Because we have, ourselves, our own history through which our understanding of history in general and Napoleon in particular has been forged.

What research on collective memory and on collective remembering has for now largely ignored is that people have a "history in front of history," what I propose to call a trajectory of remembering. To conclude my Napoleon example, what would probably make my sister and me talk about him in different ways are our own different pasts. While I studied social sciences in the UK, my sister studied law and lived in the US. Whereas I was in a context where Napoleon was considered to be the evil man finally defeated in Waterloo and the one who attempted to destroy local cultural differences, my sister studied the man at the origin of the first civil code and lived in a country where Napoleon was one of these exotic French things, almost at the same level as baguettes and berets. Thus, when we talk about him today, our discourses are not just forged in the interactions with others and objects - to borrow Grossen's notion of context (Grossen, 2001) - but also by our own past. 


\section{Trajectories and development}

Humans live and develop in irreversible time (Valsiner, 1994), creating unique trajectories (Zittoun et al., 2013). These trajectories can account for how people relate to the world, give meaning to it and adopt or resist meanings proposed by others (Zittoun, 2006, 2012). Indeed, throughout our life, we internalise social and cultural values and systems of meaning and multiply experiences from which we can take a distance and draw generalisations (Zittoun, 2012). That is, by moving through a multitude of spheres of experience throughout our lives, we encounter different ways of understanding the world and of producing knowledge about it. From life at home, to groups of friends, school, and later, work or family life, we all move through different spheres of life both in the long-term - when we change jobs, for instance - and in the short term - moving daily from home to the public sphere, for example. Each of these spheres of experience come with norms, values, expectations, and systems of meaning. By taking distance from them, we can produce generalisations or integrations, where we develop a more global understanding of certain aspects of life.

In time, we develop personal life philosophies (PLP) - personal understanding of the meaning of life that take the form of more or less simple philosophical maxims that we use to interpret new experiences (Zittoun et al., 2013). These do not need to be unique (and often are not), but they are given a unique value in one's personal life through personal experiences. Clichés such as "two wrongs don't make a right" or "fool me once, shame on you; fool me twice, shame on me," for instance, can seem like meaningless cultural tropes, until a series of personal experiences turns them into a life lesson. Generally, however, PLP take a simpler form, such as when one concludes after a string of heartbreaks that love can only hurt, or after having mastered a long-coveted skill with much effort that hard work is always rewarded (Zittoun et al., 2013). Therefore, our past, through the experiences we have, the values and ideas we are introduced to, and the meanings we give to it, shapes how we understand and act in the present. And although this idea is, in the end, quite basic for any clinical psychologist, it is often forgotten in other areas of psychology.

Adapting this literature to RCP and TCP, we can conceptualise the latter as the result of a development process where, in time, people learn to think about the collective past by reflecting on what they have heard and said about it in different contexts. Going back to the framework introduced in Chapter 3, we can propose the model presented in Figure 5.1. As a reminder, we conceptualised TCP as the process by which a socially-located self, in interaction with a socially-located present and imagined audience, uses cultural resources to produce a discourse on the historical past. Adding a temporal dimension, we obtain a prismatic model where what is said about the collective past in the present is in continuity with what has been said in the past, and oriented towards what may be said in the future. In other words, discourses on the collective past are constructed over time: Each time I discuss Napoleon, for instance, I build on all the previous times I have talked and 


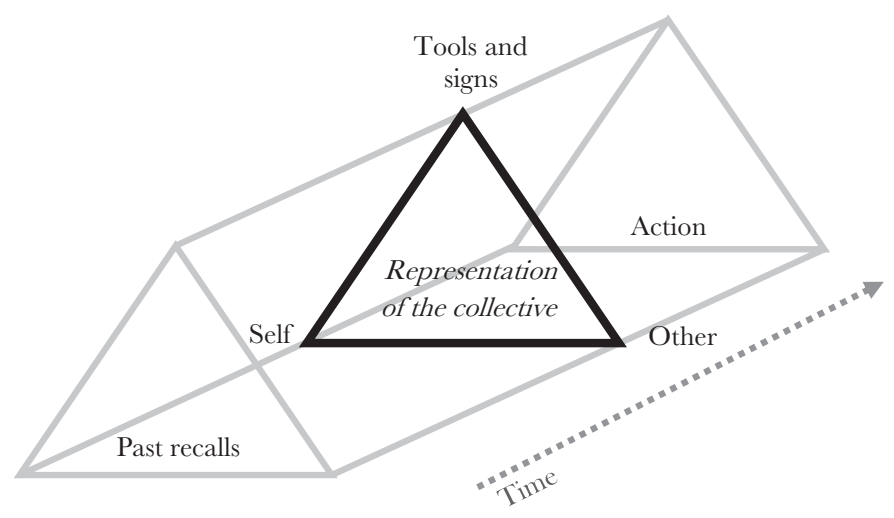

Figure 5.I Trajectory of remembering.

Source: adapted from de Saint Laurent and Zittoun, 2017.

heard about him. But more fundamentally, each time I talk about the collective past, I do so from a perspective that was forged by my past experiences of history. Migrating, for instance, and discovering for the first time that different countries have widely different accounts of World War II, has forever changed the way I talk about the collective past, making me question, every time, what stories other groups might have to tell about it.

Of course, it does not entail that we all, all the time, become very reflexive about our discourses on history, but that it is a developmental process, characterised by change and transformation across our life span. In other words, what we say about history evolves in time, even minimally, as we experience hearing and talking about it. This means that understanding how people think about the collective past requires adopting a life course perspective, best indicated for the study of developmental processes (Elder, 1998). This perspective focuses on individual trajectories, and in particular, on the moments of transitions and ruptures. Indeed, periods of change can lead to the construction of new meanings and result in intransitive (irreversible) qualitative changes in any period of life (Zittoun, 2012). Therefore, life course perspectives are not interested in objective and social marked transitions in one's life, but in the subjective experience one has of their life and the changes it goes through. As a result, it takes as the unit of analysis the interrelation between the discourses of the self and the unfolding course of one's life.

But can such a general perspective on development be applied to such a specific aspect of people's life? Does our relation to the collective past indeed form a trajectory? While RCPs and TCP do not necessarily have a very important place in most people's life - although, when we look at family narratives and national identities, there is much more than may appear at first sight - it does not mean that it doesn't play a role in their personal trajectories. The aim of the 
following study is thus to explore how people come to develop, in time, specific or unique representations of the collective past, by analysing their trajectories of remembering, and thus to offer a beginning of an answer to the question set out in Chapter 3: How do people come to develop specific or unique representations of the collective past?

\section{Analysing trajectories}

In order to reconstruct these trajectories of remembering, the elicitation method used was qualitative interviews, because they "provide in-depth information pertaining to participants' experiences and viewpoints of a particular topic." (Turner, 2010 , p. 754). This is a frequently employed method in qualitative research, to the point of being quasi-systematically used - and overused - regardless of its fit with the research questions (Potter \& Hepburn, 2005). However, it is a good means of collecting biographical data (Hopf, 2004), as long as one remains aware that the data thereby obtained is not a "perfect account" of reality but a construction in the interaction with the researcher (Brinkmann, 2016).

While answering the research question could have been done, in an ideal world, through a longitudinal study, these are extremely costly both in terms of time requiring years of research and participants - to account for the many dropouts. Nonetheless, a posteriori accounts also present their own advantages: They may not always produce the most factually accurate narratives, yet they are meaningful ways, for the participants, to explain who they are today and why they think the way they do. That is, while they may not produce the most detailed accounts of what happened, they provide the most relevant accounts, as time may have given distance to the participants to reflect, and because subsequent events may have highlighted important aspects of one's life that did not seem so relevant at the time.

The specific method used was a semi-structured interview; that is, somewhere between the informal conversation and the standardised interview (Gall et al., 2003). This method, in conjunction with a narrative approach, is best fitted for the collection of biographical data (Hopf, 2004). Interview techniques especially designed for the collection of life story exist (e.g., Atkinson, 2001; Rosenthal \& Fisher-Rosenthal, 2004), but the interest here is not in the whole life story of the person, but on the evolution, in time, of their relation to history. Moreover, although people are quite familiar with mainstream autobiographical accounts, the same cannot be said about the history of their relation to history, which may require more specific prompts. Instead, participants were encouraged to tell stories about different episodes or aspects of their lives related to history, an open form of narrative interview (Hopf, 2004).

The interview participants were contacted at a theatre play that offered a critical and pluri-vocal perspective on the history of the Israel-Palestine conflict (Rosenstein, 2014). The aim of the sampling was not to be "representative," but was chosen for two theoretical reasons (Glaser \& Strauss, 1967; Valsiner \& Sato, 
2006). First, because the play proposed a very critical perspective on history, and was advertised as doing so, it made it very likely that the participants would have themselves developed a unique relation to history or at the very least to have been pushed to reflect on the topic by the play itself. Second, because the play was complex and dialogical, it opened itself to a multitude of interpretations, making the participants' understanding of the play an interesting way to "check" the effect of their life story on their relation to history. Participants were told, upon being recruited for the interviews, that I was a psychologist interested in their relation to history, but that I was neither interested in historical accuracy, nor a historian or a specialist on the topic.

Nine interviews were thus conducted in February and March 2014 in Brussels (7) and in May and June 2015 in Geneva (2), where the play was shown at these periods, with spectators (7) and members of the staff around the play (2). The size of the sample was chosen following the principle of saturation (Glaser \& Strauss, 1967), that is "when the collection of new data does not shed any further light on the issue under investigation" (Mason, 2010, para. 2). Such saturation is always temporary - something new can always be discovered in the analysis and not be saturated - but generally speaking, we can say that saturation is reached when adding new data does not add to the model constructed from the analysis (Strauss \& Corbin, 1998). While the sample used here is small, the "modest" aims of the study (to look at how some people come to challenge hegemonic representations of the past) and its inscription in a larger project made saturation easier to reach (Mason, 2010).

The semi-open interviews conducted with the participants aimed at uncovering how they came to see the play or participate in it, as well as their past encounters with history (in school, at home, during travels, etc.). Each interview lasted between 45 and 90 minutes and all were conducted in French. Of the nine interviews conducted in Belgium and in Switzerland, two were chosen for this chapter: The cases of Dominique and Genevieve. Dominique and Genevieve are both women in their late fifties or early sixties, and both have a critical relation to history. They were thus chosen because: 1) they are comparable on many aspects (age, gender, background, etc.) and yet illustrate different processes of remembering and using the collective past; and 2) they have both developed a unique representation of history.

The data was first analysed with the help of narrative and trajectory analysis (Rosenthal, 1993). The interviews were cut into segments referring to different periods of the participants' lives and then organised in chronological order. This allowed me to focus on the transitions and ruptures in their understandings of history and their relation to it. Each period was analysed with the model proposed in Figure 5.1, which means, concretely, looking at: 1) the content of the discourses reported about history (e.g., what is the story about?); 2) the resources that have been used to construct said discourses (e.g., referring to books, using metaphors); 3) the audiences to whom these discourses are addressed (e.g., traces of voices of others, replies to quoted discourses); and 4) the transformations and 
continuities with the previous period (e.g., is the general narrative frame similar? Are the resources different?). However, the tendency to present the past as an explanation for the present (Cameron et al., 2004) - probably especially strong when talking to a psychologist, whose job is often perceived as one of explaining people's behaviours as a consequence of their past - needs to be taken into account to avoid overinterpretations.

Because of the vast amount of autobiographical data presented, important alterations were made to both cases in order to ensure anonymity. These modifications were done after the full analysis in order not to alter critical elements. These transformations concern names, places, dates, occupations, and, where necessary, historical events that were changed into equivalent ones for our purposes.

\section{Case I: Dominique}

Dominique is a Belgian woman born in the 1950s into a family of communist artists. The first part of her life is characterised by the gap she feels between what she is told at home and what is taught to her in the religious school to which her parents sent her for education. This is how she explains it, by referring to an incident that took place when she was eight years old:

D: My parents always told me that Julien Lahaut - well, you're not Belgian, so Julien Lahaut is a communist who screamed "long live the republic" when ... when the King Baudouin was taking the oath. So you know there was Leopold III who collaborated [with the Nazis] ... and he never came back, then there was a regency, and when his son came of age ... [...] Well, it was a huge mess. It was not just the question of the return of the king; it was that people had the option between [...] a more Socialist or a more Catholic Belgium. [...] So this guy yells "long live the republic" [...] and [later] he got shot down at home. They rang his bell, shot through the door, and they killed him. In 1950. Well ... that's what my parents always told me. And one day, at school, we talk ... we talk about the king. And I tell this story. And they tell me it's not true. [...] That it's a lie. So I have always learned that the official story had nothing to do with the true story. [...]

C (THE AUTHOR): And how did you react when you were a little girl $[\ldots]$ ?

D: I learned that I'd better shut up. [...] I didn't belong to the right social class. [...] So pfff, I'd better not be ... I would say politely, they would tell me it was wrong, and I would shut my mouth.

In this extract, Dominique shows the gap in understanding history between home and school. At home, her parents would tell her stories that illustrated their convictions and discuss historical events through these lenses. However, when she tries to talk about this with a different audience, she gets told off and learns to stay quiet. She clearly sides with her parents - they tell the "true story" she compares to 
the "official" one - but, perhaps, does not master enough, as a child, the resources her parents use to build this story and thus cannot defend it at school.

As she grows into an adolescent, however, her relationship with both her parents and school changes. She says about school:

D: I was pretty happy about how I was taught history, because in my school there were humanists and leftists, and so I was always taught history between economical causes and consequences. [...] So I was always very conscious, well, made conscious, but in a well-argued manner, about the accumulation of capital [...] so each time I was reading a book about that I was thinking, well yes!

Here, we can note two main changes in this period, as compared to her early childhood. First, there seems to be a change in the type of audience that school represents: It is now a place where you can learn from "humanists," and not a strict Catholic school where she feels she does not belong. Second, she starts being given resources to understand history: Although we can assume that her parents - whom she defines as very communist - already made her familiar with historical discourses centred on the notion of capital, she adds this time "but in a well-argued manner." Where her parents' stories had left her without the resources to defend them, she seems here to be introduced to new tools that help her forge her own opinion. If the last sentence gives us a clue about the type of resources she starts using, these are developed in the following extract about her relations at home, where she talks about her mother:

D: And it's true that she used to annoy me a lot because for instance, when Stalin died, she cried about it. And ... well ... she didn't understand a thing about de-Stalinization. Yes, well, she didn't read a thing either. But me, I had read, I was 12 and a half, 13, and I had read a lot of things and I would think: but how can she not know? And how can she ... I was shocked by the lack of analysis, [...] of objective support. [...] And for me, the historical critique was part of my survival, maybe. Because I had an extremely violent, extremely anger prone mother. And so it was in my best interest to know very well ... that.

Here, we can see a shift at home: The family discourses that she used to take for granted are now considered as the ones without "objective support." In the following years, Dominique enrols in a Trotskyist group because it was "against Stalin" and perhaps her parents. She reports that she argued about these issues with her mother, and that she started reading a lot, not only about the roots of communism, but also World War II. From a little girl listening avidly to her parents' stories about the past, she becomes an adolescent arguing against them with the help of what she learns in school and in books, which seems to be a way to resist her "extremely violent" mother. And in the following years, she takes part in political 
movements against colonialism and in women's rights demonstrations, against her parents' approval, and develops new friendships in these militant groups. But if she opposes her parents, she interestingly does so while remaining extremely close to their values: She still identifies herself as a communist, but of a different kind. It seems that she found a way to position herself that would not alienate her at home or in school and would allow her to have her own voice.

Not much seems to change in Dominique's relation to history in the following decades. While the late 1980s are marked by the birth of her two sons, she is surprisingly silent about the collapse of the USSR. But when asked, at the end of the interview, which historical event she would love to change most, she replies:

D: I don't know. I don't know, I don't know. [3 s] Because I don't see one event ... ok, when the Vietnamese thumbed their nose at the Americans, we could only be happy. [2 s] To do what? [3 s] That's it.

C: hum ...

D: When the Chinese separated themselves from the yoke of ... the Soviets, but to do a cultural revolution ... with the horrors they did. And a society, I would say, more than unequal ... I am not talking about misery in ... in economic misery. I'm talking about intellectual misery.

She does not seem to propose events she would like to change, but events on which her interpretation changed: From the hope of an international Trotskyist revolution that would show another communism other than Stalinism, it turned into despair about yet another communist inspired dictatorship. The difficulty in making sense of this turn of events is made clearer when I ask her about how she thinks current events will be remembered in the future, for instance the Arab Spring (the interview took place in March 2014). She replies:

D: For me there is not one and only one Arab Spring. But for me all these stories about Islam I don't care. [...] The Taliban are not funny, but the Red Guard was not either. [...] I don't know what we will remember of it [4 s] these are countries ... None of them, although they produce necessary resources, none of them has its own industry. [...] They are consumers of the powerful countries, [...] [like us] who are hands and feet tied to the American older brother.

After this, she goes on about the capitalist system, and concludes that we are all "fully enslaved" to it. What is interesting here is that Dominique's discourse does not change: In the stories she tells about the 1990s and onward, she refers to the same audience (especially her mother and her friends in militant groups), uses the same resources (mainly books and newspaper articles) and tells similar stories about class warfare and the opposition between the Americans and others, whether they are soviets, communists, socialists, etc. The world, however, did 
change: Communism ended in a way that did not leave much hope for its partisans in Western Europe, and international politics have seen the arrival of new major players - mainly India, China, and Brazil - that make reading the world in terms of USA/Russia opposition look slightly dated. As a result, Dominique seems to take a certain distance from her past understandings of history - as for instance when she talks about Vietnam - and to take part in less political actions: She reports participating in unionist movements during these years, but no mention is made of political engagements, in stark contrast to what she reports of the previous decades. In today's world, her positioning seems at times problematic; she talks about a few recent incidents where she quite strongly argued against interlocutors in ways quite at odds with the situation.

However, this (relative) lack of change does not need to be interpreted as an inability to adapt to the present. Instead, it can be interpreted as quite functional: 40 years on, Dominique is still able to maintain a relationship with her difficult mother and yet to resist her by arguing for a different understanding of the collective past. If the end of communism is not evoked by Dominique as a strong transition in her relation to history, it may then be because it did not change much the opposition to her mother's favoured communism. If resisting hegemonic representations of history fuelled Dominique's social and political engagement, it seems also to have been a resource to resist difficulties in her own family.

\section{Case 2: Genevieve}

Genevieve is a social worker born in the 1960s to a Belgian father and a Polish mother. Although her father is fascinated by history, especially World War II, they do not talk much about it at home. Her mother, who left Poland after World War II, only tells stories about pre-war Poland, with one notable exception:

G: And my mother for instance, well ... often in these situations people who suffered a lot they don't talk about, about that part of their life, me, when I was a kid, she would talk to me about her house that was like an absolute Eden. Until 39. [...] The only comments that I got when I was a child was if I did not eat, "you will finish your plate," very calmly, not even angry, not even, not even rising her voice, "you will finish your plate because people in the ghetto they ate the grass in between the pavements." Bang. [...] But this is, this a way to ... how are we going to call this way to tell a story, for instance, what is this way to tell history, if your mother tells you that when you're a child? [...] And that, at the same time, you are nourished by what the ghetto was because we had books in the library with well, images and all, so I knew very well.

Here, it seems that while Genevieve gets knowledge about the past from books she reads on her own and does not discuss with her parents, such knowledge is made alive by her mother's discourses and is actually necessary to interpret them. 
In interactions with her mother, and using the books she read as resources to represent the past, Genevieve builds a story of what happened, or at least an image strong enough to stick with her 40 years later. Very early on, then, she is put in a position where she has to construct her own understanding of the past, between the remarks of her mother - which do not really amount to a story - and what she discovers, alone, in books. In that sense, she is quite an obvious illustration of the model self-other-cultural tool presented above: She constructs a representation of history through the interaction with others and the use of cultural resources.

In the early 1980s, however, an experience profoundly changed her relation to history. She moved to Poland, against her mother's advice, and was asked by a Belgian newspaper to interview Polish people who resisted during World War II. As her mother had left her country before the 1950s, she had depicted a rather different Poland than what Genevieve found when she arrived, during a period of great repression. And she says:

G: I arrived, so naïve, thinking the Poles are such patriots it will be so easy to interview them on, on resistance during World War II. What I didn't know is that most of them thanks to the great Yalta were sent by Stalin to Siberia for 15 years. [...] It was dangerous to leave them in this new communist country that had such a radiant future, we were not going to keep people of the old regime who were going to mess it up. [...] If I had interviewed them one or two years before, when $[\ldots]$ when the wind of freedom was rising, I think they would have told me many things. But they had just had a lid closed on their faces [...] and Jaruzelski [the Soviet-controlled Polish president] was there with his tanks. So I was confronted with people who did not want to talk at all, because they were scared, simply. So I had to develop all sorts of strategies to interview them. And that's where I realised that there are really two histories, you see. [...] People would yell at me. [...] "you know that us, we fought for you, and we all ended up behind the iron curtain and that, we were here, and there," and it's true that the Poles were everywhere, in Africa and in the UK, that, that, "this is the payback we got, we ended up behind the iron curtain and in Siberia, so please excuse me but we don't really want to ..." And we were never told that in school.

C: Yes ...

G: Never never never never never. [2 s] And so there were really two readings of history that ... that were, were ... for me it was the first time that I was really shaken to the core thinking [2 s] things are never really black and white. Things are never told ... It's not because I learnt it in school that it is true. It's not because I read it in a book that it is true. And ever since, I, I, I, well my parents used to read a lot [...] and they just died and, and, and I wonder but what am I going to do with all these history books because these are stories that are already not true anymore today because in the meantime researches were done that show [that they were wrong]. 
During her stay in Poland, two "lessons" seemed to change Genevieve's relation to history. First, as she says, she discovered that history is multiple and thus a matter of perspective. Interestingly, she did so by interacting with a group to which she, in some ways, belongs, being Polish and identifying as such (she reports being "yelled at" by these interviewees for being Polish and yet not speaking the language, which means that she introduced herself as Polish). Second, she learnt something that was never (with much insistence on the never) introduced to her in school, and the intensity of her reaction looks like a response to the level of the betrayal. Interacting with these Polish resisters and discovering their story made her question what she had learnt so far and how simple - "black and white" - it looked. And these doubts seem to remain today, as the end of the excerpt shows.

If this event left Genevieve very sensitive to the perspectival nature of history, her journey does not end there. About ten years later, just after the Scud crisis with Saddam Hussein, she visited Israel, during a period of great tensions. She talks about the religious extremists there and how they have a very specific discourse on history. I ask her what they say:

G: Well, that it's the holy land and, there is no discussion to have. It's, it's always the same story, you see. It's, it's, they are the chosen people, the thingy, and well everything we know, you see. Without, with no possibility to have a dialogue with these people ... they are really insane, you know. [...] I was walking with a friend who was 55 at time and who was wearing a shirt with sleeves up to here [shows her wrists] and who had just left this button open [shows her neck] and she was called a Nazi. Well first the insult has nothing to do with [laughs], well, nothing. You just want to tell them, "poor dude, just shut up."

This experience seemed to have put a limit to her openness to the diversity of perspectives on history: If the others refuse dialogue - because they are not accessible to logic - then it is pointless to engage with them. If she can interact with their arguments and the resources they use to build their accounts of the past - she does so just after in the interview - she cannot or will not do so with their perspectives. And this leads her, at times, to a paradox: Although she defends a perspectival understanding of history, she also insists on how "real facts" have shown these extremists were wrong about it, and she uses them to dismiss their perspective.

As a young girl, Genevieve's relations to history had been mainly centred on the books she would read and the remarks from her mother, full of connotations. A first transition, however, changed her understanding of "official" accounts of the past. Others, and what they had to say about history from their own perspective, thus became a great resource to understand the past. A second transition put a limit to this openness to other's discourses: Those who are not rational and refuse alternatives should not be interacted with. In a way, it is possible to see this second transition as a "re-balancing" of Genevieve's relation to history. Indeed, 
although openness and flexibility are often considered as quite desirable psychological qualities - ensuring people's adaptability - taken to the extreme they also leave people at the mercy of any change in their environment and may threaten their sense of coherence and stability. In the case of Genevieve, it meant accepting discourses that ran contrary to other convictions she had - like the fact that a woman should be allowed to unbutton the uppermost button of her shirt in public. Hence, developing a "rule" to resist some perspective - history should not be discussed with those who are not accessible to logic and reason - may be a way to strike a necessary balance.

\section{Ruptures and resources}

Through these two case studies, I have attempted to show how people's relation to history can be understood as the product of a trajectory marked by ruptures and transitions, the internalisation of social and cultural values, the construction of new meanings, and, in the end, by intransitive qualitative changes. In the first case, that of Dominique, the analysis highlighted how the internalisation of her family's values created a rupture in school, from which she concluded that she did not fit in there and should therefore remain silent. This meaning was challenged during adolescence, when she was faced with teachers who were more open to her values and a difficult relation with her family. This second transition led her to develop her own version of her family's values - allowing her to both resist her mother and socialize in militant groups - through the use of books and various specialised texts. This second understanding is still what she uses today to interpret history. In the second case, that of Genevieve, the analysis showed how she started using books and pictures to make sense of the discourses of her mother, which were full of historical connotations. However, a strong rupture occurred when she visited Poland as a young adult and was confronted with new discourses about history. This made her question what she had learnt before - and what she had not been told - and to develop a rather perspectival understanding of history. However, a second rupture occurred a decade later, limiting the discourses she would agree to be open to.

In both cases, personal trajectories shaped how the participants remember and understand the past, which is actively acknowledged in the interviews: Both Dominique and Genevieve themselves refer to their past to explain their present understanding of history. Past events do not just influence their relationship to history: Through time, experiences create layers of meaning through which the past can be understood. Indeed, meanings do not cancel each other out but, through consecutive ruptures, participate in the construction of a rich system of values and understanding of the world. Contradictions and paradoxes, then, are part of their trajectories and are forged through contradictory and paradoxical experiences. As a result, each person's representation of history is unique, even within a rather homogenous social group - here, both participants belong to the same generation and grew up in quite close social classes with leftist values. This is especially 
clear in the way they react to the play they went to see: Genevieve questions the "missing perspectives" in the story and Dominique talks about her pro-Palestinian activism in her youth and economic questions.

Through these trajectories, Dominique and Genevieve seem to have developed a general understanding of history that they apply to the various events they talk about in the interviews. Indeed, they generalise from experience both how history is built or ought to be built - for instance, when Genevieve "discovers" that history is a matter of perspectives - and general story lines that organise how they talk about subsequent events - for example, when Dominique talks about the Arab Spring and develops a narrative based on economic transformations. I propose calling these generalisations about memory metamemory. This form of memory rests on cultural concepts and cultural narrative templates (as described, for instance, by Wertsch, 2008), which are culturally shared ways to understand the world or to tell a story, but it differs from them since it is built and given value and meaning through personal experiences. It thus has a deeply personal resonance, as do Personal Life Philosophies (Zittoun et al., 2013). For instance, one can learn in school that there is always more than one side to a story (cultural concept), but this is not the same thing as discovering it through the encounter with another telling an extremely different story about a past one considered one knew, like Genevieve did.

What is also notable here is that two types of tools seem to play a central role in the transformation of these women's representations of history. First, books and other textual resources (as they may be presented in school) are recurrent resources. Surprisingly, however, very few references are made to historical movies and novels, when they are usually considered as extremely important resources for collective memory. However, participants may simply choose not to refer to those in the context of the interview - although the participants in the study presented in the next chapter did. Second, interactions with others and the stories they tell are an important resource too. Interestingly, it seems that the "channel" through which a rupture is brought about is also the one that will be later favoured. Indeed, for instance, Genevieve's first rupture is introduced through the discourses of others, and it is what she later uses as a resource to build narratives on the past. Dominique, on the other hand, is first unsettled by discourses in school and yet it is through the textual resources introduced by teachers later in her life that she builds her representations of the past. But both tools - others and texts - share a common feature: Neither is blindly used, but they are instead a resource with which one interacts and dialogues in order to build an account of the past. For instance, when Dominique reads, as a young teenager, communist manifestos and historical books, she agrees with some ("thinking well yes!") and yet remains critical in front of others (especially those which overlook economical dimensions, as she explains later in the interview). Developing critical RCPs, thus, is deeply oriented towards others and RCPs built in the interaction with their voices, whether it is face-to-face or through books and other media. 


\section{Personal world philosophies}

In this chapter, I have argued that personal trajectories, through rupture and reorganisations, lead to specific ways of remembering the past and thus, potentially at least, to a critical perspective towards hegemonic or one-sided representations of history. In the cases of Dominique and Genevieve, this was done through the use of textual and dialogical resources that helped them both build unique accounts of the past and criticise "official" narratives. But for them, the critique did not stop there: They have both been involved in activism and social action, that they linked, during the interview, to their critical outlook not only on history, but on society in general. This is particularly clear in the case of Dominique, where her relation to history is part of a general understanding she has of the world, largely borrowing from communist ideologies. Genevieve, on the other hand, described adopting, in her work as a social worker, a position similar to the one she has in front of history: Considering that there is not one truth and the world is made up of multiple perspectives, with the exception of extremist ideologies - defined, there again, in religious terms. This parallel between representations of history and of the social world was present, to a certain degree, in all the participants I interviewed for this study (see also de Saint Laurent, 2018).

It thus appears that, in a way similar to that described by Zittoun et al. (2013) about the development of Personal Life Philosophies (PLP) through the life course, we also produce what could be called Personal World Philosophies (de Saint Laurent, 2018). That is, we develop unique understandings of the world we live in that build upon the meanings, ideas, symbols, and values we have encountered and that we integrate in personal ways. In the case of Dominique, she produced her own representation of how the world is organised, borrowing from different aspects of communism and socialism as she discovered them at home, at school, and in her political actions. Her PWP then shapes how she interprets not only the past, but also the present and the future: Primarily in economic terms and as revolving on an ideological confrontation between capitalism and communism. Other participants developed PWP focusing on different aspects of social life - for instance centred on the role of war or communication between groups - but used them in similar ways. Indeed, these representations were most salient when they were asked to discuss the present and the future in light of the past, as well as when they would evoke several time periods at once. That is, PWP allowed them to make connections between different time periods and to draw generalisations from these temporal dialogues. That is, the way we think about the past is characterised by temporal heteroglossia - the simultaneous consideration of multiple time periods as different voices in a dialogue.

While I hope this chapter has shown that the textual and dialogical resources we encounter throughout our lives have the potential to transform the way we think about the collective past, two questions remain. First, as argued before, representations of the $\mathrm{CP}$ are pervasive, and we will very likely be confronted with RCPs that differ from our own at one point or another. Yet, these encounters do 
not always lead to any transformation of how we understand or relate to the past. Under what circumstances, then, do new representations of the collective past emerge? Second, even when change does occur, people do not simply "replace" one representation with another, but instead appropriate and integrate RCPs in unique ways. What are the processes through which new RCPs are constructed? In other words, what resources are used to construct representations of the collective past? These are the questions the next chapter will attempt to answer.

\section{Note}

1 Parts of this chapter are reproduced from de Saint Laurent, C. (2017b). Trajectories of resistance and historical reflections. In N. Chaudhary, P. Hviid, J. Villasden, P. Marsico \& J. Valsiner (Eds.), Resistance in everyday life: Constructing cultural experiences (pp. 49-63). Singapore: Springer.

\section{References}

Atkinson, R. (2001). The life story interview. In J. Gubrium \& J. Holstein (Eds.), Handbook of interview research (pp. 120-140). Sage Publications. https://doi. org/10.4135/9781412973588.n9

Beim, A. (2007). The cognitive aspects of collective memory. Symbolic Interaction, 30(1), 7-26. https://doi.org/10.1525/si.2007.30.1.7

Brinkmann, S. (2016). Methodological breaching experiments. Steps toward theorizing the qualitative interview. Culture \& Psychology, 22(4), 520-533. https://doi. org/10.1177/1354067X16650816

Brockmeier, J. (2002). Remembering and forgetting. Narrative as cultural memory. Culture \& Psychology, 8(1), 15-43. https://doi.org/10.1177/1354067X0281002

Cameron, J. J., Wilson, A. E., \& Ross, M. (2004). Autobiographical memory and selfassessment. In D. R. Bleike, J. M. Lampinen \& D. A. Behrend (Eds.), The self and memory (pp. 207-226). Psychology Press.

de Saint Laurent, C. (2018b). Thinking through time. From collective memory to collective imagination. In C. de Saint Laurent, S. Obradović \& K. Carriere (Eds.), Imagining collective futures. Perspectives from social, cultural and political psychology. Palgrave Macmillan.

Dudai, Y., \& Carruthers, M. (2005). The Janus face of Mnemosyne. Nature, 434(7033), 567-567. https://doi.org/10.1038/434567a

Elder, G. H. (1998). The life course as developmental theory. Child Development, 69(1), 1-12. https://doi.org/10.1111/j.1467-8624.1998.tb06128.x

Gall, M. D., Gall, J. P., \& Borg, W. R. (2003). Educational research. An introduction. Allyn and Bacon.

Glaser, B., \& Strauss, A. (1967). The discovery of grounded theory. Strategies for qualitative research. Aldine Publishing Company.

Grossen, M. (2001). La notion de contexte. Quelle définition pour quelle psychologie? Un essai de mise au point. In J.-P. Bernié (Ed.), Apprentissage, développement et significations (pp. 59-76). Presses Universitaires de Bordeaux.

Hopf, C. (2004). Qualitative interviews. An overview. In U. Flick, E. von Kardoff \& I. Steinke (Eds.), A companion to qualitative research (pp. 203-208). Sage Publications. 
Liu, J. H., \& Hilton, D. (2005). How the past weighs on the present. Social representations of history and their role in identity politics. British Journal of Social Psychology, 44, 537-556. https://doi.org/10.1348/014466605X27162

Mason, M. (2010). Sample size and saturation in $\mathrm{PhD}$ studies using qualitative interviews. Forum Qualitative Sozialforschung/Forum: Qualitative Social Research, 11(3), Art. 8. http://nbn-resolving.de/urn:nbn:de:0114-fqs100387

Potter, J., \& Hepburn, A. (2005). Qualitative interviews in psychology. Problems and possibilities. Qualitative Research in Psychology, 2(4), 281-307. https://doi.org/10.1191/1 478088705qp045oa

Rosenstein, A. (2014). Décris-ravage. Théâtre Océan Nord.

Rosenthal, G. (1993). Reconstruction of life stories. Principles of selection in generating stories for narrative biographical interviews. The Narrative Study of Lives, 1(1), 59-91.

Rosenthal, G., \& Fisher-Rosenthal, W. (2004). The analysis of narrative-biographical interviews. In U. Flick, E. von Kardoff \& I. Steinke (Eds.), A companion to qualitative research (pp. 259-265). Sage Publications.

Strauss, A., \& Corbin, J. M. (1998). Basics of qualitative research. Techniques and procedures for developing grounded theory (2nd ed.). Sage Publications.

Turner, D. (2010). Qualitative interview design. A practical guide for novice investigators. The Qualitative Report, 15(3), 754-760.

Valsiner, J. (1994). Irreversibility of time and the construction of historical developmental psychology. Mind, Culture, and Activity, 1(1-2), 25-42. https://doi.org/10.1080/ 10749039409524655

Valsiner, J., \& Sato, T. (2006). Historically structured sampling (HSS). How can psychology's methodology become tuned in to the reality of the historical nature of cultural psychology? In J. Straub, D. Weidemann, C. Kölbl \& B. Zielke (Eds.), Pursuit of meaning (pp. 215-251). Transcript.

Wertsch, J. (1997). Narrative tools of history and identity. Culture \& Psychology, 3(1), 5-20. https://doi.org/10.1177/1354067X9700300101

Wertsch, J. (2008). The narrative organization of collective memory. Ethos, 36, 120-135. https://doi.org/10.1111/j.1548-1352.2008.00007.x

Wertsch, J., \& Batiashvili, N. (2012). Mnemonic communities and conflict. Georgia's narrative template. In I. Marková \& A. Gillespie (Eds.), Trust and conflict. Representation, culture and dialogue (pp. 37-48). Routledge.

Zittoun, T. (2006). Transitions. Development through symbolic resources. Information Age Publishing.

Zittoun, T. (2012). Lifecourse. A socio-cultural perspective. In J. Valsiner (Ed.), The handbook of culture and psychology (pp. 513-535). Oxford University Press.

Zittoun, T., Valsiner, J., Vedeler, D., Salgado, J., Gonçalves, M. M., \& Ferring, D. (2013). Human development in the life course. Melodies of living. Cambridge University Press. 


\section{Resources and processes to think about the collective past}

As we have seen in the previous chapters, our representations of the collective past (RCPs) are not the direct product of the discourses we may have heard, the others we have interacted with, or the demands of the situation at hand: RCPs are the result of how we actively engage with them, and so of the resources we do end up employing and how we choose - or manage - to use them. In this chapter, I thus propose to focus on the resources and processes we utilise when thinking about the collective past (TCP). To do so, I first briefly review the literature on historical thinking and historical reasoning. I then introduce the dialogical experiment that was conducted to analyse TCP, where the participants were confronted with different discourses about an ongoing conflict with important historical ramifications. After analysing the resources and processes that the participants used when discussing the events and their historical roots, I present a model of TCP focused on the dialogical tensions that run through RCPs - between the general and the particular and between the objective and subjective - and that can lead to the emergence of new representations, as well as the main elements that contribute to the construction of RCPs - meaning, sense, factual knowledge, and schemas.

\section{Historical thinking}

Historical thinking and historical reasoning have long been an object of research, but most often with a focus on history education. Historical reasoning, for instance, has been defined as "a process in which central facts and concepts are arranged to build an interpretative historical case" (van Boxtel \& van Drie, 2004, pp. 89-90). Both concepts have been used mainly to talk about children's understanding of history, although they have, at times, been applied to history research itself (e.g., Ringer, 1989), or more exceptionally to political sciences (Redhead, 2002). They are indeed usually employed in reference to the types of thinking or reasoning skills children need to acquire in order to think about history like professionals would, and experts are often used as the baseline for comparison of performance. Seixas and Morton (2013), for instance, have developed a framework highlighting six historical thinking concepts that children need to acquire: Historical significance, primary (vs. secondary) source evidence, continuity and change, cause and 
consequence, taking historical perspectives, and the ethical dimension of historical interpretations.

Research on historical thinking and historical reasoning has also highlighted five main abilities that history education should aim at developing in children (van Drie \& van Boxtel, 2007): Asking historical questions (e.g., van Drie \& van Boxtel, 2011), using sources (e.g., Barton, 1997; Wineburg, 1991), contextualising (e.g., Reisman \& Wineburg, 2008), arguing (e.g., Pontecorvo \& Girardet, 1993), and using concepts (e.g., Schoeman, 2007). Historical perspective taking has also been recently appearing as a potential sixth ability, although a common definition remains to be found (Hartmann \& Hasselhorn, 2008; Páez et al., 2017).

However, as Wineburg (1999, p. 491) puts it:

Historical thinking, in its deepest forms, is neither a natural process nor something that springs automatically from psychological development. Its achievement, I argue, goes against the grain of how we ordinarily think. This is one of the reasons why it is much easier to learn names, dates, and stories than it is to change the fundamental structures that we use to grasp the meaning of the past. The odds of achieving mature historical understanding are stacked against us in a world in which Disney and MTV call the shots. But it is precisely because of the uses to which the past is put that these other aims take on even greater importance.

The aim of Wineburg's argument was to cut the debates on what kind of history should be taught to children (a more glorified version of the past, or one insisting on its darker aspects), to instead focus on how and why history should be taught. However, it highlights an important aspect of historical thinking in the literature: It is often constructed in opposition to collective memory. Indeed, if we need to teach children how to think properly about the past, it is to avoid the dangers of how we "naturally" represent the past, usually studied under the heading of collective memory. It is not to say, of course, that researchers studying historical thinking "look down" at how adults represent the past, but rather that the aim of their work is to help children develop an understanding of the collective past that avoids the excesses RCPs can lead to - from dangerous nationalisms to the denial of past crimes.

Unfortunately, it does mean that much of the literature on historical thinking is not particularly relevant for our purposes, because it focuses on what children, teenagers, and young adults ought to do and how to teach it to them, and not on how adults actually do it. In what follows, I thus propose to look at how adults think about the collective past, and in particular what the resources and processes are that participate to the construction of RCPs, through an empirical and exploratory study. While the literature on historical thinking provides a background against which we can study TCP in adults, its normativity limits its usefulness in our context. Instead, the analysis and the model presented in this chapter use, as a basis, the literature presented in the previous chapters, and in particular that on sociocultural psychology presented in Chapter 1, and on TCP in Chapter 3. 


\section{A Dialogical Experiment}

\section{Rationale}

In order to study, in a given situation, what resources and processes people employed for TCP, I constructed a Dialogical Experiment, where participants were exposed to dialogical stimulus that would encourage the construction of new representations of the past. That is, the participants were experiementally exposed to different positions on an event - as different voices - and asked to interact with them. A Dialogical Experiment is thus a qualitative experiment where the stimulus is built based on dialogical assumptions - that the social world is made up of various perspectives that constititute as many voices - and with the aim of articifially recreating said voices. In some ways, then, this method shares some basic characteristics with focus groups, where the latter would allow for more "organic" interactions between people having different positions on a social object. For as artificial as they may be, dialogical experiements do offer two advantages. First, focus groups can be difficult and costly to organise, in particular if one wants to explore a multitude of social positions and how they interact. Second, because they are more directly focused on interactions, they do not permit the fine-grained analysis of how people construct RCPs that was the objective here, as it is not feasible in a collective context.

More fundamentally, dialogical experiments belong to the family of experiments, as the type of design that is the simplest and most efficient way of observing the participants' reaction to a predefined stimulus (Moscovici \& Perez, 2003). As a qualitative experiment, it does share much with its quantitative counterparts, yet differs widely in some other aspects. On the one hand, qualitative experiments do use, too, the introduction of a stimulus to provoke a certain reaction that is then measured and analysed. On the other hand, they do so within a very different paradigm. First, this type of experiment does not consider that there is a direct causal link between the stimulus and the response, but that the reactions of the participants are the product of the interactions between them, as wilful agents, and the task proposed by the experimenter. Second, it is not interested in the quantification of reactions to variables, but in the processes that the participants display to solve the task. Qualitative experiments, thus, are not interested in quantifying the results of causal relations, but in analysing the dynamic relations between participants and the tasks given to them. They are thus particularly useful to study the resources and processes people use when thinking about an event of the collective past.

While qualitative experiments now seem quite the oddity - the word experiment being strongly associated with "mainstream psychology" - it has not always been the case. Indeed, the methods used by Bartlett (1932), Vygotsky (1981), and Piaget (1964) were all forms of qualitative experiments, and they have inspired generations of researchers who still today conduct studies using methodologies that are rooted in these works (e.g., Breux et al., 2014; Mehmeti \& Perret-Clermont, 2016; Wagoner \& Gillespie, 2014). Moreover, qualitative experiments do offer some advantages over 
other qualitative methods - although this, of course, always depends on the research questions one is trying to answer - and there is much to gain by reinstating them in qualitative studies. First, experiments allow researchers to use a broad range of interventions, not limiting these to interview questions, and therefore are more adaptable to specific research questions. Second, they systematise the material proposed to the participants, offering the possibility to compare patterns of interactions between different people. Third, qualitative experiments do not consider that the participants' answers are a reflection of their reality outside the laboratory, a common mistake in qualitative interviews (Brinkmann, 2016), but the product of their understanding of the task at hand. As such, they are especially fitted to the study of psychological processes, especially microgenetically (Wagoner, 2009), through the observation and analysis of the processes by which people make sense of the experimental situation and start to act within it.

\section{Design}

The Dialogical Experiment designed for this study was divided into two parts. The first part was a qualitative interview, asking participants to choose three historical events important to them and to explain why they chose them. The questions and follow-ups aimed at reproducing, in a shorter version, the type of data obtained in the study presented in the previous chapter, and thus give some background information that would help interpret the participants' responses to the experiment.

The second part of the study was the qualitative experiment per se: Participants were asked to react to statements on the ongoing (at the time, May 2015) Ukrainian conflict, presented in the form of a cardboard game-like set. They were asked to take part in a "dinner party," represented by a set of cardboard tables, and to pick different vignettes containing statements about the conflict. The tables were organised by "side" of the debate: Ukraine, Russia, International community, Local population. Participants chose from which table to pick each statement, but the specific statement was taken at random.

On average, the participants each picked four texts, usually evenly distributed between the tables. After each vignette, they were asked to summarise what they had just read, and to say how they would respond to the author of the text. The 16 texts (four per table) were constructed using newspaper articles and organised around two dimensions: Neutral vs. partisan perspective and fact-based vs. experience-based perspectives. All the information presented was as "correct" as possible (it represented the perspectives of real people and all facts included had been checked against several sources), but the statements in themselves were artificially constructed for the experiment (a debriefing document was given to the participants, clarifying how the vignettes had been made). A summary is presented in Table 6.1.

The Ukrainian conflict was chosen both for its complex historical ramifications, especially in Central and Eastern Europe, and because it was recent enough at the time of the interviews (May 2015) to make it likely for most participants to be able to discuss it at ease - and hopefully also for them to be more open to change. All 
Table 6.I Summary of the vignettes presented to the participants

\begin{tabular}{|c|c|c|c|}
\hline Table & Statement & Side & Based on \\
\hline \multirow{3}{*}{ 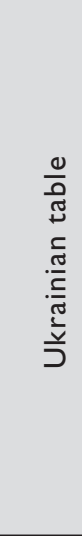 } & $\begin{array}{l}\text { 01. Statement from the Ukrainian } \\
\text { Military Spokesman claiming } \\
\text { that Russia is invading } \\
\text { Ukraine using figures from the } \\
\text { American intelligence source } \\
\text { 02. Statement from a Ukrainian } \\
\text { professor explaining the role } \\
\text { of Russian propaganda in } \\
\text { Eastern Ukraine }\end{array}$ & Pro Kiev & Facts \\
\hline & $\begin{array}{l}\text { 03. Ukrainian protestor explaining } \\
\text { that all they wanted was to be } \\
\text { free of Russian influence }\end{array}$ & Pro Kiev & Experience \\
\hline & $\begin{array}{l}\text { 04. Ukrainian writer explaining } \\
\text { the role of corruption in motivating } \\
\text { the demonstration }\end{array}$ & Pro Kiev & Experience \\
\hline \multirow{4}{*}{ 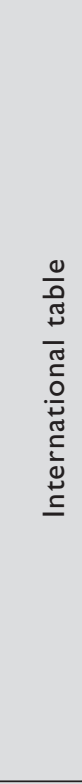 } & $\begin{array}{l}\text { 05. British journalist arguing } \\
\text { that we don't know what is } \\
\text { really going on in Ukraine, as we } \\
\text { don't even know which side the } \\
\text { snipers who attacked the protestor } \\
\text { were working for }\end{array}$ & Neutral & Fact \\
\hline & $\begin{array}{l}\text { 06. Japanese journalist arguing } \\
\text { that both sides are doing } \\
\text { terrible things by using illegal } \\
\text { and violent weapons }\end{array}$ & Neutral & Fact \\
\hline & $\begin{array}{l}\text { 07. American journalist explaining } \\
\text { that although the referendum } \\
\text { in Crimea is dubious, most Crimean } \\
\text { are Russian, so we don't have the } \\
\text { right to prevent them from } \\
\text { becoming part of Russia }\end{array}$ & Pro Russia & Fact \\
\hline & $\begin{array}{l}\text { 08. Irish journalist explaining } \\
\text { that there are now recordings and } \\
\text { photographs that prove } \\
\text { that Russia and the separatists are } \\
\text { very probably behind the plane } \\
\text { crash }\end{array}$ & Pro Kiev & Fact \\
\hline \multirow{2}{*}{$\begin{array}{l}\frac{0}{0} \\
\frac{0}{ \pm} \\
\frac{0}{0}\end{array}$} & $\begin{array}{l}\text { 09. Mother of a Russian soldier } \\
\text { demanding to know what happened } \\
\text { to her son who died on a mission } \\
\text { he was told was in Russia, but who } \\
\text { was filmed in combat in Ukraine }\end{array}$ & Neutral & Experience \\
\hline & $\begin{array}{l}\text { 10. Tatar activist explaining how for them } \\
\text { the conflict in Crimea didn't change } \\
\text { anything, as neither side has ever } \\
\text { respected their human rights }\end{array}$ & Neutral & Experience \\
\hline
\end{tabular}


Table 6.I continued

\begin{tabular}{|c|c|c|c|}
\hline Table & Statement & Side & Based on \\
\hline 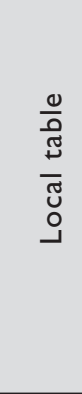 & $\begin{array}{l}\text { II. Local woman stuck in Eastern } \\
\text { Ukraine explaining how she } \\
\text { used to defend Kiev, until } \\
\text { they started being bombed, and the } \\
\text { Russians were the ones sending } \\
\text { humanitarian help } \\
\text { 12. Local woman who had to } \\
\text { flee Eastern Ukraine because } \\
\text { of the attacks, accusing those } \\
\text { who stayed behind of defending } \\
\text { Russia }\end{array}$ & Pro Russia & Experience \\
\hline $\begin{array}{l}\frac{0}{0} \\
\frac{\pi}{J} \\
\frac{\sigma}{\omega} \\
\frac{\omega}{\Delta} \\
\widetilde{x}\end{array}$ & $\begin{array}{l}\text { 13. Russian migrant in Western } \\
\text { Europe explaining how the } \\
\text { Russians are always seen as the } \\
\text { "bad guys," when other countries } \\
\text { do terrible things too } \\
\text { 14. Mayor of a small Russian town } \\
\text { near Ukraine arguing that they } \\
\text { always had a special relationship } \\
\text { with Ukraine, and that it is } \\
\text { because the US and EU meddled } \\
\text { that the problems started } \\
\text { 15. Russian member of parliament } \\
\text { explaining how Crimea was a gift } \\
\text { from the USSR to Ukraine after } \\
\text { WWII, made illegally } \\
\text { 16. Russian journalist explaining } \\
\text { that many protesters on the Maidan } \\
\text { square were neo-Nazis and that } \\
\text { some of them are now members of } \\
\text { the Ukrainian government }\end{array}$ & Pro Russia & Experience \\
\hline
\end{tabular}

the participants were Polish, and the population was then selected using historically structured sampling (Valsiner \& Sato, 2006). The aim was to find a population that would be concerned by the conflict, as identification with one side or the other changes how people react to new information (Leone \& Mastrovito, 2010), and yet distanced enough to make the use of an experimental method like the one required here ethically appropriate. In practice, because of language constraints I do not speak Polish - most of the participants were recruited through colleagues at the Academy of Special Education in Warsaw, and all had at least one university degree (five in the field of Special Education, the rest from a variety of domains, from engineering to translation).

The same principles of saturation were used for this study as for the previous one: Data was collected until the analysis of new interviews/experiments stopped 
adding new insights. However, the more ambitious goals required collecting more data, while the design imposed a different unit of analysis - the vignette - as well as stronger analytical constraints: Because of the amount of data collected per participant, it was necessary to keep their number relatively small, simply because I would not have been able to process more in the context of this study. Eleven interviews/ experiments lasting an average of 75 minutes were thereby conducted, for a total of 37 events discussed in the first part and 47 vignettes picked in the second part.

\section{Analysis}

Three series for codes were applied to the data, coding for: 1) the resources used by the participants to react to the vignette, including the sources of information used (TV, friends, books, school) and the type of information mobilised (witness accounts, historical concepts, values, formal historical chronologies); 2) the processes used by the participants when they mobilised these resources to reason about history (e.g., categorisation, narrative construction, perspective taking); 3) the "reactions" to the vignettes: What part of the vignette the participant reacted to, what tension it provoked, and the overall agreement or disagreement of the participant with the vignette. The categories were open-ended and were informed by both the data and the theory. A subsequent analysis compared 1) all the responses of different participants to a specific vignette or a specific category of vignette; and 2) all the responses of a specific participant to different vignettes. In the following, I first present an overview of the data collected. I then introduce the resources used by the participants. In the third and last part of this section, I detail the processes the participants displayed and discuss the most striking ones in more depth.

\section{Thinking about the collective past}

\section{Summary of the data}

All of the 11 participants in this study adopted a rather pro-Kiev and anti-Russia perspective. Although some of them were quite cautious in their judgements - saying for instance they did not want to pick a side, yet clearly choosing one in their evaluation of the vignettes - a few others explicitly presented themselves as anti-Russia, and especially against Putin. The sentiments towards Ukraine were much more ambivalent, with participants presenting it at times as a victim of the conflict to be supported, and at others as a country that had treated Poland badly in the past.

Three of the participants repeatedly declared that they did not know enough about the situation in Ukraine to position themselves towards it. While the others all expressed a certain confidence about their evaluations of the situation, though, only two of them could be considered well informed about the conflict. This proved a bit problematic, as all the facts included in the vignettes were accurate, meaning that these two participants simply agreed with all the information provided and could not be observed evaluating truly new and potentially false information. 
The participants all shared a quite similar narrative of the situation: Russia attacked Ukraine because it was attempting to leave Putin's sphere of influence. Well-informed participants, however, tended to show more nuances in their understanding of the situation, and to defend their perspective with information that was generally considered at the time to be accurate by external observers. The others, in contrast, relied more on general judgements about the conflict - for instance declaring that all that Putin had ever wanted was power - and on historical analogies: To understand Russia's intentions, you just had to look at what it had done to countries like Poland in the past.

In terms of reactions to the vignettes, participants quasi-systematically agreed or were neutral towards statements defending Kiev (19 out of 20 times, 9 agreement and 10 neutral) - with one exception where the participant disagreed because the vignette stated that a minority of people in Eastern Ukraine was pro-Russia, and they could not believe anyone in Ukraine would do such a thing. Conversely, they generally disagreed or were neutral towards vignettes defending Russia's perspective (14 out of 15 times, 9 disagreement and 5 neutral) - with again one exception, where one well-informed participant agreed with a fact supporting Russia. Interestingly, participants disagreed more with statements based on facts when they opposed their perspective (6 times out of 9), than with those based on subjective experiences (3 times out of 6). Finally, neutral statements were reacted to differently depending on whether they were grounded in facts or in experiences: Facts implying that both parties were at fault were disagreed with in the majority of cases (4 times out of 7), but subjective yet neutral perspectives were agreed with in every case ( 5 times out of 5 ).

\section{Resources}

In order to construct their representations of conflict, and to react to the statements in the vignettes, the participants mobilised a variety of resources. In this section, I present and discuss the main sources the participants used, as well as the type of information. In the next sections, I will detail the processes with which they used such information and constructed their representations of the collective past. These presentations do not aim to be either exhaustive - they represent what I observed in the data, but other participants in other situations could have very well used different resources and processes - nor exclusive - processes do employ resources coming from specific sources, and they cannot always be easily distinguished from each other. However, what these two sections aim to do is to give a picture of how, in a given context, people construct RCPs.

\section{Media}

TV and newspapers were the most frequently mentioned source of information. It was rarely done spontaneously but rather when I would ask participants where 
they heard of the information they were mentioning. Many participants expressed a certain scepticism towards "“the media," yet they kept using what they had learnt on TV or in newspapers. For instance, this is how participant 06 reacted to vignette 02 - explaining that Russian propaganda had encouraged people in Donetsk to join the separatists:

What I know from newspapers, from TV, but of course it doesn't have to be true, but I think the ${ }^{1}$ separatists are just Russians. [...] I think this is all Russia's fault, and I understand that people ... [don't] know who is who, and who attacked, and who is the real enemy. So in their minds it's a mess. But I ... It's so easy to pass judgements when you are outside of it and you are watching TV, which doesn't have to be objective. But still, I can say that my intuition is that it's all Russia's fault.

It seems here that although information from the media is seen as potentially misleading, if it "feels" right then it is more likely to be true. And indeed, participants frequently presented their impression that some information felt true or not as a cause for judgement. However, with the exception of the two well-informed participants, none of them mentioned the quality of their media sources as compared to others. This was particularly striking in their responses to the vignettes presented as interventions from journalists: The same scepticism was applied to journalists from obscure sources, from Russia Today, or from The Guardian, regardless of the actual reputation of the source.

Globally, thus, the participants expressed a certain suspicion towards media sources - independently of the actual quality of the source - and yet it remained their main source of information. This may be due to the type of information they gathered from the media: Factual information, on the one hand, and narratives, on the other. While factual information - about the presence of neo-Nazi groups on Maidan square, for instance, or the number of troops Putin was suspected to have sent to Eastern Ukraine - was taken with a large pinch of salt, narrative accounts seemed to "stick" much more. Indeed, narratives allow us to recount, connect, and give meaning to past events. As such, they are the "canonical" form of RCPs (e.g., Brockmeier, 2002), at least in the literature on collective memory, because they bring together events and their actors, building causal relations and attributing intentions, allowing us to make sense of the past. This is for instance how participant 04 reacted to vignette 06 , explaining that both sides of the conflict had caused civilian casualties:

I would say okay, but somebody started it! [laugh] And the Ukrainian people are just defending themselves. [...] Ukraine wanted to join the European Union and [...] the government and Russia didn't want to accept it. And on Maidan, people [...] wanted to defend, in peaceful terms, their point of view. But the Ukrainian government, supported by Russians, decided to intervene, and it started. 
The narrative account built here helps participant 04 tie together the different events of the conflict - Maidan, the Russian intervention, the reaction of the Ukrainian government - and to attribute intentions to the various actors, giving a meaning to the situation at hand. A meaning that can resonate with Polish history, given how important entering the EU was for most interviewees. And while participant 04 expressed, later in the interview, some doubt about what she had heard on TV and read in newspapers, she did confirm hearing there the narrative presented above.

\section{Commonly held knowledge}

The second source of information the participants used was "commonly" held knowledge, by which I mean facts and ideas presented as known to everyone and thus as sourceless. These concerned primarily historical information, and, on the basis of the first part of the interview - where the participants were asked to choose the three most important historical events and to specify the sources of their accounts - were not actually without sources, as can be expected. Indeed, most of the participants mentioned school and TV (for more recent events) as their main sources of information for the events they chose. Moreover, they used strikingly similar events (out of 36 events selected, 24 concerned joining the EU in 2004, the end of the Communist regime in 1989, World War II, the Pope John-Paul II, or 9/11), with nearly identical narratives. Similarly, the references to history made in the second part of the interview concerned similar events - mainly World War II - and similar narratives. This is for instance how two of the participants reacted to vignette 15, where a member of the Russian Parliament defended the annexation of Crimea by explaining that it used to belong to Russia:

If we think like that, Poland can take some parts of Ukraine, Latvia and some other parts because many years ago it was ours, so ... Maybe I'm thinking in a bit of a stereotyped way, but I really don't agree with the Russian way of thinking. [...] They are not respecting the real law, the international law.

(Participant 03)

First I would say if we look at what was given, [...] we should completely change the map of Europe, because also in Poland we have places like Wroclaw, which was Breslau. It was a German city for centuries, I think. And after the war it was given to Poland. [...] Other parts of Poland, for example Lwów and Vilnius were given to Russia at the time and then to Lithuania. [...] And we live with this, we don't fight.

(Participant 04)

What differentiates these sources from the previous ones - even though in some cases both come from events seen on TV - is the fact that they were presented, by the participants, as not only commonly shared but also as representing undeniable 
facts. Only one participant expressed doubt towards the narratives he had learnt in school and at university, in a way quite similar to what participant 06 did in the first excerpt of this section about what she heard on TV. All the others presented their understanding of history as indubitably accurate, probably because it was congruent with the majority of discourses they had heard about the collective past in the Polish public space. It thus seems that one important source of information, for TCP, is "commonly" held knowledge - that is, knowledge that has been shared undisputedly within a given sociocultural context long enough to pass as a basic truth.

In most cases, this "commonly" held knowledge took similar forms to that which the participants had gathered on TV - either facts or broad narratives. However, they did also offer another type of information: General concepts, ideas, norms, or values. This is, for instance, the type of information used by participant 03 above when referring to international laws, taken here as a set of norms and values that Russia's annexation of Crimea does not respect. This broad category of information will be discussed in more detail in the section on processes, focusing on how these are constructed and used.

\section{Witness accounts}

The last important source of information used by participants is made up of witness accounts of the events, which can be split into two categories. First, personal accounts of historical events by family members were frequently used as illustrations for the commonly held facts above, most often to highlight how the stereotypes they had about Russians and Ukrainians were based on (almost) personal experiences too. Second, some of the participants had met, most often while travelling, Ukrainians or Russians with first-hand experience of the conflict. This is for instance how participant 05 reacted to the vignette explaining that Crimea used to belong to Russia (vignette 15):

Recently I spoke to one guy from Russia and one from Belarus and I can see that their point of view is completely different than most people I know. [...] They were saying that it's not like the media shows, that ... It is not like the Russians are very aggressive, because Ukrainians are also very aggressive. And of course there are so many pro-Russia people [in Ukraine]. So it's also obvious, and it cannot be ignored, because when a huge part of the population really wants to be part of Russia, it shouldn't be shown in media like this. [...] However, once again talking about the gifts that the USSR gave to Ukraine, $[\ldots]$ it should be done differently because everywhere there were some kind of gifts and now we can't just cancel everything and divide based on history.

What is interesting in his reaction - and quite typical of what happened when participants used accounts from "local" witnesses or reacted to vignettes reporting 
such perspectives - is that he both gave value to the viewpoint voiced, partially agreeing with it, and yet ultimately it did not change his opinion on the situation. Generally, the participants gave personal accounts of the events by local (or quasilocal) witnesses a special value. Indeed, they were often considered as reflecting a certain truth about the situation, where facts could lie and were looked at with much suspicion. At the same time, local accounts did not have much weight in the participants' final opinions. It is particularly striking when looking at how they reacted to experience-based vignettes: When the text read defended a specific perspective on the conflict, the participants globally followed their original assessment (agreeing with pro-Kiev statements, disagreeing with the pro-Russia ones). But when the statements were neutral, they all agreed when they were perspective-based, while disagreeing with the ones based on fact. One possible reason for this is highlighted in the reaction of participant 03 to vignette 06 :

My personal point of view is that it is really difficult to know what Russia really wants to do, and what's in Putin's head. And ... I've met a Ukrainian. That's changed my point of view of this situation [...] because you know when I was in Warsaw, okay we heard stories from the media. And as you know, the media like they can show whatever they want, and not all the things that they are telling us are real. [...] But when you have relations with concrete people, then it changes a little bit. Like she was telling me about her cousins who are fighting there, about how they collect food to send to the people who are in the conflict, how their family needs to move from the place where the fight is to some other parts of Ukraine, because they have no chance to live, because there are bombs on and on. So it's a real war. [...] So of course it was only like three people from Ukraine that I've met. But it's ... I don't know, it's more ... touching, I don't know how ...

One the one hand, the media can decide how to present reality, and to leave much out of their account, while locals offer a much more real, concrete, and complete experience of the situation. On the other hand, hearing of people living through the situation is more touching than seeing anonymous images on TV, and it can become harder to dismiss their perspective. When the participants did reject their version of events, it was either based on how they "felt" about the situation or by assuming that the witnesses were confused or manipulated - as is illustrated in the first quote by participant 06 at the start of this section (page 117).

Three phenomena stand out in the analysis of the resources used in this experiment, and how they were considered by the participants. First, and rather unsurprisingly, the perceived trustworthiness of the information used depended on whether or not they agreed with the statements. However, the causes mentioned for these disagreements varied depending on the type of source: While officials and the media were seen as manipulative and deceptive, everyday people were considered "blind" to the reality of the situation. Second, the perception of the proximity of the source with the actual events led to a certain paradox: The closer 
people were to an event, the more trustworthy and informed they were seen to be, yet it also made them more likely to be accused of having been either manipulated or to have only a partial view of the events. Finally, it appears that the participants were globally quite ineffective in evaluating sources: Not only did they not discriminate between the widely varying quality of media sources mentioned in the vignettes, they also generally could not distinguish accurately between facts and opinions. Indeed, one of the most frequent reactions to the fact-based statements defending Russia or a neutral perspective was to declare that it was "just an opinion," a reaction that the experience-based vignettes rarely provoked.

\section{Processes}

Twelve processes were found in the data, presented in Table 6.2. For each process, a brief definition and an example are provided. The last column indicates the estimated relative frequency of each process: As the participants mobilised multiple processes to react to the statements and used each of them in a more or less prominent way to construct their answer, it is impossible to fully quantify them. The last column of the table thus reflects the number of times each process was predominantly used to react to a vignette (Low: 5 times or less; Average: From 6 to 10; High: More than 10 times). The processes are grouped into three categories, depending on the types of perspectives they tend to construct and manipulate: Subjective (oriented towards personal perspectives, values, emotions, and significations), objective (oriented towards factual information, patterned organisation, and formalisation), and transversal (bringing both "objective" and "subjective" elements together). These are not, however, fixed nor exclusive categories.

In what follows, I propose to discuss in more detail interrelated processes from two categories above: Analogies and generalisations on the one hand, and imagination, identification, and perspective taking on the other. The processes belonging to the last category have either been largely discussed in the literature already (narrative construction, see for instance Brockmeier, 2002; Wertsch, 2008) or in the previous sections (i.e., source monitoring).

\section{Analogies and generalisations}

Two of the processes the participants used the most were analogies and generalisations. An analogy compares a source with a usually less-known target in order to infer information about the latter (Holyoak, 2005). In the case of RCPs, it meant that the participants compared an event they wanted either to evaluate or they knew little about, with a well-known source, usually taken from Polish history. As for generalisations, they refer to the deduction of common properties between different instances. In the study, it meant that the participants compared different stories about the past to extract generalities either about specific countries or human behaviour at large. Both processes, then, were used to make links between different periods and to evaluate the present situation. As such, they often 


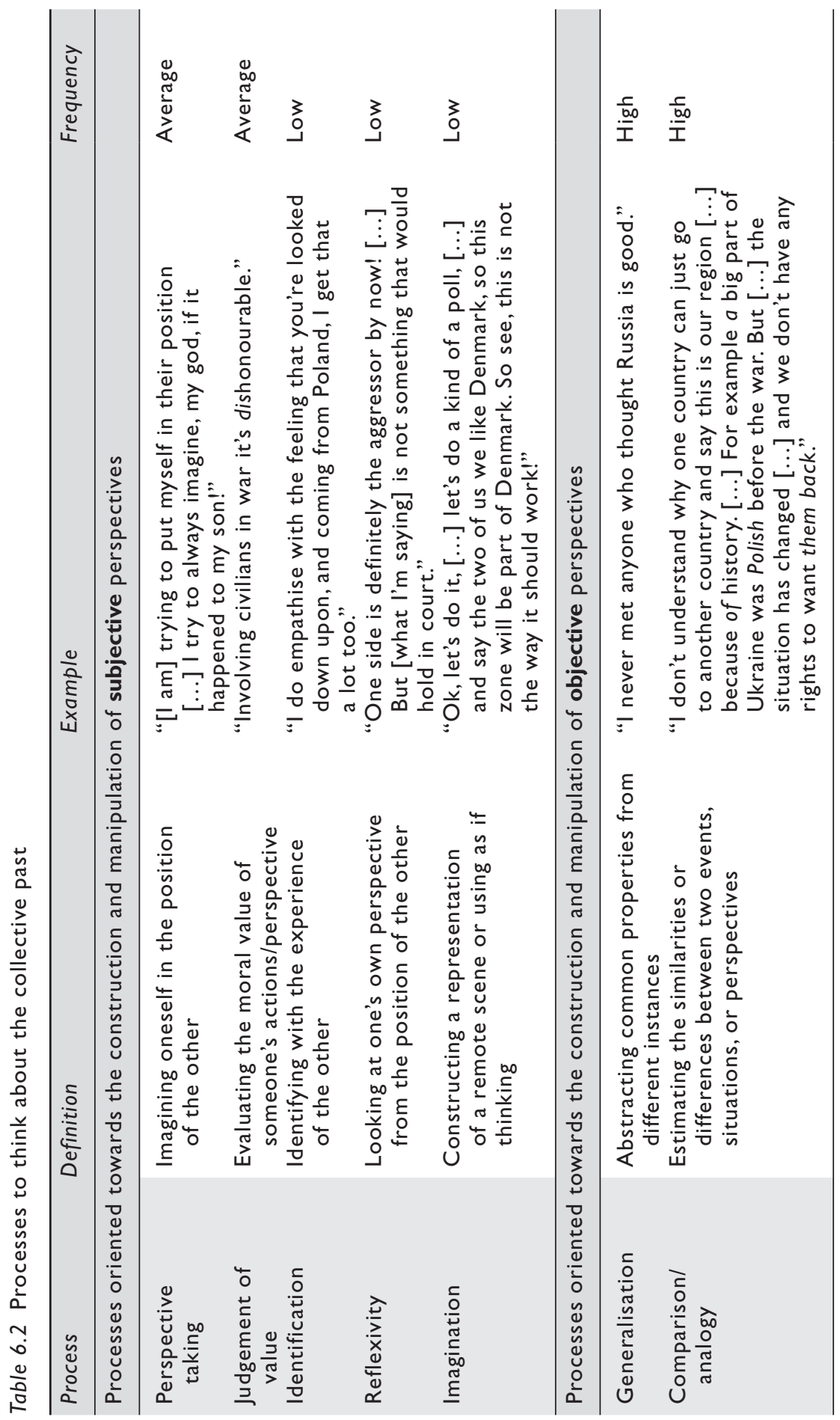




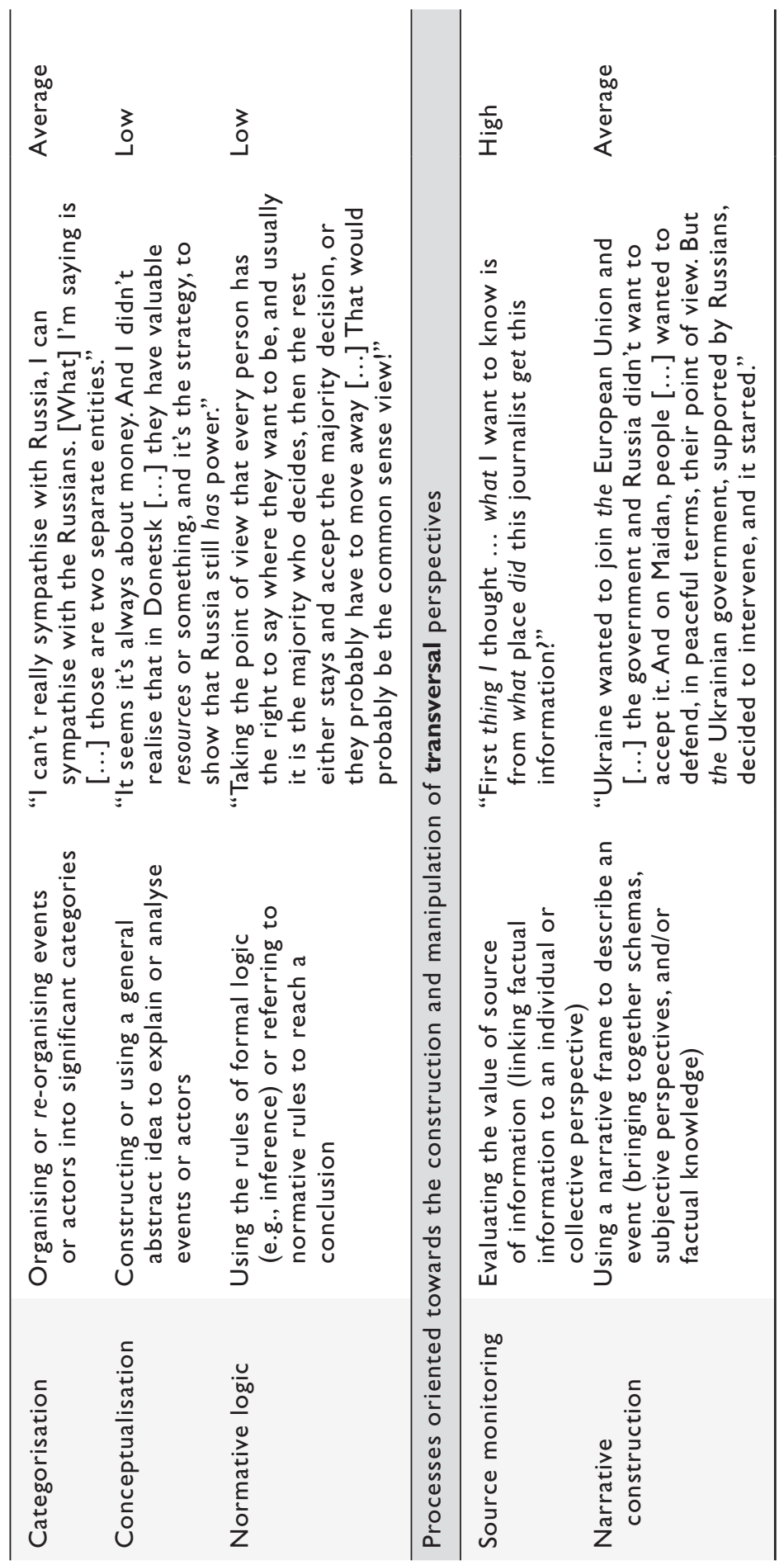


showed a tendency towards generalisation and an attempt at objectivity. On a few occasions, they were also used together, as in the following example. The excerpt below is the longer transcript of how participant 04 reacted to vignette 15 , about Crimea:

If we were to look at what was given, according to our modern vision of the law and what is illegal, we should completely change the map of Europe, because also in Poland we have such places like for example Wroclaw, which used to be Breslau. It was a German city for centuries, I think. And after the war it was given to Poland. Also the Germans may think now it was illegal, and they lost their houses. They lost everything, they had, for example, ten hours to leave, rush up and go. And people from other parts of Poland, for example Lwów and Vilnius were given to Russia at that time then to Lithuania. And they were Polish before, we lost these lands [...] We should give back Wroclaw again to Germany and take Lwów and Vilnius? And there are many places like this on our map, because it was kind of an artificial decision, one moment. And we live with this, we don't fight and the Germans don't come to kill us. [...] We all in Europe live with, especially this part of Europe, Eastern Europe, central Europe, we live with uncomfortable divisions of our map. And also, former Yugoslavia, it's the same. Somebody had to decide it's the border here or here or here, and we live with this because we appreciate the peace and the collaboration. And I know Crimea is $a$ beautiful part of Ukraine, Russia [...] but I don't see a reason to fight for it. I would like to think the borders are final and we don't fight about it anymore.

In this excerpt, participant 04 makes an analogy between Crimea and the complicated history of Poland's borders, as many other participants did. To build her analogy, she uses a very basic narrative frame to draw parallels between different events: Part(s) of a country is (are) given to another one because someone decided to change the border. This allows her to compare a chapter of the Polish history she knows well with the current situation in Crimea. Building the narrative about the history of Poland, she then refers to the subjective perspectives of those who had to leave to highlight that it was difficult for the local population, but yet that none of the countries involved now think it is illegal or comes to attack the other. From this, she constructs a generalisation: It is actually the whole of Central and Eastern Europe that lives with difficult borders. And yet, none of them complain, because they prefer peace and collaboration. This leads her to conclude that Russia has no reason or justification to claim Crimea.

Analogies and generalisations, thus, may participate in the creation of new RCPs - for instance here the representation that history left more than half of Europe with an "uncomfortable map" - in this case to solve the tension between historical and current ownership of the land. This can, in turn, be crystallised in a resource for future TCP. In the example above, when participant 04 generalises about borders in Europe, she then proposes another example (former Yugoslavia), 
using the generalisation she has just produced. Finally, and although both analogies and generalisations also make use of subjective perspectives on the situation, these processes are oriented towards the production of an "objective perspective." While its objectivity can be debated, the term reflects here the attempt to transcend one's own subjective perspective and to reach an undisputable conclusion, conversely to the next example.

\section{Imagination, identification, and perspective taking}

Imagination, identification, and perspective taking were relatively less frequent in the data than analogies and generalisation. However, they were common in the first part of the interview (where participants had to describe historical events that were important to them) and still played an important role in the second part, where participants used them principally to engage with the perspective of the author of the vignette. All three terms have been the object of extensive research, although rarely in connection to collective memory, but this is beyond the scope of this paper (see de Saint Laurent, 2018b for a discussion of imagination and collective memory; see de Saint Laurent \& Glăveanu, 2018 and Glăveanu \& de Saint Laurent, 2018 for a discussion of identification and perspective taking). For the purpose of this chapter, we can define imagination as the process of engaging with alternative or future possibilities (as if and future thinking), which include imagining oneself in scenes or events of the past (imagining what it would have been like to be there). As for identification and perspective taking, the former can be defined as the process of finding similarities between oneself and others, and the latter as imagining being in the place of the other; that is, attempting to see the world from their perspective. All three processes are thus intersubjective - they emerge at the interaction between the perspectives of different subjects (Gillespie \& Cornish, 2010) - and are deeply interrelated. Perspective taking, for instance, can encourage identification by making one realise that self and other would behave similarly in the same situation. Similarly, identification and imagination can support perspective taking, as in the excerpt below. In this segment, participant 11 is reacting to a vignette where a woman in Eastern Ukraine explains that the Ukrainians have been bombing them and killing their children, while the Russians brought humanitarian help (vignette 11). The author of the vignette then explains that she now supports the Russians, a position none of the participants agreed with, although many expressed it only indirectly, as was the case with participant 11. Here is how she reacted:

There are two voices in me. One is trying to put myself in their position, also as a mother now. I would say, obviously thinking of survival, [...] I haven't been in that ... fortunately, but I try to always imagine, my God, if it happened to my son, for example. I'd try to survive, so I would lean towards somebody who is actually, you know, showing me a helping hand. So I could in a way understand why they choose Russia. But then, knowing my history 
side, and what we have gone through and learning from, you know, from books mostly, all from people stories about the past [...] not always who is smiling and helping you could see now is going to the one who going to stay supportive in the future. [...]. But then you're left alone, and if you have no help, no support, no bandages, no food for your children, what do you do? So the history shows, you know, survival is the first instinct and in the pyramid, the Maslow's pyramid, you know, the physiological needs are the first ones you have to have to actually continue living and go to the top of the pyramid. So I guess in this way, you think that the Russians are the guys because they help to survive. Whereas pro-Kiev people didn't. So in a way, I would try not to judge.

In this excerpt, participant 11 starts by voicing a tension - as other participants did on a few occasions. Although she does not express it directly, it seems to be between the perspective of the woman in the vignette and the impossibility, for her, of seeing Russia as helping (an issue shared by almost all the participants and seemingly having its roots, as is shown in the excerpt above, in their representations of Polish history). To solve this tension, she first tries to take the perspective of the woman in the vignette, through both identification ("as a mother now") and imagination ("if it happened to my son"). The representation of the situation she hereby constructs matches the one of the Ukrainian woman, so that she "could in a way understand." However, this clashes with both what she read in books about history (taken as factual knowledge) and the general idea that "not always who is smiling and helping ... stay[s] supportive in the future." This seems to be, indirectly, a reference to Russia's behaviour towards Poland at the end of World War II: While the Polish communist narrative presented the USSR as the saviour of Poland at the end of the war, post-communist narratives have insisted on events like the Warsaw Uprising, in 1944, that was crushed by the Germans while the Russian army decided not to intervene. Although participant 11 insists, throughout the interview, on remaining neutral about Russia, she did choose, in the first part of the interview, the Warsaw Uprising as one of the most important historical events for her. This generalisation can thus also be read, perhaps, as an attempt to avoid looking biased or judgemental. This statement, however, leaves participant 11 still torn between the two positions ("but then you're left alone"), and it is the introduction of a new concept that solves the tension by placing survival as the highest value. Thus, although she clearly does not agree with the woman in the vignette, she can understand her behaviour and, to a certain extent, accept that it does not fit with her general understanding of the situation.

This example and the previous one shows the importance of both "objective" and "subjective" aspects in TCP. That is, they illustrate how TCP relies both on processes more typically associated with the classic idea of thinking (e.g., generalisations) and intersubjective processes for which collective memory is often accused of being biased (e.g., identification). However, both in the examples above and in the rest of the data, there was no direct link between the use of 
"objective" perspectives and more complex or open thinking - quite the contrary: Participants using imagination, perspective taking, and identification tended to be more reflexive and more open to the position of the other, even when they did not agree with the authors of the vignettes. Finally, these examples also illustrate how different processes can bring together multiple aspects of RCPs in order to produce and evaluate both "subjective" and "objective" perspectives. What I propose in the next section is to construct a model of RCPs that allow us to account for the resources and processes on which it relies, and thus, ultimately, of how new RCPs may emerge.

\section{Emergence in representations of the collective past}

The analysis of the resources and processes used by the participants to think about the collective past has highlighted two important aspects of TCP. First, it is an open-ended activity, and no list of processes and resources could ever be exhaustive. Second, it is the subject of multiple tensions, between objective and subjective accounts of the past on the one hand, and between local information (e.g., witness accounts) and general understandings (e.g., shared narratives seen on TV). What I propose to do now is to build a model of RCPs that can account for these tensions and for how TCP can lead to the emergence of novel representations. For this purpose, I have regrouped the multiple elements and aspects of RCPs into four categories: Meaning, sense, factual knowledge, and schemas. After presenting each category in turn, as well as the role it played in TCP in the data collected, I will conclude this chapter by presenting the general model articulating all four.

\section{Four elements}

\section{Meaning}

The first element of RCPs that appeared through the analysis is meaning. As explained in Chapter 3, meaning refers to the signification given to an object and that is assumed to be shared with others (Zittoun, 2017). However, as dialogical approaches to thinking have shown, people are exposed to a multitude of meanings held by different social groups. In the experiment, participants referred, for instance, to the main meanings given to the role of Russia in the Ukrainian conflict (as interfering versus helping), supposed that I was aware of them, and yet did not necessarily agree with them. Meaning, then, can be taken more globally as referring to the general signification and value given to a situation and that is assumed to be shared by a group of people.

And indeed, most of the vignettes in the experiment were read by the participants as defending a certain meaning with which they agreed or not, which changed how they reacted to the statements. They often voiced the different sides 
of the debate and reacted to them, even when the vignette they had just read was neutral. This is for instance what participant 04 did when she reacted to the statement saying that both sides had committed crimes by explaining how Russia had started the conflict to prevent Ukraine from entering the EU (page 117). She did not dispute the facts presented in the vignette (she "would say okay") but the implied meaning was that both sides were guilty, which was a source of tension for her. She then argued her case using a very broad narrative, not including factual information but focusing on the intentions and the meaning of the conflict for the different actors involved.

Meanings were used in three main ways to make sense of the conflict in Ukraine and build a representation of it. First, general meanings were used to frame the situation and to make sense of the discourse of others. For instance, vignette 02 was hard to understand for some participants, who seemed to have missed the general argument of the statement. The vignette was about how separatists in Eastern Ukraine had started to broadcast Russian propaganda to change people's minds. Participant 10, for instance, has a partner who is a journalist working in Eastern Ukraine and who struggled to access some information about the separatists. After reading the vignette, she said: "I think it's a question about free journalism, and what happened to Nemtsov when he was killed." She then went on to explain that it was very difficult for journalists to know what is going on in Eastern Ukraine, "to be informed in an objective way." After deploring this lack of clear information, saying that it's "very difficult" and "very confusing," she argued that higher forces (like Russia) were controlling the situation anyway, a conclusion she had arrived at already by the end of the previous vignette. Thus, by linking the vignette to the question of free journalism, she used a general meaning shared by journalists to make sense of the discourse of the other. Then, she solved the tension provoked by the lack of objective information by reframing the situation: Obtaining proper information from Eastern Ukraine would be useless anyway, as the situation is controlled by higher forces elsewhere. This is the second use participants made of meanings in historical reasoning: They used them to reframe the situation, disabling the tension.

Third, meanings were used as a "higher" value to solve tensions between perspectives. This is for instance what participant 11 did in the excerpt on pages 125-126, where she sympathised with a Ukrainian stuck in the conflict and siding with the Russians. In her reaction, she clearly voiced the tension she felt ("there are two voices in me") - a regular occurrence in the data - and attempted to solve it. To do so, she used a meaning she considers of a higher value: The first thing on the Maslow pyramid is survival, and it is thus what is of utmost importance. Her conclusion, then, is that she should not judge the choices of the woman in the vignette.

Two main conclusions on meaning can be drawn. First, meanings do not just act as reflections of the subjective perspectives of the participants, but they allow them to locate themselves and their interlocutors in the social field, and to understand what the other is saying by anchoring it to a known social discourse. Linking 
the vignettes and their own discourses to general perspectives on the conflict not only facilitated comprehension, but also made communication with me, a foreign researcher, possible. Second, as had been long noted by Bartlett (1932), meanings tend to "stick" to memory more than facts. Participants lacking factual knowledge thus used them to argue for their case, referring to what "people say" when asked to justify their position. Because meanings crystallise and condense the perspectives of generalised others, often in the form of broadly painted stories (as participant 04 used), they are easily understood both by speakers and audiences and they are thus versatile tools to reason about history.

\section{Sense}

The second element of RCPs that emerged from the analysis is sense. Sense generally refers to the personal signification taken by an object, shaped by people's unique trajectories (Zittoun, 2017). However, as is the case for meanings, our lives are not populated solely by the sense we give to objects, but also by those of others - in a dialogical fashion. And indeed, the experience-based perspectives proposed in the experiment - introducing the participants to new senses of the situation - were often sources of tension for the participants, who did not dismiss them as easily as they did fact-based ones. What often characterised the participants' reactions was empathy and identification, even when they did not necessarily agree with the general meaning the vignette was supporting, as participant 11 did on pages $125-126$.

Personal sense was used in three main ways for TCP. First, they used it as an orienting tool, as it gave an emotional value to the situation that participants tended to particularly trust. Second, it acted as a frame for the situation, as meanings did, especially for participants who seemed to either lack factual knowledge or who struggled to understand the vignettes. For instance, participant 07 was a coach and personal trainer who believed that states cannot protect their populations, and that one should learn to defend oneself. In the experiment, he defended the idea that a proactive attitude was the only way to "win in life;" mixing selfhelp and survivalism in a unique way, as he explained in the first part of the interview, is at the centre of how he lives his life. And it is this personal sense that he used to respond to each of the vignettes he read. For example, when reacting to vignette 01 , on Russia invading Ukraine, he concluded that it showed that the world is not civilised anymore, implicitly arguing that he was right to believe that states cannot protect their citizens. Later, when he read a vignette about a woman who fled the conflict in Eastern Ukraine and who is accusing those who stayed of supporting Russia (vignette 12), he replied by saying that she should think for herself, and that none of the people who won in life were conformists. The third use participants made of sense was to take the perspectives of others. That is, they used the subjective and personal elements of the vignettes to try to put themselves in the position of the other and to evaluate the situation from this perspective. In some cases, they also identified with the other (e.g., "trying to put myself in their 
position, also as a mother now"), although this was not always done when participants used perspective taking.

Globally, people's subjective perspective, either those of the participants or those of others, played a major role in how the participants thought about the Ukrainian conflict. These were given a unique value, insofar as they did not incarnate too directly the interest of a social or national group - Putin's perspectives, for instance, were strongly rejected, as were those of Russian journalists and politicians. These often existed in tension with general meanings held by the different actors. In addition, the analysis of the uses of personal sense highlights the strong tension, in RCP and TCP, between the collective and the individual, the general, and the particular. On the one hand, and although the senses given to the situation are seen as partial and limited, they are given a specific value because they represent the individual perspectives of "normal" people, with whom the participants can identify. On the other hand, general meanings have a validity given by their consensual nature and the fact that they reflect a more distant perspective on the situation; however, they are often considered to be defending the specific interests of social groups and people in power. Sense and meaning, thus, operate in a dialogical tension that prompts TCP and participates in the construction of new RCPs.

\section{Factual knowledge}

The third element of RCPs that emerged was factual knowledge. By factual knowledge, I mean objective factual information that exists independently of its interpretation. Of course, knowledge is a discursive construction (Potter, 1996), and what may count as a fact is often open to discussion. But from both an epistemic and an epistemological perspective, certain things, albeit resting on socially constructed conventions, can be considered objectively true, such as the height of Mount Everest (Searle, 1995), or in our case, the date of the World War II armistice. Its signification can be discussed, either in the form of its meaning or its sense, but its truthfulness has been or can be established.

Factual knowledge was employed in three main ways in the experiment. First, participants used the knowledge they had of the situation to evaluate what they were reading in the vignettes. For instance, one of the statements referred to the roles of neo-Nazi supporters in the Maidan movement in Kiev (vignette 16). The two participants who had not heard about this before both doubted the quality of the source, a Russian journalist. The two other participants who picked this vignette had, on the contrary, heard about this before and had checked the information. They both used this as a resource to react to the vignette, agreeing with its content and discussing its consequences. Second, participants used factual knowledge to argue for their perspective on the situation. For instance, participant 03 discussed a vignette on the plane crash in Ukraine, that said that there was proof that Russia had delivered weapons like the ones involved in the crash to the separatists (vignette 8). She agreed with the vignette and argued that it was 
probably right because she knew from a friend in Eastern Ukraine that Russia was using propaganda to hide information. Third, participants used factual knowledge to evaluate how likely another piece of information was to be true. For example, participant 03 read a vignette on a Crimean Tatar activist, complaining about how both the Ukrainians and the Russians mistreat them and do not respect their human rights (vignette 10). Participant 03 works in inclusive education and has intercultural experience in the field. Although she did not agree that both sides are equally bad, she made the parallel with how Russia and Ukraine treat children with special needs, and she said:

I saw that it's more medical, they are still focusing on what's wrong from the medical point of view, it's not the environment, it's the people. [...] It doesn't matter if they [the children] don't have the same rights. [... So in relation to human rights, from the perspective of people with disabilities and special needs kids in education, I think I can see the difference [with Western countries].

She then concludes that it is very possible that both Russia and Ukraine did not respect human rights in Crimea.

In conclusion, it seems that although people remember meanings and senses more easily than factual knowledge, the latter has a special status. Once its trustworthiness has been established, it provides unambiguous content on which to base historical reasoning and to evaluate the information provided by others. While meaning and sense seem to primarily orient reasoning, factual knowledge gives it content and grounds it in facts that are supposed, for the participants, to be undisputable. However, as seen when discussing the resources employed by the participants to think about the conflict, establishing that a piece of information was indeed a trustworthy fact often proved problematic.

\section{Schemas}

The last element of RCPs found was schemas, a notion proposed by Bartlett (1932) and discussed in Chapter 3. As a reminder, schemas are patterned organisation of information or experiences that allow us to react in an adapted manner in new situations. The participants used a wide range of schemas, including generalisations (e.g., when participant 07 concludes that the Ukrainians need to think for themselves because winners are never conformists), comparisons and analogies (e.g., participant 03 compares the East/West differences in inclusive education to come to a conclusion about the human rights situation of the Tatars), narrative constructions (e.g., participant 04 uses a basic narrative template about aggression to describe the situation in Ukraine), categorisation, and concepts. These were also often used in combination. For instance, participant 09 read a vignette where the mayor of a small Russian town near Ukraine is accusing the US and the EU of encouraging hate against the Russians, to the point that the Ukrainians started 
to build a wall at the border, when Ukraine and Russia used to be "sister nations" (vignette 14). And she says:

Unfortunately, I don't agree with this man! [...] He says that the United States, Europe, they are trying to build a wall between Ukraine and Russia [...] I do not agree with this because first of all, [...] Europe and the United States they try to help people in Ukraine, with military help, and humanitarian help. [...] And second [...] who was the first to build this wall? It's Ukraine or Russia? I think that this is Russia, because they come and [...] they punish them for this [...], because of the Ukrainian situation about the European Union.

In a previous answer, she had explained that Russia is invading Ukraine because the Ukrainians wanted to join the EU, and that international community was not doing anything, when it should have been helping Ukraine. There is thus a change of narrative here, and it looks like she borrowed the narrative schema she read in the vignette to build a comparison by reversing all the roles. This is especially visible at the end, where she arrives at the contradictory conclusion that the Russians are both invading Ukraine ("they come") and building a wall at the border with Ukraine as punishment for attempting to enter the EU, although it would actually play against this invasion. She thus follows these schemas to the end, using two different resources, one proposed by the "interlocutor" (the speaker in the vignette) and one she constructs in her reply.

Schemas are thus versatile, flexible tools that people mobilise to organise the information available to them when they engage in TCP. They can be more or less concrete - from specific and specialised concepts to vague narrative frames and can be used in combination. As with the previous categories, and in spite of how they have often been considered in psychology (Wagoner, 2013), they are not a static structure but an active process. They are also particularly powerful resources for TCP because they crystallise past TCP - through their "patterns," as Bartlett proposed in his definition of schemas - either from oneself or from others. Indeed, historical concepts, narrations, common analogies, etc., are the product of TCP and can be shared with others who may in turn use them. As such, schemas act in RCP as cultural, social, and cognitive resources that allow people to produce and share historical knowledge.

\section{A model of how we construct representations of the collective past}

A conceptual model of how we think about the collective past and how new representations of it may emerge can now be proposed, based on the findings presented above, and shown in Figure 6.1. To start, a brief summary of the multiple functions of each element within the analysis is necessary.

First, meanings, the general signification given to the situation by different groups, play a central role to position actors, speakers, and audiences within the 


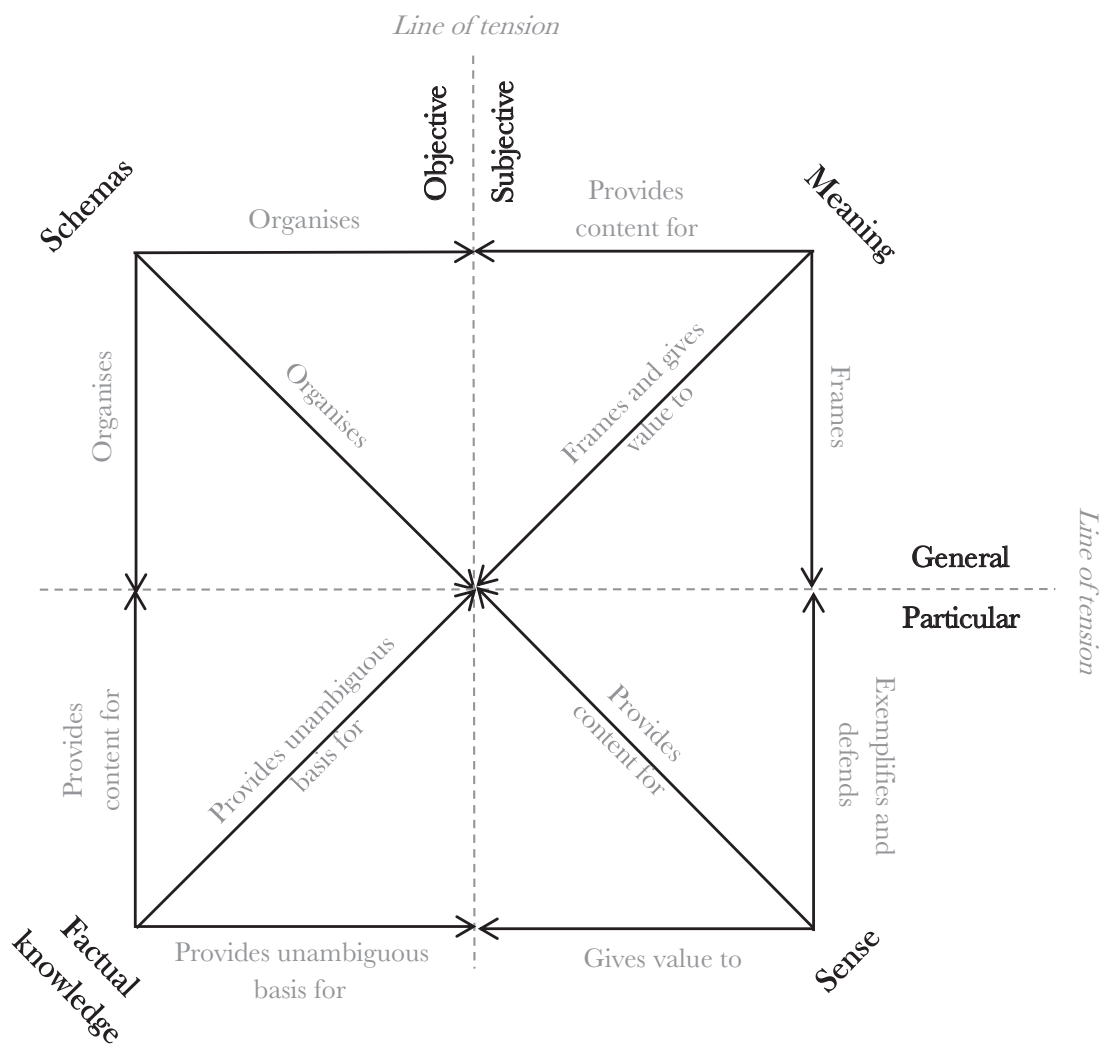

Figure 6.I Model of how we construct representations of the collective past.

social field, and provide a frame and give value to the situation. They allow people to socially locate discourses and to communicate with others. Second, senses, as personal perspectives on history, help participants orient their responses to the discourses of others - through personal values, emotions, and empathy - and to help them take in the perspectives of others. This is in part because they are associated with "real" and "normal" people, instead of social groups and those who represent them and their interests. Meanings and senses, thus, represent "subjective" perspectives on the situation - in singular (sense) or in plural (meaning) - which people construct and interact with in order to think about the collective past.

Third, factual knowledge provides both content and an unambiguous basis for RCPs. Indeed, although what "counts" as a fact is constructed in discourse and through social practices, it does not mean that facts do not exist, either from an epistemological or an epistemic standpoint. What this study showed is that people are aware of the perspectival nature of social reality but use what they consider to be undisputed facts as a resource to defend subjective perspectives on 
the situation. Fourth, schemas play a central role in organising information, using semi-abstract patterns, such as narrative frames, and bringing together the different elements of RCP. As such, they are both the basis and outcome of TCP. That is, they both allow for it to happen, by providing flexible frames to organise and produce knowledge, and can be the result of TCP, where patterns are extracted from RCPs. Moreover, schemas can be communicated with others, for instance in the shape of historical concepts or categories.

Factual knowledge and schemas represent, in opposition to meanings and senses, the "objective" side of RCPs. Namely, they are an attempt to capture the situation from a "bird's-eye view." This is not to say that schemas and facts exist independently from the perspective from which they are constructed or used, but that they are mobilised in an attempt to transcend such subjectivity. RCPs exists in the tension between these "objective" and "subjective" perspectives on the past. A second tension can be found between "general" and "particular" resources. One the one hand, meanings and schemas provide general perspectives on the situation by crystallising past experiences, regrouping multiple perspectives, and organising information. On the other hand, senses and factual knowledge offer particular information about the situation and personal perspectives on it. They provide the specific content of an RCP but are also justifications and illustrations for general perspectives. This second tension is also fundamental for TCP, as both the "general" and the "particular" participate in the construction of RCPs.

Presenting these elements in isolation is of course a theoretical artifice: Using an analogy, for instance, does not mean using only a schema but also building parallels between facts or perspectives. Narratives are probably the best illustrations of how these elements represent dimensions of RCPs and not entities, as a story can easily refer to all four of them at the same time.

\section{Conclusion}

In this chapter, I have proposed a dialogical experiment as a study to explore how people think, in a concrete situation, about the collective past. I have looked at the main sources the participants used - information from TV and newspapers; "commonly" held knowledge, most often learnt in school; and witness accounts - as well as the multitude of processes they employed when engaged in TCP. This has led me to argue that our representations of the collective past are constructed with elements belonging to four main categories: 1) The shared meanings given to the events, often associated with specific social groups; 2) the local sense that specific actors make of the situation; 3) the factual knowledge upon which one can build an account of what happened; and 4) the schemas used to organise information in more general patterns and link it to other events. Finally, I have argued that the elements are organised around two tensions.

First, between objective and subjective representations of what happened. Most of the research on collective memory has shown how glorifying and subjective accounts of the past tend to be the norm. Yet, this shows that people do try to 
build more objective representations of what happened, but they often lack the resources required to do so. In particular, they primarily rely on information heard at home or in school - which would mostly remain a broadly painted narrative, even if it had been of good quality in the first place - or that they have seen on TV. The need to teach children how to use and evaluate sources of information that has been highlighted in research on historical thinking is indeed urgent. The challenge, nonetheless, is also to teach them where to look for such information in the future. Finally, this tension between a desire to be objective and to account for the subjective perspective of actors sheds a new light on the distinction between "natural" and "reasoned" forms of thinking (e.g., Evans, 1989; Kahneman, 2013): They may not be concurrent ways of thinking in different situations or simply the product of different levels of cognitive efforts, but they may instead represent two ways of understanding the world that we often try to bridge.

The second tension, between the general and the particular, reflects our attempts at learning lessons from the past, while making sense of its local specificities. It is often assumed that collective memory constitutes a more general understanding of the past - for instance, by using a single narrative frame for most national events (e.g., Liu \& Hilton, 2005; Wertsch, 2008) - yet many of the participants in the experiment showed a particular interest for very local accounts. This aspect of RCPs deserves further exploration in future research. On the one hand, being able to use the past to make sense of the world necessarily implies using some forms of generalisations. On the other hand, it is precisely these generalisations that can lead people to simply see, in current and past events, exactly what they want to see, and to read them as simply another illustration of what they believe. This is also where the work of historians and collective memory profoundly differ, and why experts cannot be used as a model against which to measure lay people. The aim of history is to methodically study the past, but we use our RCPs, in everyday life, to understand the societies we live in, to imagine where we may be going, and to decide what is the best course of action in the present. These different aims necessarily require different processes and resources.

Ultimately, the tensions that are at the heart of how we represent the collective past can never be resolved, even with the best history education imaginable. But it is why RCPs are never fixed, nor static, and why the debates on the meaning and role of the past will always remain open.

\section{Note}

1 Italics indicate that the quote was edited for English (with no alteration of meaning and only where it seemed necessary to facilitate understanding).

\section{References}

Bartlett, F. C. (1932). Remembering. A study in experimental and social psychology. Cambridge University Press. 
Barton, K. C. (1997). "I just kinda know." Elementary students' ideas about historical evidence. Theory \& Research in Social Education, 25(4), 407-430. https://doi.org/10.1080/ 00933104.1997.10505821

Breux, S., Arcidiacono, F., \& Perret-Clermont, A.-N. (2014). Reprendre la parole de l'autre dans une situation d'entretien piagétien. TRANEL, 60, 109-120.

Brinkmann, S. (2016). Methodological breaching experiments. Steps toward theorizing the qualitative interview. Culture \& Psychology, 22(4), 520-533. https://doi.org/10.1177/ $1354067 X 16650816$

Brockmeier, J. (2002). Remembering and forgetting. Narrative as cultural memory. Culture \& Psychology, 8(1), 15-43. https://doi.org/10.1177/1354067X0281002

de Saint Laurent, C. (2018b). Thinking through time. From collective memory to collective imagination. In C. de Saint Laurent, S. Obradović \& K. Carriere (Eds.), Imagining collective futures. Perspectives from social, cultural and political psychology. Palgrave Macmillan.

de Saint Laurent, C., \& Glăveanu, V. P. (2018). Cultural psychology and politics. Otherness, democracy and the refugee crisis. In B. Wagoner, I. Brescó de Luna \& V. P. Glăveanu (Eds.), The road to actualized democracy (pp. 181-197). Information Age Publishing.

Evans, J. (1989). Bias in human reasoning. Causes and consequences. Erlbaum.

Gillespie, A., \& Cornish, F. (2010). Intersubjectivity. Towards a dialogical analysis. Journal for the Theory of Social Behaviour, 40, 19-46. https://doi.org/10.1111/ j.1468-5914.2009.00419.x

Glăveanu, V. P., \& de Saint Laurent, C. (2018). Taking the perspective of others. A conceptual model and its application to the refugee crisis. Peace and Conflict: Journal of Peace Psychology, 24(4), 416-423.

Hartmann, U., \& Hasselhorn, M. (2008). Historical perspective taking. A standardized measure for an aspect of students' historical thinking. Learning and Individual Differences, 18(2), 264-270. https://doi.org/10.1016/j.lindif.2007.10.002

Holyoak, K. J. (2005). Analogy. In K. J. Holyoak \& R. G. Morrison (Eds.), The Cambridge handbook of thinking and reasoning (pp. 117-142). Cambridge University Press.

Kahneman, D. (2013). Thinking, fast and slow (1st ed.). Farrar, Straus and Giroux.

Leone, G., \& Mastrovito, T. (2010). Learning about our shameful past. A socio-psychological analysis of present-day historical narratives of Italian colonial wars. International Journal of Conflict and Violence (IJCV), 4(1), 11-27. https://doi.org/10.4119/UNIBI/ijcv.57

Liu, J. H., \& Hilton, D. (2005). How the past weighs on the present. Social representations of history and their role in identity politics. British Journal of Social Psychology, 44, 537-556. https://doi.org/10.1348/014466605X27162

Mehmeti, T., \& Perret-Clermont, A.-N. (2016). Seeking success of migrant students through designed tasks. A case study with Albanian students in Switzerland. In A. Surian (Ed.), Open Spaces for Interactions and Learning Diversities. (pp. 137-150). Sense Publishers.

Moscovici, S., \& Perez, J. (2003). La méthode expérimentale. In S. Moscovici \& F. Buschini (Eds.), Les méthodes des sciences humaines (pp. 59-83). Presses Universitaires de France.

Páez, D., Bobowik, M., \& Liu, J. H. (2017). Social representations of the past and competences in history education. In M. Carretero, S. Berger \& M. Grever (Eds.), Palgrave handbook of research in historical culture and education (pp. 491-510). Palgrave Macmillan. https://doi.org/10.1057/978-1-137-52908-4_26

Piaget, J. (1964). Six études de psychologie. Gonthier. 
Pontecorvo, C., \& Girardet, H. (1993). Arguing and reasoning in understanding historical topics. Cognition and Instruction, 11(3/4), 365-395.

Potter, J. (1996). Representing reality. Discourse, rhetoric and social construction. Sage Publications.

Redhead, M. (2002). Making the past useful for a pluralistic present. Taylor, Arendt, and a problem for historical reasoning. American Journal of Political Science, 46(4), 803-818. https://doi.org/10.2307/3088435

Reisman, A., \& Wineburg, S. (2008). Teaching the skill of contextualizing in history. The Social Studies, 99(5), 202-207. https://doi.org/10.3200/TSSS.99.5.202-207

Ringer, F. K. (1989). Causal analysis in historical reasoning. History and Theory, 28(2), 154-172. https://doi.org/10.2307/2505033

Schoeman, S. (2007). Cognitive processes in history. Learners' explanation of the causes of colonialism in Africa. South African Journal of Education, 27(4), 709-727.

Searle, J. R. (1995). Construction of social reality. Allen Lane.

Seixas, P., \& Morton, T. (2013). The big six: Historical thinking concepts. Nelson Education.

Valsiner, J., \& Sato, T. (2006). Historically structured sampling (HSS). How can psychology's methodology become tuned in to the reality of the historical nature of cultural psychology? In J. Straub, D. Weidemann, C. Kölbl \& B. Zielke (Eds.), Pursuit of meaning (pp. 215-251). Transcript.

van Boxtel, C., \& van Drie, J. (2004). Historical reasoning. A comparison of how experts and novices contextualise historical sources. International Journal of Historical Learning, Teaching and Research, 4(2), 89-97.

van Drie, J., \& van Boxtel, C. (2007). Historical reasoning. Towards a framework for analyzing students' reasoning about the past. Educational Psychology Review, 20(2), 87-110. https://doi.org/10.1007/s10648-007-9056-1

van Drie, J., \& van Boxtel, C. (2011). In essence I'm only reflecting. Teaching strategies for fostering historical reasoning in whole-class discussion. International Journal of Historical Learning, Teaching and Research, 10(1), 55-66.

Vygotsky, L. S. (1981). The instrumental method in psychology. In J. Wertsch (Ed.), The concept of activity in Soviet psychology (pp. 134-188.). M. E. Sharpe.

Wagoner, B. (2009). The experimental methodology of constructive microgenesis. In J. Valsiner, P. Molenaar, N. Chaudhary \& M. Lyra (Eds.), Dynamic process methodology in the social and developmental sciences (pp. 99-121). Springer.

Wagoner, B. (2013). Bartlett's concept of schema in reconstruction. Theory \& Psychology, 23(5), 553-575.

Wagoner, B., \& Gillespie, A. (2014). Sociocultural mediators of remembering. An extension of Bartlett's repeated reproduction method. British Journal of Social Psychology, 53(4), 622-639. https://doi.org/10.1111/bjso.12059

Wertsch, J. (2008). The narrative organization of collective memory. Ethos, 36, 120-135. https://doi.org/10.1111/j.1548-1352.2008.00007.x

Wineburg, S. (1991). Historical problem solving. A study of the cognitive processes used in the evaluation of documentary and pictorial evidence. Journal of Educational Psychology, 83(1), 73-87. http://dx.doi.org/10.1037/0022-0663.83.1.73

Wineburg, S. (1999). Historical thinking and other unnatural acts. Phi Delta Kappan, 80(7), 488-499.

Zittoun, T. (2017a). Symbolic resources and sense-making in learning and instruction. European Journal of Psychology of Education, 32(1), 1-20. https://doi.org/10.1007/ s10212-016-0310-0 


\section{Conclusion}

The three studies presented in this book explored quite different yet interrelated aspects of how we represent the collective past: How it is used in a "natural" setting and how it positions the speaker; how it develops across the life course; how it is constructed in an experimental situation. The aim of this conclusion, thus, is to "connect the dots" of the previous three chapters by taking stock of what has been proposed and argued from a more general perspective, as well as the consequences it may have. It is not to bring all the studies together in a larger, allencompassing model, that would confine it more to a modelling challenge than to a real theoretical contribution. In the first section, I thus summarise the findings of the three studies. The general aim of this book was also to propose a new understanding on how we represent past, by studying it as a form of social thinking and from a sociocultural perspective. In the second section of this conclusion, I thereby propose to summarise the five main takeaways of this perspective, and what it brings to the study of collective memory. Finally, I conclude with some of the practical applications of the works presented in this book.

\section{How we think about the collective past}

The aim of this book was to look at how people actively think about the collective past, and how they mobilise it to understand the social world within which they live. For this purpose, three studies were developed, each addressing a different question:

1) How are representations of the collective past constructed and mobilised in interactions?

2) How do people come to develop specific or unique representations of the collective past?

3) What resources are used to construct representations of the collective past, and how are they employed?

However, most questions were addressed, indirectly, by more than one study. I thus now propose to discuss each question in turn and summarise what answers the empirical studies and the models presented brought to it. 


\section{Representing the collective past in interactions}

The first question, concerning how we represent the collective past in interactions, led to two main findings. First, collective memory is constructed in dialogue with others, and second, it is dialogical. Although both points are linked, they differ in the sense that the first one refers to the importance of social interactions and communication in the construction of collective memory, while the second one refers to the dialogical nature of social knowledge. Let us address them in turn.

The studies developed in this book showed that our representations of the collective past (RCPs) are constructed in relation to what others say about the past or are imagined to be thinking about it. First, it was shown that discourses on history are always addressed to someone. That is, discourses on history are part of an ongoing conversation about the meaning of the past, and understanding what people say about it requires understanding what broader conversation it is part of and through what conversations it was forged. Second, what people choose to say about the past positions them in the social field - as defending a certain political opinion, for instance, or as having a certain type of knowledge. This goes beyond picking a side in an ongoing conflict, and it is also linked to more subtle or micro social positions - such as one's relation to one's mother or to more general relations to the world - such as positioning oneself as a critique of human relations in general. Third, it was found that social interactions have a paradoxical effect on RCPs: On the one hand, it can polarise people's positions on the past, sometimes to the point of caricature, while on the other hand, it is because people share some common ground that they can argue about the past. Fourth, others proved to be a source of knowledge and opinions about the past, which could be used to construct RCP and whose trustworthiness or expertise were not left unquestioned. Globally, thus, it can be said that our RCPs are forged through social interactions, giving them content and shape, as well as their orientation and aims.

This book also showed that our RCPs are dialogical, at two levels. First, they are constructed in dialogue with alternative representations - often introduced by others, but also sometimes by the self, making them more fundamentally dialogical than the previous paragraph would imply. In other words, thinking about the collective past (TCP) not just in interactions with others, but in dialogue with alternative interpretations of the past. However, RCPs are dialogical at a second level as well. They are produced, on the one hand, in tension between a desire for presenting an objective, unbiased version of the past, and a will to account for the subjective perspectives of those who participated in it. On the other hand, they also exist in tension between a tendency to generalise our understandings of the world and an inclination towards producing specific, localised narratives that respect the particulars of the situation. These two tensions are dialogical in the sense that they produce accounts of the past that are in dialogue with alternative narratives that focus on different aspects of history - e.g., local personal stories vs. general ideas about human nature that explain what happened. 
Because RCPs are dialogical and forged in interactions, they are dynamic constructions that remain open to change. However, it does not mean that people change their opinion on history in every conversation or every time they encounter a new perspective or piece of information. This is, in part, the issue the next question aimed to tackle.

\section{Developing unique representations of the collective past}

The second question this book aimed to answer was how people come to develop unique RCP, and to resist or challenge hegemonic representations. Three important findings can be highlighted here: 1) TCP is developmental; 2) RCPs are linked to broader representations of the world; and 3) both alternative subjective accounts of the past and alternative objective facts have the potential to lead people to challenge existing historical representations. Let us now examine each claim in turn.

First, the way we think about the collective past is developmental, in the sense that it is constructed through processes that unfold over the course of one's life. As people navigate the social world, they encounter different versions of the past - in school, at home, in popular culture, in political discourses, in museums, etc. - that may be in tension with each other. While it is often unproblematic, one version being considered "truer" than the others, it has the potential to lead to ruptures. These can be experienced quite violently, among other things, because these ruptures may be touching other areas of one's life, such as one's relation to one's mother or one's trust in what is taught in school. These ruptures lead to transitions, during which one's understanding of history is irremediably changed in order to make sense of the rupture, for instance by considering history to be a matter of perspective. While supposing that everyone experiences ruptures in their relation to history would be jumping the gun, the coexistence, in the social field, of so many narratives about the past means that people must learn to navigate these - as did my participants, albeit perhaps not always in such a strong way - and that we all, in one way or another, learn to resist other RCPs that may challenge our own. That is, we develop metamemories representations of how memory works - and Personal World Philosophies personal sets of values and ideas about the world that borrow from common knowledge - that help us navigate the different social discourses about the past. Indeed, development is not the perpetual rewriting of one's psyche, and people can learn to integrate different perspectives to build a representation of the past that suits most of their needs, be they social - positioning oneself towards others or semiotic - finding meaning in the past. In the case of history, it may take the form of a process of secondarisation, the distancing of "oneself from an object of knowledge, to elaborate it so as to transform personal experience in a more generic and abstract form" (Zittoun \& Grossen, 2013), a process usually associated with school but also found here. 
Second, RCPs are deeply linked to people's more general understanding of the world. On the one hand, RCPs provide resources to think about more general issues, while on the other, the meanings people give to the world - their Personal World Philosophies - inform the meaning they give to specific historical events. This relation will be discussed in more detail below, but an important point can be made here: RCPs are the product of an "effort after meaning" (Bartlett, 1932), both for the specific event one is referring to and the world we live in. This is why it has the potential to create ruptures in people's lives: It is not just about learning new facts, but discovering that not all that one learnt in school is true; it is not just about debating the history of colonisation, it is about questioning the status quo. People's relation to history, the perspectives they choose to defend, the narrative frames they use, and the sources they rely on thus depend on more than the social and cultural "factors" that collective memory has sometimes been reduced to such as showing allegiance to one's social group and defending its interests, or simply using "whatever" cultural resources one is familiar with. Instead, it relates to how people understand the world they live in and the people they share it with, in a two-way relationship.

Third, two categories of information seem to have the potential to create ruptures in one's historical representations. Alternative subjective accounts which question one's understanding of the past and come from a trusted (enough) source, can lead one to develop new representations of history and to challenge what one has learnt so far. This can also result in changes in the ways history in general is represented, and in particular, how people believe it to be constructed - metamemory - leading them to the conclusion that collective memory is a matter of perspectives. Alternative objective facts that make people question the validity of some stories can play a similar role, provided too that they are trusted enough. Here again, as in other places where the word "objective" was used in this book, it refers to people's - researchers and participants alike - attempts towards a truth that would not depend on the person who utters it. An impossible endeavour, but that still deeply permeates the way we think about the world. While alternative facts seem to provoke a lot of immediate rejection based on the sources from which they emanate, they nonetheless can lead to important ruptures as well as changes in metamemory - for example, towards thinking that history is all false because it is written by the victors. Some participants seemed to trust one type of information more easily than the other, although both worked best in conjunction - when a subjective story included alternative facts.

In summary, people do not "inherit" RCPs from their social and cultural environment, but they use social and cultural resources as well as the RCPs they encounter to construct their own understanding of the past, and of the world. This is a developmental, life-long process, through which people learn to navigate the various representations and resources given to them, be it by integrating them, systematically rejecting some perspectives, or anything in between. 


\section{Constructing representations of the collective past}

The third question this book aimed to answer was how RCPs are constructed, and in particular, with what resources and processes. Some of the results concerning this question have been discussed already: Interactions and dialogical tensions participate in the construction of RCPs, and new representations may be the product of transitions provoked by alternative facts and perspectives. Beyond the repetition of the lists of resources and processes that were found in Chapter 6, three general points can be made.

First, RCPs are the product of an effort after meaning - as discussed in the two sections above - and are thus constructed as an attempt to make sense of what happened, what is happening, or what may happen. However, this is also a cognitive endeavour: It was found that people construct RCPs by manipulating complex information and making (what they believe to be) informed judgement about it. This is not to say, of course, that it is not deeply social and cultural, nor oriented towards meaning, characteristics that cognitive processes share anyway. But it does mean that constructing and manipulating RCPs is an intellectual activity where people try to be rational agents - using for instance, formal logic, conceptualisations, and analogies.

Second, this research showed that RCPs are flexible systems of knowledge that rely on four categories of elements: Shared meanings, personal sense, general schemas, and specific facts. These elements are used to produce discourses about the past and can be sources of tensions that may lead to reorganisations or new representations. They do not constitute a fully consistent whole, but are not fully disarticulated either, allowing for both adaptation and coherence. They also represent "poles" of what the participants appeared to believe would be a "perfect" account of the past - at the same time including individual perspectives and general significations, specific knowledge, and broader ideas - and yet often seemed irreconcilable. While I have discussed these tensions primarily in the third study, they were found in almost every fieldwork. As such, I would not consider them to be the "absolute" and "necessary" elements of RCPs, but what our cultural practices have defined as constituting the "proper" way to talk about the past.

Third, this research showed that a large range of psychological processes is involved in historical reasoning, building on the four elements discussed just above. While the third study resulted in 12 processes, it merely highlighted that people can use "whatever" processes and resources are available and relevant to them when reasoning about the past. It also showed the importance of processes that have often been overlooked when discussing collective memory - and social thinking in general - such as imagination and perspective taking. Other processes, such as conceptualisation and narrative construction, have been given a central role in history education (for the former) and collective memory studies (for the latter), and were found to be relatively marginal, especially in comparison to the extremely frequent generalisations and analogies used by the participants. 
In summary, it was found that new RCPs emerge as the result of tensions between their components and in an effort after meaning. TCP is a flexible, openended process that relies on a multitude of psychological processes and sources, that are both semiotic and cognitive, general and particular.

\section{Collective memory from a sociocultural perspective}

Beyond the empirical aims of the studies presented in the second half of this book, this book also aimed at making theoretical contributions that can be globally grouped into two categories: 1) the elaboration of a sociocultural approach to historical representations that takes into account its developmental, social, semiotic, and dialogical aspects; and 2) the reframing of the concept of collective memory to focus on different aspects of the phenomena it refers to. That is, moving beyond the idea of collective memory as only the memory of the collective, and towards the study of how people understand history as a whole and use it to think about the world.

Despite the fact that I have avoided, in the last three chapters of this book, the term of collective memory, it is now time to return to it. Indeed, while I believe that it is too broad an umbrella term and that a new and more precise terminology needs to be developed to discuss how we relate to the collective past, it is a concept one is not easily rid of, and for two main reasons. First, it is now widely used in psychological research, and it is an odd and complicated exercise to completely avoid it. Second, and more importantly, it does refer to a set of interrelated phenomena about the collective past that are also interesting to discuss as a whole. This is because they share common features, be it from a theoretical perspective (they share some social and psychological processes), an epistemological and epistemic perspective (they question how knowledge about the past is constructed both in everyday life and in scientific research), a methodological perspective (they often present similar challenges in their study), or a social perspective (they are part of a broad category of social activities about the past and its commemoration). That is, I would argue that what we need is to move with and beyond collective memory, considering it more of a field of research than a specific scientific concept.

With this perspective in mind, I propose, in this section, five concepts and ideas from sociocultural psychology used in this book that are applicable to collective memory and can shed a new light on this phenomenon.

\section{Collective memory as a symbolic resource}

Collective memory can be considered a dynamic symbolic resource - a cultural element that is used to make sense of a rupture (Zittoun et al., 2003) - for two reasons. First, it can be used as a resource to give meaning to present ruptures or difficulties that are anticipated to be coming. Many of the participants in study 3, 
for instance, mobilised the history of Poland and Russia during World War II to make sense of the rupture provoked by the Russian intervention in Ukraine, using it as a symbolic resource through an analogy. Second, collective memory can itself be the product of a symbolic resource: It too is a rupture that is made sense of with the help of cultural elements. This is what makes of collective memory a truly "dynamic" symbolic resource: As the past is mobilised to understand the present or imagine the future, it always has the potential to be reinterpreted, to best fit the needs of the situation.

\section{Collective memory as constructed in dialogues}

Collective memory is constructed in dialogues at two levels. First, it emerges in interactions with others, who can be both a resource for collective memory that is, by providing information, ideas, or meanings - and a "target" - that is, someone towards whom the speaker is positioning herself. Indeed, the stories one chooses to tell, the facts one chooses to believe, and the actors one chooses to identify with all locate the person in the social field, and define which others are seen as similar to the self or fundamentally alien to it.

Second, at a more fundamental level, and as we have seen above, collective memory is dialogical: It is constructed in orientation toward an other (Linell, 2009) and around thematic antinomies (Marková, 2000). Five types of antinomies were found to play a role in collective memory: 1) between different interpretations of the past (e.g., between France as the defender of human rights and France as a colonial empire); 2) between different interpretations of memory (e.g., between the past as a matter of perspective and the past as verifiable facts); 3) between the general and the particular (e.g., between the specifics of an event and one's general understanding of history); 4) between the objective and the subjective (e.g., between the official records of what happened and the statements of direct witnesses); and 5) between different time periods (e.g., between periods predating the modern economy and the ones that came after). These antinomic couples are at the basis of collective memory and historical reasoning, fuelling discourses and debates about the past, and always have the potential to lead to the emergence of new historical representations.

\section{Collective memory as a developmental process}

Collective memory is a developmental process. On the one hand, it unfolds in time, and evolves as people encounter new interlocutors, resources, and situations, and as they become familiar with various systems of values and narratives about the past. It is not a succession of stages that come to replace each other, but a complex integration between the different "layers" of one's relation to the past. On the other hand, it relies on a multitude of psychological processes that have themselves a developmental history, such as imagination (Zittoun \& Gillespie, 2016), perspective taking (Martin \& Gillespie, 2010), concept formation (Van der Veer \& Valsiner, 1991), or 
narrative construction (Habermas, 2007). This further contributes to making collective memory a developmental process.

This takes place at two levels. First, at the level of the course of one's life, people's relation to history evolves with the ruptures and transitions the person may experience. Second, at a more micro level, the emergence of a new historical representation, too, unfolds in time and is not a sudden or immediate change. In the third study, for instance, participants who changed their mind did so slowly over the course of several vignettes, and never left with a completely different opinion than the one they had at the start. This points to an interesting possibility: That collective memory is indeed contextual - changing as the context changes - but that it develops at a slower pace than the spheres of experiences we live in succeed each other. That is, while we may encounter new experiences, people, narratives, resources, values, and ideas at a very fast pace, constructing a representation of the world based on these is a process that takes times and that slowly develops as we learn to integrate these in a meaningful system of knowledge.

\section{Collective memory as a thinking process}

Collective memory is also a thinking process, in two ways. First, it is an effort after meaning (Bartlett, 1932) - an attempt to find "reasons" for what happened or is happening. Second, it is also a cognitive, "rational" effort to understand the world and its history. My point here is not to make a clear distinction between semiotic and cognitive processes, but to highlight that they have tended to reflect some ways of thinking more than others, as their respective fields of study have clearly embraced by choosing different objects of study. Globally, thus, we can say that semiotic processes are oriented towards finding meaning through open-ended and socially- and culturally-oriented processes (such as imagination or narrative construction), while cognitive processes have been oriented towards reaching solutions to problems, through close-ended, logic-oriented processes (such as analogies or categorisations). This does not imply that one does not borrow from the other, but that both reflect different aspects of thinking that are deeply interrelated, yet represent different orientations, a distinction that is not new (e.g., Bruner, 1990; Evans \& Over, 1996). This means that collective memory cannot be reduced, on the one hand, to processes of categorisation, source monitoring, or generalisation that would be "biased" by the desire to defend the interests of one's group, or, on the other hand, to processes of narration, imagination, or perspective taking that would only aim at making sense of what happened. What makes collective memory such a complex and interesting phenomenon is precisely the fact that it relies on all these processes and interrelates them.

\section{Collective memory as a tool to think about the world}

Finally, collective memory is a tool to think about the world: It is oriented towards understanding and acting in the social world. In that sense, collective memory 
is more linked to social thinking than to memory per se - an idea also reflected in the choice of literature in Chapter 2. Thus, it is not about "travelling through time," but about creating dialogues between different periods of time. Indeed, it is because we can superpose different eras that we can give them meaning, allowing us to see what is similar, different, or related, and thus use the past to give meaning to the present. Analogies, generalisations, and narratives play here a central role, as they allow people to make one period relevant for the other by superposing them, applying the conclusions of one to the other, or making one a consequence of the other. As a result, collective memory is part of a wider system of knowledge social knowledge - that it participates in shaping and is shaped by in turn. On the one hand, it provides resources, examples, and frames that one can use to understand the world we live in - using what we believe happened but yet did not experience. On the other hand, our representations of the world, what we deem to be possible, to be desirable, or to be "natural" for human beings, shapes the stories we will believe to be true about the past and the meaning we will give to them.

\section{Implications for education, policy, and society}

Finally, to conclude this book, I would like to discuss some of its practical implications for education, policy, and society. While this has been only indirectly my aim, I believe that the work presented here can have some very practical consequences - which is, in the end, always the final goal of any research, no matter how academic.

From an educational perspective, seven main implications can be outlined:

1) Importance of metamemory: The way people understand collective memory in general and how history is written is a central part of their relation to the past. It is thus necessary to include it in history education and to discuss the roots and consequences of the main representations of collective memory.

2) Importance of alternative narratives: Encountering alternative narratives has undeniable consequences in adults' relation to history, both because it changes how they understand it - usually towards making them more reflexive - and because it can lead them to doubt sources they used to trust - such as school or their family - in a manner that is sometimes painful to them. It is thus important to introduce children to alternative narratives (Psaltis et al., 2017), a method has already successfully been implemented in cases of conflicts (e.g., Goldberg \& Ron, 2014), and to guide them in the process. It also seemed, in the cases analysed in this thesis, that the introduction of widely different narratives - not just "the other side" of the conflict or the other discourses one may hear in the public sphere - has a beneficial effect.

3) Importance of sources: Being able to evaluate sources of information appears to be critical in people's historical reasoning. The importance of 
teaching children how to identify and evaluate sources has already been emphasised in history education (e.g., van Boxtel \& van Drie, 2004). What this work showed, however, is that people may not be aware of their own biases towards source monitoring, something that could be included in history education. More importantly, sources of information are fast evolving in the age of internet and social media, and new strategies need to be developed in this regard.

4) Importance of factual knowledge: Having sufficient historical knowledge to be able to discuss history, and to dispose of less ambiguous information about the past seems to play a great role in people's ability to reason about history. This is quite unsurprising, but it deserves to be noted as it tends to disappear from history education research and recommendations (e.g., Psaltis et al., 2017; van Drie \& van Boxtel, 2007).

5) Importance of teaching the difference between facts, meanings, and subjective experiences: People rely on these forms of knowledge to discuss the past and are aware of the fact that they have different statuses, as was shown in Chapter 6. Indeed, factual claims, interpretations of the significations of events, and people's subjective experiences of them do not have the same ontogenetic and epistemic status. Teaching children how to differentiate between these, and how they can all be questioned, albeit differently, could be an invaluable resource to help them navigate alternative narratives. Being able to make the difference, for instance, between challenging the interpretations of past events and challenging the veracity of verifiable historical facts could help students understand and respond better to issues such as negationism, or the rise of conspiracy theories.

6) Importance of imagination, perspective taking, and identification: Because imagination plays a role in people's relation to history, it is important to include it in education and not to leave it entirely to historically inspired movies and novels, which may offer very biased pictures of the past. In this case, and as with perspective taking, it is also important to make children sensible to the fact that our impression of what it was like, what it would have been like to be there, and how we would have behaved then may not be quite accurate, as this may support misinterpretations of the past (for instance, over-estimating resistance during World War II by imagining that we would have necessarily participated in it, a myth debunked in part by Milgram's experiment). Moreover, it is important to problematise issues of identification, and how/why we tend to identify more our groups with heroes or victims.

7) Importance of generalisations, analogies, and categorisations: While history education has long highlighted the importance of cognitive processes such as conceptualisations (e.g., Tutiaux-Guillon \& Bataillon, 1992), less has been said about children's ability to make connections between distant periods or places - a tendency globally not encouraged in history. However, adults frequently use generalisation, analogies, and categorisations to 
connect, compare, and discuss different historical periods, and to make the past relevant for the present and the future. Thus, teaching children these processes could be beneficial, by helping them use the past more efficiently to think about the world and the present, and by helping them question dubious analogies and generalisations.

Globally, thus, the implication of this research for history education is that its scope should be extended to support children's understanding of the past in general and their ability to mobilise it efficiently.

This also has consequences for policy and society. First, almost all the implications presented above can also be applied to the development of museum exhibits, cultural programmes, and commemorations of history. Second, at a more political level, the research discussed and constructed in this book shows that attempting to impose a unified narrative is a vain endeavour: Collective memory is organised around antinomic oppositions, and trying to produce a monologue about the past only polarises the positions of others. Third, if what is said about the past matters so much for the present and for the future, then more checks should be put in place not to leave abusive uses of history unsanctioned. While some forms of historical denial are punished by law in some countries - it is for instance illegal in France to deny a genocide that has been recognised by the state - most abusive uses of the past are left unquestioned. However, glorifying the past to make a point about the present - for instance through Brexit's "Take back control" or Trump's "Make America Great Again" - does have consequences for the way periods characterised by colonialism or segregation are understood. The point is not to say that these should be punished by law, but that perhaps they should not be left to become major political slogans without any public discussion on the matter. Fourth, national myths should be put into perspective (Psaltis et al., 2017), for instance by comparing them with the myths of other nations or to the other facets of the past that historical research has uncovered. That is, the aim is not to rid ourselves completely of any complaisant version of the past - after all, thinking of our nations as championing justice, equality, and freedom is also what pushes people to take action when they do not - but not to consider them as an undeniable truth that reflects who we (and others) essentially are.

Finally, and most importantly, collective memory gives us the impression that nations are both natural and eternal, to the point that living without them seems unimaginable (Billig \& Marinho, 2017). They give us a sense that the world we live in is the logical and direct conclusion of the past, and that the future can only be the prolongation of this trajectory. Being able to question historical narratives, interpretations of the past, and more generally how we construct representations of the world thus has tremendous potential. It has the potential to make us free to imagine new societies, new ways of being together, and new ways of relating to our environment, that perhaps would be less inclined towards nationalism, populism, and exclusion. 


\section{References}

Bartlett, F. C. (1932). Remembering. A study in experimental and social psychology. Cambridge University Press.

Billig, M., \& Marinho, C. (2017). The politics and rhetoric of commemoration. How the Portuguese Parliament celebrates the 1974 Revolution. Bloomsbury Publishing.

Bruner, J. S. (1990). Acts of meaning. Harvard University Press.

Evans, J., \& Over, D. E. (1996). Rationality and reasoning. Psychology Press.

Goldberg, T., \& Ron, Y. (2014). "Look, each side says something different." The impact of competing history teaching approaches on Jewish and Arab adolescents' discussions of the Jewish-Arab conflict. Journal of Peace Education, 11(1), 1-29. https://doi.org/ 10.1080/17400201.2013.777897

Habermas, T. (2007). How to tell a life. The development of the cultural concept of biography. Journal of Cognition and Development, 8(1), 1-31. https://doi.org/10.1080/ 15248370709336991

Linell, P. (2009). Rethinking language, mind and world dialogically. Interactional and contextual theories of sense making. Information Age Publishing.

Marková, I. (2000). Amédée or how to get rid of it. Social representations from a dialogical perspective. Culture \& Psychology, 6, 419-460. https://doi.org/10.1177/1354067X0064002

Martin, J., \& Gillespie, A. (2010). A neo-Meadian approach to human agency. Relating the social and the psychological in the ontogenesis of perspective-coordinating persons. Integrative Psychological and Behavioral Science, 44, 252-272. http://dx.doi. org/10.1007/s12124-010-9126-9127.

Psaltis, C., McCully, A., Agbaria, A., Makriyianni, C., Pingel, F., Karahasan, H., Carretero, M., Oguz, M., Choplarou, R., Philipou, S., Wagner, W., \& Papadakis, Y. (2017). Recommendations for the history teaching of intergroup conflicts. COST IS 1205 Working Group.

Tutiaux-Guillon, N., \& Bataillon, F. (1992). La conceptualisation en histoire. In F. Audigier (Ed.), Didactiques de l'histoire, de la géographie, des sciences sociales (Vol. 1-173-180). INRP.

van Boxtel, C., \& van Drie, J. (2004). Historical reasoning. A comparison of how experts and novices contextualise historical sources. International Journal of Historical Learning, Teaching and Research, 4(2), 89-97.

Van der Veer, R., \& Valsiner, J. (1991). Understanding Vygotsky. A quest for synthesis. Wiley-Blackwell.

van Drie, J., \& van Boxtel, C. (2007). Historical reasoning. Towards a framework for analyzing students' reasoning about the past. Educational Psychology Review, 20(2), 87-110. https://doi.org/10.1007/s10648-007-9056-1

Zittoun, T., Duveen, G., Gillespie, A., Ivinson, G., \& Psaltis, C. (2003). The use of symbolic resources in developmental transitions. Culture \& Psychology, 9, 415-448. https:// doi.org/10.1177/1354067X0394006

Zittoun, T., \& Gillespie, A. (2016). Imagination in human and cultural development. Routledge.

Zittoun, T., \& Grossen, M. (2013). Cultural elements as means of constructing the continuity of the self across various spheres of experience. In M. B. Ligorio \& M. César (Eds.), Interplays between dialogical learning and dialogical self (pp. 99-126). Information Age Publishing. 


\section{Index}

abduction 65

action 56-58

activity theory $16-17$

agentivity 9

analogies 84, 121-125, 146-148

Austin, J. 32

autobiographical memory $7,10,38-40$

Bakhtin, M. 14-15, 58-59

Bartlett, F. 41-43, 56, 62-63, 111, 129, 131-132

Belgium 98-99

Brexit 2-3, 59, 148

Bruner, J. 6-7, 11-12, 14, 45, 56, 84

collected memory 38-39

collective memory $36-37,52-53$,

143-146; history of 37-38

collective remembering 41-42

colonialism 76-78, 87, 99-100, 148

communism 98-101

corpus construction 72

critical psychology 20-21

cultural psychology see sociocultural psychology

cultural tools 7-8, 16, 20, 43-44, 55-57, 61-63, 105, 132, 145-146

Cultural-Historical Activity

Theory 16-17

cultural-historical psychology 8

culture 6-7

development see life course

dialogical experiments 111-115

dialogism 14-15, 58-59, 85-87; dialogical methodologies 111-112; dialogical self $16,58-59$; memory as dialogical 139-140, 144 discursive psychology 32-36; approach to memory $42-43$

Engeström, Y. 16-17

epistemology 17-21, 130, 147; see also pragmatism

factual knowledge 117, 121, 123, 130-131, 133-134, 142, 144, 147

France 72-73, 76-87

French revolution 76-82, 85-87

generalisations: as a process $41,62,94$, 105-106, 121-126, 135, 147-148; in research $18-19,64-65$

Gillespie, A. 8-9, 15-16, 21, 59, 71,125

Halbwachs, M. 37-38, 41

Hermans, H. 10, 16, 58-59

historical analogies see analogies

historical reasoning see historical thinking

historical thinking 109-110, 145-146; see also TCP (thinking about the collective past)

history education 62-63, 109-110, 146-148

imagination 122, 125-127, 147

immigration 70-74, 76-79, 83

intentionality $9-10,54,56$

interactions 58-60, 70-71, 73-74, 84-86, $105,139-140,144$

intersubjectivity 6-7, 58-59;

see also perspective

taking

interviews 96-97, 112 
life course 9, 60-61, 65, 94-95, 104-106, 140-141, 144-145; see also trajectories of remembering

Marková, I. 15, 32, 34-35, 58-59, 144

Mead, G.H. 8-9

meaning 127-129, 132-134

meaning-making $57,62,70,82-87,94$, $106,127,129,133-134,142-144$

media $3,116-121,147$

mediation 16-17, 43-44, 61-62

metamemory 105, 141, 146

methodology 17-20, 64-66; see also corpus construction; dialogical experiments; naturally occurring data; interviews; qualitative experiments; trajectory analysis

Moscovici, S. 31-32, 58, 111

narratives $7,44-46,55,62,70,84,93$, 96-98, 105, 117-119, 123, 131-132, 134,146

national identity see social identity

nationalism 43, 63, 70-71

naturally occurring data $71-72$

parliamentary debates 71-73

Peirce, C.S. 14, 21

perspective taking $8,110,122,125-127$, 130,147

Poland 102-103, 112-132

politics 2-4, 53, 55-59, 71-73, 83-87, 92-93, 148

pragmatism 21

psychosocial memory 40-41

qualitative experiments 111-112

RCP (representation of the collective past) 53-54, 86-87, 91-92, 94-95, 105, 109, $127-135,138-143$

reasoning 14, 28-30, 145; see also historical thinking

ruptures $30,60-61,84,104-105,140-141$; see also life course

Russia 43, 45, 112-132

schemas 41, 62-63, 131-134 semiotic 13-14, 57, 62, 86, 145; see also meaning-making; meaning; semiotic prism; sense

semiotic prism 14

sense 129-130, 133-134

Shweder, R.A. 6-7, 10, 12-13

signs $8,14,16,54-56,61-63,85$

social cognition 28-31

social construction $32-33$

social identity $28,39-40,45-46,70-72$, $82-87$

social representations 31-32, 34-35, 39

social thinking 27-28, 145-146

sociocultural psychology 6-10;

epistemology of 17-20; history of

11-13; methods 64-66

speech act 32

symbolic resources $84,143-144$

TCP (thinking about the collective past) 54-56, 91-92, 94-95, 109-110, 127-135, 138-143

temporal heteroglossia 106

tools see cultural tools

trajectories see life course; trajectories of remembering; trajectory analysis

trajectories of remembering 60-61, 92-96, 104-106, 140-141, 144-145

trajectory analysis $97-98$

transitions see life course

Ukraine 112-132

United States 2, 55, 57-58, 148

Valsiner, J. 7, 12-14, 64-65, 94

Vico, G. 11

Völkerpsychologie 11

Vygotsky, L.S. 8, 12, 16-17, 56, 61-62

Wertsch, J. 16, 43-45, 61-62, 70, 93

Wineburg, S. 110

witness accounts 119-121

World War II 76-78, 86-87, 101-102, 118, 124-126

Wundt, W. 11

Zittoun, T. 9, 14, 60-61, 65, 94-95, 106, 127,129 


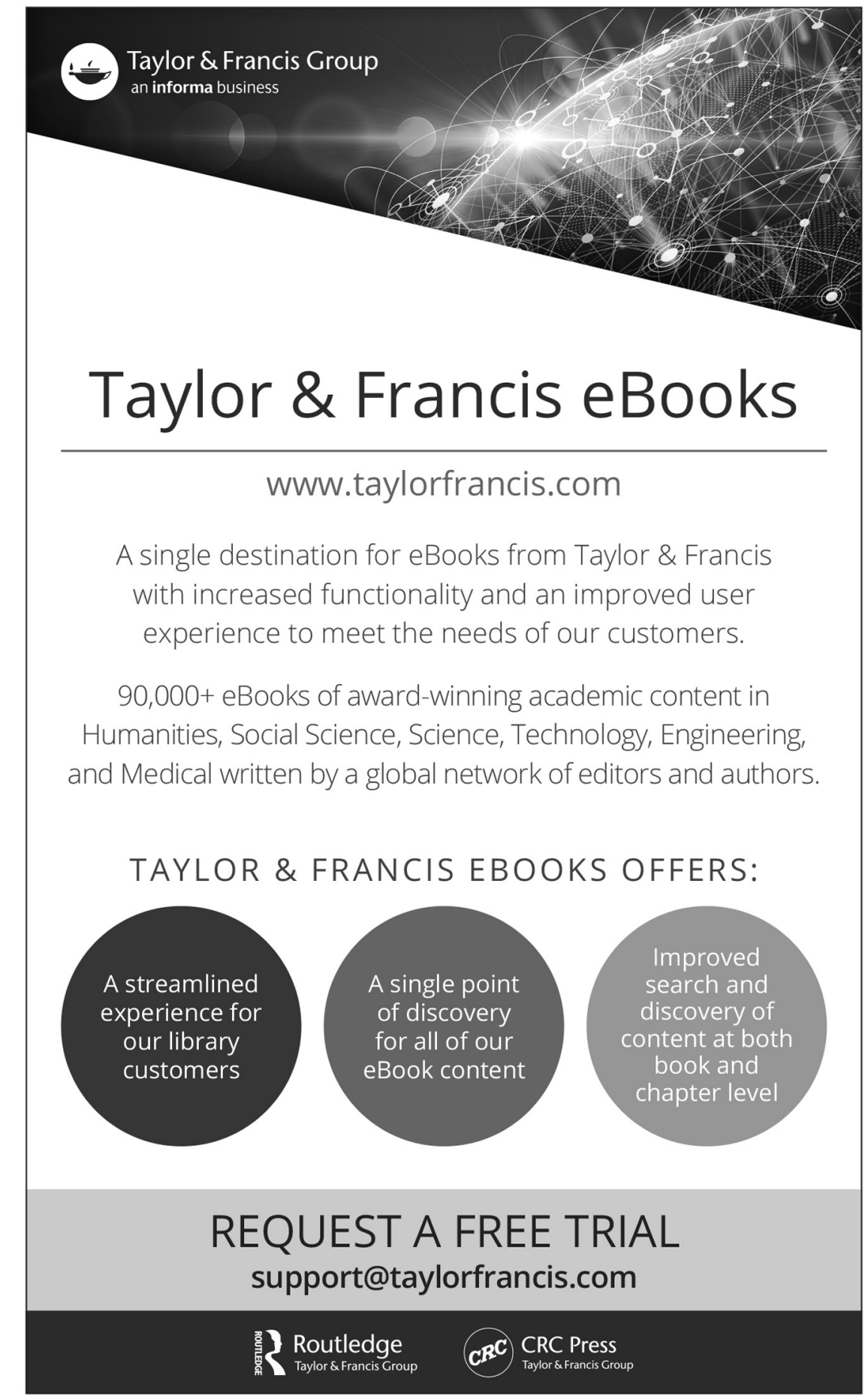

